\title{
I.S.Mu.L.T. Hyaluronic acid injections in musculoskeletal disorders guidelines
}

\author{
Antonio Frizziero ${ }^{1}$ \\ Filippo Vittadini ${ }^{2}$ \\ Francesco Oliva $^{3}$ \\ Giovanni Abatangelo ${ }^{11}$ \\ Serenella Bacciu ${ }^{8}$ \\ Anna Berardi 4 \\ Michela Bossa ${ }^{8}$ \\ Roberto Buda ${ }^{7}$ \\ Daniela Buonocore ${ }^{12}$ \\ Filippo Calderazzi ${ }^{5}$ \\ Antonio Carolla ${ }^{5}$ \\ Francesco Ceccarelli ${ }^{5}$ \\ Cosimo Costantino 6 \\ Maurizia Dossena ${ }^{12}$ \\ Cesare Faldini 7 \\ Paolo Finotti ${ }^{1}$ \\ Calogero Foti 8 \\ Luigi Frizziero ${ }^{13}$ \\ Stefano Galletti ${ }^{14}$ \\ Giuseppe Gasparre ${ }^{1}$ \\ Alessio Giai Via ${ }^{15}$ \\ Asmaaa Mahmoud ${ }^{8}$ \\ Stefano Masiero ${ }^{1}$ \\ Giovanni Merolla 8 \\ Alberto Migliore ${ }^{16}$ \\ Simone Natali ${ }^{7}$ \\ Simone Nicoletti ${ }^{17}$ \\ Antonello Padolino ${ }^{8}$ \\ Leonardo Pellicciari ${ }^{8}$ \\ Eleonora Piccirilli ${ }^{3}$ \\ Eleonora Pintus ${ }^{7}$ \\ Giuseppe Porcellini 8 \\ Davide Romiti ${ }^{6}$ \\ Marco Terreni ${ }^{12}$ \\ Alessandro Valent ${ }^{18}$ \\ Francesca Vannini ${ }^{7}$ \\ Manuela Verri ${ }^{12}$ \\ Antonella Vertuccio ${ }^{10}$ \\ Marco Vetrano ${ }^{10}$ \\ Maria Chiara Vulpiani ${ }^{10}$ \\ Nicola Maffulli ${ }^{18}$ \\ 1 Department of Physical and Rehabilitation Medicine, \\ University of Padova, Padova, Italy \\ 2 Venezia FC Medical Staff, Venice, Italy - Department \\ of Physical and Rehabilitation Medicine, Casa Di \\ Cura Giovanni XXIII, Monastier di Treviso, Italy \\ 3 Department of Orthopaedics and Traumatology, \\ University of Rome "Tor Vergata", Rome, Italy \\ 4 UOC of Immunohaematology and Transfusion \\ Medicine, Santo Spirito Hospital, Pescara, Italy
}

5 Orthopaedic and Trauma Department, Parma University, Parma, Italy

6 Rehabilitation Medicine, Department of Clinical and Experimental Medicine, Parma University Hospital, Parma, Italy

7 Rizzoli Orthopaedic Institute, University of Bologna, Bologna, Italy

8 Physical and Rehabilitation Medicine, University of Rome "Tor Vergata", Rome, Italy

9 Shoulder and Elbow Unit, "D. Cervesi" Hospital, Cattolica, Italy

10 Physical Medicine and Rehabilitation Unit, Sant'Andrea Hospital, "Sapienza" University of Rome, Rome, Italy

11 Department of Histology, Microbiology and Medical Biotechnology, University of Padova, Padova, Italy

12 Department of Biology and Biotechnology "L. Spallanzani", University of Pavia, Pavia, Italy

13 Department of Rheumatology, Villa Toniolo Hospital, Bologna, Italy

${ }^{14}$ Musculoskeletal ultrasound School, Italian Society for Ultrasound in Medicine and Biology (SIUMB), Bologna, Italy

15 Department of Orthopaedics and Traumatology, Hip Surgery Center, IRCCS Policlinico San Donato, San Donato Milanese (MI), Italy

16 Unit of Rheumatology, "Ospedale S. Pietro FBF", Rome, Italy

${ }_{17}$ Orthopaedic and Trauma Department, San Jacopo Hospital, Pistoia, Italy

18 Fisioclinics Formigine Clinic, Modena, Italy

${ }^{19}$ Department of Musculoskeletal Disorders, Faculty of Medicine and Surgery, University of Salerno, Baronissi, Salerno, Italy; Centre for Sports and Exercise Medicine, Barts and The London School of Medicine and Dentistry, Mile End Hospital, London, UK

Corresponding author:

Filippo Vittadini

Venezia FC Medical Staff

Department of Physical and Rehabilitation Medicine, Casa Di Cura Giovanni XXIII, Monastier di Treviso, Italy E-mail: filippo.vittadini@gmail.com

\section{Summary}

Intra-articular and peri-articular hyaluronic acid (HA) injections are widely used to treat several musculoskeletal pathologies. Although clinical 
outcomes are often positive for different conditions, an holistic consensus on this topic is still lacking. Our work is divided in two main sessions: in the first section we analyzed the preclinical bases for HA treatment in musculoskeletal pathologies, while in the second part we discussed the evidence on the use of HA injections in each district of musculoskeletal system. The aim of this work is to provide to the physician a feasible guideline rapidly to consult in the clinical practice.

Level of evidence: la.

\section{Approach to guidelines}

These recommendations developed through a process of systematic review of the literature and expert opinion, to be used to improve the quality of care and rationalize the use of resources.

Clinical decisions on individual patients require the application of the recommendations, based on the best scientific evidence and clinical experience of the physician.

\section{Methodology}

The Authors were divided into four groups:

- a coordinator conceived and organized the work and the groups, and selected the most important questions on the topic at hand;

- a overseeing group controlled the development of the work and discussed the recommendations;

- the group of the experts individually received a question and developed the answers according to the rules of EBM, when it was possible;

- the group of preparation and evaluation of literature drew up the text and assisted the group of experts in evaluating the literature.

\section{Methods and criteria of study selection}

For the research were consulted the following databases:

- PubMed

- Embase

- Google Scholar

- Cochrane Library.

Randomized controlled trials (RCTs); systematic reviews; to follow if missing the first two, the other levels of evidence. The literature is updated at December, 2016.

\section{Level of evidence \\ Level of evidence}

Criteria for analysis and inclusion

I Meta-analyses and systematic reviews of randomized controlled trials (RCTs) of high quality, or
RCTs with minimum or low risk of bias. Systematic reviews of high quality relative to cohort studies or case-control.

II Cohort studies or randomized case-control high quality, with minimal risk of confounding or bias and with high or discrete probability of causation.

III Case-control studies and retrospective comparison of well-conducted with reasonable probability of causation.

IV Non-analytic studies as case series or individual cases.

\section{Level of recommendation}

\section{Level of recommendation Criteria for analysis}

A Supported by at least two studies of level lb or from a review level la ("it was shown").

B Supported by at least two independent studies of level II or extrapolations from studies of level I ("it is possible").

C Not supported by adequate studies of level I or II ("indications").

D Indications of experts ("there is no evidence").

\section{Hyaluronic acid}

Hyaluronic acid (HA) is a non-sulfated glycosaminoglycan (GAG), formed by repetitive units of glucuronic acid and $\mathrm{N}$-acetyl glucosamine, widely express in the extracellular matrix (ECM) to confer protection, shape and mechanical support to cells and tissues. HA for its composition and expression is a key-component of cartilage and tendon structures, where it contributes to viscoelastic properties ${ }^{1-5}$. Stiff segments, linked by flexible domains to confer a super-helix, form the 50$70 \%$ of the molecule ${ }^{6}$. Therefore, viscoelastic properties of HA solutions can therefore be explained by the development of a dynamic three-dimensional network formed by transient associations between stiff segments $^{7-9}$

However, the importance of this molecule depends in part by its structure and hygroscopic properties, in part by the interaction with a large number of surface and intracellular receptors: CD44 glycoproteins, ICAM-1 and RHAMM, HARE, and intracellular proteins binding the hyaluronic acid CDC37, RHAMM/IHABP, P-32 and IHABP4 ${ }^{10-12}$.

\section{Injection techniques and good clinical practice} Intra-articular and peri-articular procedures should be accomplished in adequate clinical settings following evidence based medical recommendations and a point-to-point procedure ${ }^{13-15}$ :

- collect history and clinical examination;

- obtain oral/written informed consent;

- prepare the equipment;

- prepare the patient;

- disinfect the skin before and after the injection;

- program follow-up evaluation.

The equipment required is:

- gloves/sterile gloves;

- sterile swabs and sterile draps;

- prepacked sterile needles and syringes; 
- disinfectant (iodopovidone/chlorexidhine);

- synovial fluid collection bottles;

- sterile ultrasound kit (only for US-guided injection);

- emergency kit ${ }^{16,17}$.

The choice of the right needle is mandatory, considering the characteristics of the target joint. A needle of 21 gauge should be preferred in large joints as the shoulder or the knee, while 23-25 gouge needles are indicated in small joints ${ }^{13}$. Deep joints as the hip required the adoption of spinal needles (length of 3,5 inches; 8-9 centimeters) ${ }^{18}$.

Clinicians should identify any possible contraindications to the procedure. Absolute contraindications are: systemic infections and bacteremia, articular infections, skin lesions in the area, osteomyelitis, septic arthritis, unstable coagulopathy and severe thrombocytopenia, allergy (hypersensitivity) to any of the components and pregnancy. Injections procedures should be carefully performed in patients that use anticoagulants or other medications that alter INR. Injections should be avoid in patients with prolonged bleeding time or platelet count $<100000 / \mu l^{18}$.

Generally, adverse effects are local and well-tolerated. Common local side effects are redness and pain in the site of injection ( $<72$ hours after injection). Septic arthritis is rare (1:1000), while some cases of calcium pyrophosphate dihydrate crystal deposition disease (CPPD) are documented to be exacerbated by hyaluronic acid injections. Cross-linked products were related to severe acute inflammatory reaction (SAIR), a pseudo-septic condition probably related to immune-response mechanisms ${ }^{13,19,20}$.

\section{Key points}

- The injection should always be performed respecting sterile standardized procedures. It is mandatory to carefully disinfect the area preferring chlorhexidine preparations, mixtures of chlorhexidine gluconate and ethyl alcohol, iodopovidone solutions and analogs.

- The choice of the needle should consider the type of injection, the characteristics of the target joint and patient.

- Injection could be precede by arthrocentesis, which is helpful to the diagnosis of underlying pathological process in selected patients.

- Patients should observe a waiting period of 20-30 minutes in an outpatient facility after the injection.

KEY WORDS: musculoskeletal injection, guidelines, hyaluronic acid, principles, accuracy, disinfection.

\section{Hyaluronic acid properties in joint disorders and osteoarthritis}

It was demonstrated that HA should protect articular environment through several mechanisms of action: anti-inflammatory effect, chondroprotection, analgesic effect, subchondral bone protection and increased production of endogenous HA.
Anti-inflammatory effect

Several in vitro and in vivo studies suggest that antiinflammatory action is determined by the reduction of the principal mediators of inflammation as IL-1 ${ }^{21}$, TNF- $\mathrm{a}^{22}, \quad \mathrm{IL}-6, \quad \mathrm{IL}-8^{23}$ and prostaglandin E2 (PGE2) $^{24,25}$. Interaction with CD44 leads to decrease in IL-1 $\beta$ and metalloproteinases (MMPs) in cartilage and synovial fluid ${ }^{21,26}$, decrease in PGE2 expression in synovial fluid ${ }^{27}$, increase of TIMP-1 production and inhibition of anti-inflammatory response ${ }^{28}$.

New products as HYADD-4 (Hymovis ${ }^{\circledR}$, Fidia Farmaceutici SpA, Abano Terme, Italy) and H/L-HA (Sinovial HL®, IBSA SA, Switzerland) may determine a better anti-inflammatory response 29,30 .

\section{Chondroprotection}

Chondroprotection is determined by the reduction of chondrocyte apoptosis and by the increase in chondrocyte proliferation and viability, with the consequent increase in the production of ECM components (GAGs and PGs) ${ }^{31-34}$. Increased viability and proliferation is due in part to the down-regulation of proteolytic enzymes as MMPs and aggrecanases (ADAMTS) ${ }^{35-38}$.

Anti-apoptotic effects is linked to different mechanisms as Fas/Fas-ligand and mithocondrial function ${ }^{39}$ 44.

\section{Analgesic effect}

HA seems to exert analgesic effects through different mechanisms. In part, this action should be explained by the modulation of nociception due to down-regulation of main inflammatory mediators, as PGE2 and bradykinin ${ }^{45-49}$. Furthermore, viscoelastic properties of HA should reduce mechanical forces transmitted to nociceptive endings ${ }^{50-52}$. Recent findings evidenced that HA can induce activation of k-opioid receptor (KOP), suggesting other possible pathways of analgesic activity ${ }^{53}$.

\section{Subchondral bone protection}

$\mathrm{HA}$ can directly reduce osteoblast expression of MMP-13 and IL-1B induced expression of MMP-3, ADAMTS-4 and ADAMTS-554,55. HA should also act on osteoclasts enhancing expression of osteoprotegerin (OPG) and inhibiting RANK-ligand 56,57 .

\section{Production of endogenous $H A$}

$\mathrm{HA}$ injections determine a concentration dependent increase of endogenous HA production ${ }^{57}$. Endogenous HA concentration was found to be increased also at 3 and 6 months post-injection ${ }^{58-61}$.

\section{Keypoints}

- HA intra-articular injections could determine disease-modifying effects through several mechanisms of action: anti-inflammatory effect, chondroprotection, analgesic effect, subchondral bone protection and increased production of endogenous HA.

- Currently it is not clear whether any formulation is 
superior as disease-modifying molecule.

- New formulations (HYADD-4, H/L-HA) may determine a greater anti-inflammatory effect.

Level of recommendation: $A$.

KEY WORDS: hyaluronic acid, chondroprotection, cartilage, subchondral bone, anti-inflammatory, intraarticular, osteoarthritis, chondrocyte, osteoblast.

\section{Hyaluronic acid properties in soft tissues: tendons, ligaments and bursas}

\section{Tendons}

HA should enhance tenocyte viability and proliferation and reduce collagen III production, while it is not well established if HA may determine increase in collagen I production $62-64$

\section{Keypoints}

- In Achilles tendinopathy, HA injections stimulate healing process, reducing adhesion formation and regulating the expression of vascular endothelial growth factor (VEGF) and type IV collagen ${ }^{65}$.

- In rotator cuff diseases, HA injections exert mechanical (anti-adhesion) and biological effects (reduction of PGE2, C4S, IL-1 and modulation of leukocytes migration) ${ }^{66}$.

- In patellar tendinopathy, HA injections associated to rest should increase anabolic metabolism of tenocytes 67,68 .

Level of recommendation: $B$.

\section{Ligaments}

Actually, there are no evidences that support the use of $\mathrm{HA}$ injections in ligament pathologies or a direct action of HA on ligament structure. Some trials suggest the possible role of early $\mathrm{HA}$ injection after $\mathrm{ACL}$ surgery 69

Level of recommendation: $D$.

\section{Bursas}

Some studies have recently investigated the possible role of US-guided injections importance in different bursas, including the subacromial bursa ${ }^{70}$; however, it is not univocally known whether HA could improve the composition of the synovial fluid of bursa pathologies $^{71}$.

Level of recommendation: $D$.

\section{Hyaluronic acid in shoulder disorders}

Shoulder pain is common in general population ${ }^{72}$ and could be referred to rotator cuff tendinopathy, glenohumeral osteoarthritis or acromionclavear osteoarthritis ${ }^{73,74}$. Capsulitis should also be considered and it could be idiopathic or secondary to intraarticular and extra-articular pathologies. The use of NSAIDs is considered the first line treatment, but injection procedures should be indicated in non-responders patients.

\section{Glenohumeral injections}

Intra-articular injections in glenohumeral joint are widely used in clinical practice and several studies promote the efficacy in short and medium term ${ }^{75-84}$ (Tab. I). Intra-articular injections in glenohumeral joint are proposed for different pathologies, as osteoarthritis and rotator cuff pathology and frozen shoulder.

Level of recommendation: $A$.

\section{Adhesive capsulitis}

Several Authors evaluated the role of HA injections in adhesive capsulitis, but in many studies patients affected by AC represent a subgroup ${ }^{75,84,85-88}$. Injection therapy should be considered in a multimodal approach that includes capsular stretching and exercise therapy.

Level of recommendation: $B$.

\section{Subacromial injections}

Five studies were selected (Tab. II) ${ }^{89-93}$. Subacromial injections are proposed in rotator cuff pathology or subacromial space syndrome. This procedure should be ultrasound-guided to permit sufficient accuracy.

Level of recommendation: $A$.

\section{Key points}

- Intra-articular injections in glenohumeral joint should determine a great efficacy in osteoarthritis in short and medium term, while the procedure is not superior to other therapies in ROM improvement in adhesive capsulitis.

- Ultrasound-guided subacromial injections improve pain and function in rotator cuff pathology.

- There is lack of evidence about the possible role of $\mathrm{HA}$ in acromion-clavicular disorders.

KEY WORDS: hyaluronic acid, tendon, tendinopathy, ligaments, extra-articular.

\section{Hyaluronic acid in elbow disorders}

\section{Lateral epicondylitis}

Lateral elbow pain could be reported in several pathologies as chondromatosis, chondral lesions, intra-articular loose bodies, elbow instability or posterior interosseus nerve syndrome.

Thus, correct differential diagnosis is mandatory to achieve good clinical outcomes.

Several conservative modalities were described to treat lateral tennis elbow syndrome, while surgery is indicated only in refractory cases.

Only one RCT and few level IV trials investigated the possible role of HA in epicondylitis (Tab. III)68,94,95.

These studies are heterogeneous for methodologies neither use US-guidance.

Level of recommendation: $B$.

\section{Elbow osteoarthritis}

Elbow is not a common site of osteoarthritis, characterized by cartilage loss, osteophytes formation and intra-articular loose bodies.

The low prevalence should partially explain that the 
Table I. Selected studies on intra-articular glenohumeral injections.

\begin{tabular}{|c|c|c|c|c|c|c|}
\hline $\begin{array}{l}\text { Author } \\
\text { and year }\end{array}$ & $\begin{array}{l}\text { Study } \\
\text { design }\end{array}$ & Protocol/pathology & $\begin{array}{l}\text { Follow-up } \\
\text { (weeks) }\end{array}$ & $\begin{array}{l}\text { Outcome } \\
\text { measures }\end{array}$ & Results & $\begin{array}{l}\text { Level of } \\
\text { evidence }\end{array}$ \\
\hline $\begin{array}{l}\text { Blaine et al. } \\
2008^{75}\end{array}$ & $\mathrm{RCT}$ & $\begin{array}{l}5 \text { injections of Hyalgan }{ }^{\circledR}(221 \\
\text { patients) } \\
3 \text { injections of Hyalgan }{ }^{\circledR}+2 \\
\text { injections of placebo } \\
\text { ( } 218 \text { patients) } \\
5 \text { injections of placebo } \\
\text { ( } 221 \text { patients) } \\
\text { Chronic shoulder pain }\end{array}$ & 26 & $\begin{array}{l}\text { VAS pain } \\
\text { scale }\end{array}$ & $\begin{array}{l}\text { Pain reduction in } \\
\text { treated groups until } 26 \\
\text { weeks of follow-up }\end{array}$ & I \\
\hline $\begin{array}{l}\text { Kwon et al. } \\
2013^{76}\end{array}$ & $\mathrm{RCT}$ & $\begin{array}{l}3 \text { injections of Supartz }{ }^{\circledR}(150 \\
\text { patients) } \\
3 \text { injections of placebo } \\
\text { (150 patients) } \\
\text { Gleno-humeral osteoarthritis }\end{array}$ & 26 & $\begin{array}{l}\text { VAS pain } \\
\text { scale, } \\
\text { responder } \\
\text { percentages } \\
\text { in OMER- } \\
\text { ACT-OARSI }\end{array}$ & $\begin{array}{l}\text { Significant } \\
\text { improvement in pain } \\
\text { and function for } \\
\text { treated group } \\
\text { compared to control } \\
\text { group at all endpoints }\end{array}$ & \\
\hline $\begin{array}{l}\text { Merolla et al. } \\
201177\end{array}$ & $\begin{array}{l}\text { Retrospective } \\
\text { controlled }\end{array}$ & $\begin{array}{l}3 \text { injections of Synvisc } \AA \\
\text { (51 patients) } \\
3 \text { injections of } 6 \text { - } \\
\text { methylprednisone acetate (33 } \\
\text { patients) } \\
\text { Gleno-humeral osteoarthritis }\end{array}$ & 24 & $\begin{array}{l}\text { VAS, } \\
\text { Constant- } \\
\text { Murley }\end{array}$ & $\begin{array}{l}\text { Significant } \\
\text { improvement in pain } \\
\text { and function for } \\
\text { treated group } \\
\text { compared to control } \\
\text { group at all endpoints } \\
(p<0,05)\end{array}$ & III \\
\hline $\begin{array}{l}\text { Ozgen et al. } \\
2012^{78}\end{array}$ & $\begin{array}{l}\text { Perspective } \\
\text { randomized }\end{array}$ & $\begin{array}{l}3 \text { injections of Synvisc }{ }^{\circledR} \\
\text { (12 patients) } \\
\text { Standard rehabilitative } \\
\text { treatment (12 patients) } \\
\text { Supraspinatus tendinopathy }\end{array}$ & 4 years & $\begin{array}{l}\text { VAS, ROM, } \\
\text { SASES } \\
\text { score }\end{array}$ & $\begin{array}{l}\text { Significant } \\
\text { improvement in both } \\
\text { groups }(p<0,001) \\
\text { without differences }\end{array}$ & II \\
\hline $\begin{array}{l}\text { Park et al. } \\
2013^{84}\end{array}$ & $\begin{array}{l}\text { Perspective } \\
\text { randomized }\end{array}$ & $\begin{array}{l}2 \text { injections with ND device } \\
\text { (45 patients) } \\
2 \text { injections with ND } \\
\text { corticosteroid ( } 45 \text { patients) } \\
\text { Adhesive capsulitis }\end{array}$ & 6 & VNS, ROM & $\begin{array}{l}\text { Significant } \\
\text { improvement in both } \\
\text { groups for pain, } \\
\text { statistically better } \\
\text { improvement in } \\
\text { external rotation for HA } \\
(p<0,001)\end{array}$ & II \\
\hline $\begin{array}{l}\text { Rovetta \& } \\
\text { Monteforte } \\
1998^{89}\end{array}$ & $\begin{array}{l}\text { Perspective } \\
\text { randomized }\end{array}$ & $\begin{array}{l}8 \text { injections of Hyalgan }{ }^{\circledR}+ \\
\text { triamcinolone acetonide }+ \\
\text { exercise ( } 15 \text { patients) } \\
8 \text { injections of triamcinolone } \\
\text { acetonide + exercise ( } 15 \\
\text { patients) } \\
\text { Adhesive capsulitis }\end{array}$ & 24 & VAS, ROM & $\begin{array}{l}\text { Significant } \\
\text { improvement in pain } \\
\text { and function for } \\
\text { treated group } \\
\text { compared to controls } \\
\text { at all endpoints } \\
(p<0,001)\end{array}$ & II \\
\hline $\begin{array}{l}\text { Hsieh et al. } \\
2012^{90}\end{array}$ & $\mathrm{RCT}$ & $\begin{array}{l}3 \text { injections with ND device } \\
\text { (35 patients) } \\
\text { Physical therapies } \\
\text { (35 patients) } \\
\text { Adhesive capsulitis }\end{array}$ & 12 & $\begin{array}{l}\text { SPADI, } \\
\text { ROM, } \\
\text { SF-36 }\end{array}$ & $\begin{array}{l}\text { Significant } \\
\text { improvement in both } \\
\text { groups }(p<0,001) \\
\text { without differences }\end{array}$ & I \\
\hline
\end{tabular}

role of HA is not well established and limited in secondary osteoarthritis. Only two case series investigated HA in elbow osteoarthritis (Tab. IV) ${ }^{96,97 .}$ Level of recommendation: $C$.
Keypoints

- Low grade evidences support HA injections in elbow tendinopathies. 
Table II. Selected studies of subacromial space injections

\begin{tabular}{|c|c|c|c|c|c|c|}
\hline $\begin{array}{l}\text { Author } \\
\text { and year }\end{array}$ & $\begin{array}{l}\text { Study } \\
\text { design }\end{array}$ & Protocol/pathology & $\begin{array}{l}\text { Follow-up } \\
\text { (weeks) }\end{array}$ & $\begin{array}{l}\text { Outcome } \\
\text { measures }\end{array}$ & Results & $\begin{array}{l}\text { Level of } \\
\text { evidence }\end{array}$ \\
\hline $\begin{array}{l}\text { Meloni et al. } \\
2008^{91}\end{array}$ & $\mathrm{RCT}$ & $\begin{array}{l}5 \text { injections of Hyalgan } \AA \\
\text { ( } 28 \text { patients) } \\
5 \text { injections of placebo } \\
\text { ( } 28 \text { patients) } \\
\text { Supraspinatus tendinopathy }\end{array}$ & 48 & $\begin{array}{l}\text { VAS pain } \\
\text { scale }\end{array}$ & $\begin{array}{l}\text { Significant } \\
\text { improvement in pain } \\
\text { and function for } \\
\text { treated group } \\
\text { compared to controls } \\
\text { at all endpoints } \\
(p<0,001)\end{array}$ & 1 \\
\hline $\begin{array}{l}\text { Chou et al. } \\
2010^{92}\end{array}$ & $\mathrm{RCT}$ & $\begin{array}{l}5 \text { injections of } A r t z \circledR \\
(25 \text { patients) } \\
5 \text { injections of placebo } \\
\text { (26 patients) } \\
\text { Gleno-humeral osteoarthritis }\end{array}$ & 2 years & $\begin{array}{l}\text { VAS, } \\
\text { Constant- } \\
\text { Murley }\end{array}$ & $\begin{array}{l}\text { Significant } \\
\text { improvement in pain } \\
\text { and function for } \\
\text { treated group } \\
\text { compared to controls } \\
\text { at all endpoints } \\
(p<0,001)\end{array}$ & 1 \\
\hline $\begin{array}{l}\text { Tagliafico } \\
\text { et al. } 2011^{93}\end{array}$ & $\begin{array}{l}\text { Perspective, } \\
\text { open-label }\end{array}$ & $\begin{array}{l}2 \text { injections of high molecular } \\
\text { weight HA ND ( } 33 \text { patients) } \\
\text { Gruop that refused infiltrative } \\
\text { therapy } \\
\text { (60 patients) } \\
\text { Massive rotator cuff lesion } \\
\text { combined to advanced gleno- } \\
\text { humeral osteoarthritis }\end{array}$ & 24 & $\begin{array}{l}\text { VAS, } \\
\text { Constant- } \\
\text { Murley }\end{array}$ & $\begin{array}{l}\text { Significant } \\
\text { improvement in pain } \\
\text { and function for } \\
\text { treated group at } 1,2,3 \\
\text { and } 4 \text { months follw-up, } \\
\text { without statistical } \\
\text { differences compared } \\
\text { to controls at } 6 \text { months }\end{array}$ & III \\
\hline $\begin{array}{l}\text { Moghtaderi } \\
\text { et al. } 2013^{29}\end{array}$ & $\mathrm{RCT}$ & $\begin{array}{l}3 \text { injections of Fermathron }{ }^{\circledR} \\
\text { ( } 20 \text { patients) } \\
3 \text { injections of placebo } \\
\text { (20 patients) } \\
\text { Rotator cuff tendinopathy }\end{array}$ & 12 & $\begin{array}{l}\text { VAS, } \\
\text { Constant- } \\
\text { Murley }\end{array}$ & $\begin{array}{l}\text { Significant } \\
\text { improvement in pain } \\
\text { and function for } \\
\text { treated group } \\
\text { compared to controls } \\
(p<0,001)\end{array}$ & I \\
\hline $\begin{array}{l}\text { Merolla et al. } \\
2013^{30}\end{array}$ & $\begin{array}{l}\text { Perspective } \\
\text { randomized }\end{array}$ & $\begin{array}{l}2 \text { injections of SportVis }{ }^{\circledR}(25 \\
\text { patients) } \\
\text { Standard rehabilitative } \\
\text { treatment ( } 23 \text { patients) } \\
\text { Supraspinatus tendinopathy }\end{array}$ & 12 & $\begin{array}{l}\text { Oxford } \\
\text { Shoulder } \\
\text { Score, } \\
\text { Constant- } \\
\text { Murley } \\
\text { Score }\end{array}$ & $\begin{array}{l}\text { Significant } \\
\text { improvement in pain } \\
\text { and function for } \\
\text { treated group from } 2 \text { to } \\
12 \text { weeks and in CS at } \\
4 \text { and } 12 \text { weeks } \\
\text { compared to controls }\end{array}$ & II \\
\hline
\end{tabular}

- There are not sufficient evidences to recommend or avoid HA in primary and secondary elbow osteoarthritis.

- No adverse effects were observed with HA injections in patients affected by elbow pathologies.

KEY WORDS: hyaluronic acid, lateral epicondylitis, elbow osteoarthritis, elbow stiffness, elbow injection of hyaluronic acid, medial epicondylitis, hyaluronan elbow, sodium hyaluronate elbow.

\section{Hyaluronic acid in hip disorders}

Only few randomized controlled trials investigated the use of intra-articular injections of HA in hip osteoarthritis ${ }^{98-105}$ and they are very heterogeneous for methodologies and type of HA used (Tab. V).

In a recent systematic review and meta-analysis, Piccirilli et al. concluded that HA represents a valid conservative therapeutic option for hip pathology, al- though there is lack of uniformity regarding choice of HA type, timing and number of injections ${ }^{106}$.

Level of recommendation: $B$.

Keypoints

- Viscosupplementation is the best conservative treatment for osteoarthritis and it acts on pain reduction.

- Actually there is no uniformity regarding number or timing of infiltrative procedures.

- Ultrasound-guided infiltrative procedure is the best approach in terms of safety.

- In absence of comparative RCTs, no significant outcome differences seem to occur with different molecular weight HA formulations.

- Effectiveness on symptoms is only demonstrated in mild to moderate osteoarthritis, while infiltrative therapy is not indicated for severe forms of pathology. 


\section{A. Frizziero et al.}

Table III. Selected studies on epicondylitis.

\begin{tabular}{|c|c|c|c|c|c|c|}
\hline $\begin{array}{l}\text { Author } \\
\text { and year }\end{array}$ & $\begin{array}{l}\text { Study } \\
\text { design }\end{array}$ & Protocol/pathology & $\begin{array}{l}\text { Follow-up } \\
\text { (weeks) }\end{array}$ & $\begin{array}{l}\text { Outcome } \\
\text { measures }\end{array}$ & Results & $\begin{array}{l}\text { Level of } \\
\text { evidence }\end{array}$ \\
\hline $\begin{array}{l}\text { Petrella et al. } \\
2010^{94}\end{array}$ & $\mathrm{RCT}$ & $\begin{array}{l}2 \text { injections of HA ND } \\
\text { (165 patients) } \\
2 \text { injections of placebo } \\
\text { (166 patients) }\end{array}$ & 48 & $\begin{array}{l}\text { VAS pain } \\
\text { scale, gripping } \\
\text { force with } \\
\text { dynamometer, } \\
\text { return to sport }\end{array}$ & $\begin{array}{l}\text { Significant } \\
\text { improvement in pain } \\
\text { and function for } \\
\text { treated group } \\
\text { compared to controls } \\
\text { at all endpoints } \\
(p<0,001)\end{array}$ & I \\
\hline $\begin{array}{l}\text { Kumai et al. } \\
201468\end{array}$ & $\begin{array}{l}\text { Perspective, } \\
\text { non } \\
\text { randomized }\end{array}$ & $\begin{array}{l}1 \text { injection of Suvenyl® } \\
\text { (16 patients) } \\
\text { Epicondylitis }\end{array}$ & 1 & VAS & $\begin{array}{l}\text { Improvement } \geq 2 \mathrm{~cm} \text { in } \\
\text { VAS scale in } 10 \\
\text { patients }(62,5 \%)\end{array}$ & IV \\
\hline $\begin{array}{l}\text { Tosun et al. } \\
2015^{95}\end{array}$ & $\mathrm{RCT}$ & $\begin{array}{l}1 \text { injection of laluril }{ }^{\circledR} \\
(25 \text { patients) } \\
1 \text { injection of triamcinolone } \\
\text { acetonide ( } 32 \text { patients) } \\
\text { Epicondylitis }\end{array}$ & 12 & VAS, PRTEE & $\begin{array}{l}\text { Significant } \\
\text { improvement in pain } \\
\text { and function for } \\
\text { HA+CS group at } 3 \\
\text { months and in pain at } \\
6 \text { months compared to } \\
\text { CS group }\end{array}$ & II \\
\hline
\end{tabular}

Table IV. Selected studies on elbow osteoarthritis.

\begin{tabular}{|c|c|c|c|c|c|c|}
\hline $\begin{array}{l}\text { Author } \\
\text { and year }\end{array}$ & $\begin{array}{l}\text { Study } \\
\text { design }\end{array}$ & Protocol/pathology & $\begin{array}{l}\text { Follow-up } \\
\text { (weeks) }\end{array}$ & $\begin{array}{l}\text { Outcome } \\
\text { measures }\end{array}$ & Results & $\begin{array}{l}\text { Level of } \\
\text { evidence }\end{array}$ \\
\hline $\begin{array}{l}\text { Van Brakel \& } \\
\text { Eygendaal } \\
2006^{96}\end{array}$ & Case series & $\begin{array}{l}3 \text { injections of Fermathron }{ }^{\circledR} \\
\text { (18 patients }-19 \text { joints) } \\
\text { Post-thraumatic osteoarthrtis }\end{array}$ & 24 & $\begin{array}{l}\text { VAS, EFA } \\
\text { score, } \\
\text { Broberg- } \\
\text { Morrey } \\
\text { Functional } \\
\text { Rating } \\
\text { Index }\end{array}$ & $\begin{array}{l}\text { Slight non-significant } \\
\text { improvement in pain } \\
\text { and rigidity at } 3 \\
\text { months }\end{array}$ & IV \\
\hline $\begin{array}{l}\text { Pederzini } \\
\text { et al. } 2013^{97}\end{array}$ & Case series & $\begin{array}{l}1 \text { injection of Hyaloglide® }{ }^{\circledR}+ \\
\text { arthrolysis (17 patients) } \\
\text { Arthroscopic arthrolysis (19 } \\
\text { patients) } \\
\text { Post-thraumatic osteoarthrtis }\end{array}$ & 10 & $\begin{array}{l}\text { VAS, ROM, } \\
\text { Liverpool } \\
\text { elbow score } \\
\text { (LES) }\end{array}$ & $\begin{array}{l}\text { Higher percentage of } \\
\text { patients with pain } \\
\text { reduction in HA group } \\
\text { ( } p=0,0419) \text {, significant } \\
\text { reduction in pain } \\
\text { intensity in both } \\
\text { gruops ( } p<0,0001)\end{array}$ & IV \\
\hline
\end{tabular}

KEY WORDS: hyaluronic acid, hip injections, hip osteoarthritis, hip diseases.

\section{Hyaluronic acid in knee disorders}

Knee is the most studied application of HA injections and a common site of pathology, representing over $45 \%$ of total cases of symptomatic osteoarthritis. Several high-quality meta-analyses and review of RCTs were performed (Tab. VI).

\section{Effects on symptoms}

Intra-articular injections of HA lead to symptom relief comparable or superior to traditional treatments, such as intra-articular corticosteroids, NSAIDs, analgesics, lifestyle changes and physical exercise ${ }^{107-112}$.

\section{Level of recommendation: $A$.}

\section{Structural effects}

Different studies have shown that the use of $\mathrm{HA}$ in knee osteoarthritis leads to structural improvements, including reduction of grade and extension of cartilage lesions, accompanied by decrease in synovial fluid inflammation, improvement in quantity and density of chondrocytes, increase in synovial repair processes ${ }^{113-116 .}$.

Level of recommendation: $A$.

Effects on delay of prosthetic replacement surgery Even if only few studies have been conducted on this topic, those carried out agree that repeated treat- 
Table V. Selected studies on hip osteoarthritis.

\begin{tabular}{|c|c|c|c|c|c|c|}
\hline $\begin{array}{l}\text { Author } \\
\text { and year }\end{array}$ & $\begin{array}{l}\text { Study } \\
\text { design }\end{array}$ & Protocol/pathology & $\begin{array}{l}\text { Follow-up } \\
\text { (weeks) }\end{array}$ & $\begin{array}{l}\text { Outcome } \\
\text { measures }\end{array}$ & Results & $\begin{array}{l}\text { Level of } \\
\text { evidence }\end{array}$ \\
\hline $\begin{array}{l}\text { Tikiz et al. } \\
2005^{98}\end{array}$ & $\mathrm{RCT}$ & $\begin{array}{l}3 \text { injections of Synvisc® } \\
\text { (25 patients, } 32 \text { hips) } \\
3 \text { injections of Ostenil® } \\
\text { (18 patients, } 24 \text { hips) } \\
\text { Fluoroscopic guide }\end{array}$ & 24 & $\begin{array}{l}\text { VAS, } \\
\text { WOMAC, } \\
\text { Lequesne }\end{array}$ & $\begin{array}{l}\text { Both treatments are } \\
\text { effective without } \\
\text { statistical differences }\end{array}$ & I \\
\hline $\begin{array}{l}\text { Qvistgaard } \\
\text { et al. } 2006^{99}\end{array}$ & RCT & $\begin{array}{l}3 \text { injections of Hyalgan }{ }^{\circledR} \\
\text { ( } 33 \text { patients) } \\
3 \text { injections of placebo } \\
\text { ( } 36 \text { patients) } \\
1 \text { injection of Depo-Medrol } @+ \\
2 \text { sham injections }(32 \\
\text { patients) }\end{array}$ & 12 & $\begin{array}{l}\text { VAS scale } \\
\text { during walk }\end{array}$ & $\begin{array}{l}\text { Significant pain } \\
\text { reduction in CS group } \\
\text { compared to placebo } \\
\text { and } \mathrm{HA} \text { at } 14 \text { and } 28 \\
\text { days }\end{array}$ & 1 \\
\hline $\begin{array}{l}\text { Van den } \\
\text { Bekerom } \\
\text { et al. } 2008^{100}\end{array}$ & $\begin{array}{l}\text { Perspective, } \\
\text { non } \\
\text { randomized }\end{array}$ & $\begin{array}{l}1 \text { injection of Adant }{ }^{\circledR} \\
(91 \text { patients) } \\
1 \text { injection of Synocrom }{ }^{\circledR}(20 \\
\text { patients) } \\
1 \text { injection of Synvisc }{ }^{\circledR} \\
\text { (15 patients) } \\
\text { Fluoroscopic guide }\end{array}$ & 6 & $\begin{array}{l}\text { VAS, Harris } \\
\text { Hip Score }\end{array}$ & $\begin{array}{l}\text { Significant } \\
\text { improvement in pain } \\
\text { and function for Adant } \\
\text { e Synocrom groups }\end{array}$ & III \\
\hline $\begin{array}{l}\text { Richette et al. } \\
2009^{101}\end{array}$ & $\mathrm{RCT}$ & $\begin{array}{l}1 \text { injection of Adant }{ }^{\circledR} \\
\text { (42 patients) } \\
1 \text { injection of placebo } \\
\text { (43 patients) } \\
\text { Fluoroscopic guide }\end{array}$ & 12 & VAS & $\begin{array}{l}\text { No significant } \\
\text { differences between } \\
\text { groups }\end{array}$ & I \\
\hline $\begin{array}{l}\text { Migliore et al. } \\
2009^{102}\end{array}$ & RCT & $\begin{array}{l}2 \text { injections of Hyalubrix }{ }^{\circledR}(22 \\
\text { patients) } \\
2 \text { injections of mepivacaine } \\
\text { (20 patients) } \\
\text { Ultrasound guide }\end{array}$ & 12 & $\begin{array}{l}\text { VAS, } \\
\text { Lequesne }\end{array}$ & $\begin{array}{l}\text { Significant } \\
\text { improvement in pain } \\
(p<0,05) \text { and } \\
\text { Lequesne }(p<0,001) \\
\text { for HA group at all } \\
\text { follow-up }\end{array}$ & I \\
\hline $\begin{array}{l}\text { Spitzer et al. } \\
2010^{103}\end{array}$ & $\mathrm{RCT}$ & $\begin{array}{l}3 \text { injections of Synvisc } ®(150 \\
\text { patients) } \\
2 \text { injections of } \\
\text { metilprednisolone } \\
\text { (155 patients) } \\
\text { Fluoroscopic guide }\end{array}$ & 26 & WOMAC & $\begin{array}{l}\mathrm{HA} \text { is better than CS in } \\
\text { advanced stages of } \\
\text { pathology, same } \\
\text { effectiveness in less } \\
\text { advanced stages }\end{array}$ & I \\
\hline $\begin{array}{l}\text { Atchia et al. } \\
2011^{104}\end{array}$ & $\begin{array}{l}\text { Perspective, } \\
\text { randomized }\end{array}$ & $\begin{array}{l}1 \text { injection of Durolane }{ }^{\circledR} \\
\text { (19 patients) } \\
1 \text { injection di placebo } \\
\text { (19 patients) } \\
1 \text { injection of corticosteroid } \\
\text { ( } 20 \text { patients) } \\
\text { Standard care (20 patients) } \\
\text { Fluoroscopic guide }\end{array}$ & 8 & $\begin{array}{l}\text { NRS, } \\
\text { WOMAC }\end{array}$ & $\begin{array}{l}\text { Significant } \\
\text { improvement in pain } \\
\text { and function for CS } \\
\text { group }\end{array}$ & II \\
\hline $\begin{array}{l}\text { Battaglia } \\
\text { et al. } 2013^{105}\end{array}$ & $\mathrm{RCT}$ & 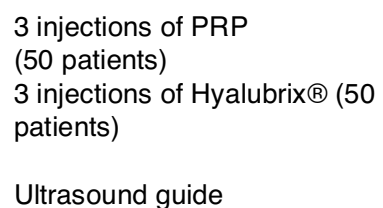 & 52 & $\begin{array}{l}\text { VAS, Harris } \\
\text { Hip Score }\end{array}$ & $\begin{array}{l}\text { Significant } \\
\text { improvement in both } \\
\text { groups }(p<0,005) \\
\text { without differences at } \\
\text { all follow-up }\end{array}$ & I \\
\hline
\end{tabular}

ments with HA infiltrations are effective in delaying total knee replacement surgery ${ }^{117-120}$.
Level of recommendation: $B$. 
Table VI. Selected studies on knee.

\begin{tabular}{|c|c|c|c|c|c|}
\hline $\begin{array}{l}\text { Author } \\
\text { and year }\end{array}$ & $\begin{array}{l}\text { Study } \\
\text { design }\end{array}$ & $\begin{array}{l}\text { Number of } \\
\text { cases }\end{array}$ & Clinical evaluation & Results & $\begin{array}{l}\text { Level of } \\
\text { evidence }\end{array}$ \\
\hline $\begin{array}{l}\text { Day et al. } \\
2004^{108}\end{array}$ & $\begin{array}{l}\text { Multicentric, } \\
\text { randomized, double } \\
\text { blind }\end{array}$ & 240 patients & $\begin{array}{l}6,10,14,18 \text { weeks } \\
\text { VAS, WOMAC }\end{array}$ & $\begin{array}{l}\text { Pain and articular stiffness } \\
\text { reduction }\end{array}$ & I \\
\hline $\begin{array}{l}\text { Bannuru et } \\
\text { al. 2011109 }\end{array}$ & Review of RCTs & $\begin{array}{l}54 \text { studies } \\
7545 \text { patients }\end{array}$ & $\begin{array}{l}4,8,12,16,20,24 \text { weeks } \\
\text { WOMAC } \\
\text { Meta-analysis }\end{array}$ & $\begin{array}{l}\text { Maximum pain reduction at } \\
8 \text { weeks }\end{array}$ & I \\
\hline $\begin{array}{l}\text { Trigkilidas \& } \\
\text { Anand } \\
2013^{110}\end{array}$ & Review of RCTs & $\begin{array}{l}14 \text { studies } \\
2289 \text { patients }\end{array}$ & VAS, WOMAC & $\begin{array}{l}\text { Maximum pain reduction at } \\
6-8 \text { weeks }\end{array}$ & I \\
\hline $\begin{array}{l}\text { Strand et al. } \\
2015^{111}\end{array}$ & Review of RCTs & $\begin{array}{l}29 \text { studies } \\
4866 \text { patients }\end{array}$ & $\begin{array}{l}\text { From } 4 \text { to } 13 \text { and from } 14 \\
\text { to } 26 \text { weeks } \\
\text { Meta-analysis }\end{array}$ & $\begin{array}{l}\text { Improvement in pain and } \\
\text { function between } 4 \text { and } 26 \\
\text { weeks }\end{array}$ & 1 \\
\hline $\begin{array}{l}\text { Waddell } \\
2006^{107}\end{array}$ & Retrospective study & 1158 patients & $\begin{array}{l}\text { VAS, severity e duration of } \\
\text { adverse event }\end{array}$ & $\begin{array}{l}\text { Slight to moderate adverse } \\
\text { events lasting less than } 48 \\
\text { hours }\end{array}$ & III \\
\hline $\begin{array}{l}\text { Pasquali et } \\
\text { al. } 2001^{115}\end{array}$ & $\mathrm{RCT}$ & 99 patients & $\begin{array}{l}7,14,21,28,35,60,120, \\
180 \text { days } \\
\text { Blood and urine tests } \\
180 \text { days } \\
\text { Arthroscopy and biopsy }\end{array}$ & $\begin{array}{l}\text { Reduction of inflamed } \\
\text { tissue, improvement of } \\
\text { edema, increase in } \\
\text { fibroblasts and collagen }\end{array}$ & I \\
\hline $\begin{array}{l}\text { Navarro- } \\
\text { Sarabia et al. } \\
2011^{114}\end{array}$ & $\begin{array}{l}\text { Multicentric, } \\
\text { randomized, with blind } \\
\text { assessor }\end{array}$ & 306 patients & $\begin{array}{l}6,12,24 \text { e } 48 \text { months } \\
\text { VAS, OARSI criteria, } \\
\text { OMERACT-OARSI criteria }\end{array}$ & $\begin{array}{l}\text { Ripetitive cycles of intra- } \\
\text { articular HA lead to an } \\
\text { improvement lasting til one } \\
\text { year after the end of } \\
\text { treatment }\end{array}$ & I \\
\hline $\begin{array}{l}\text { Turajane et } \\
\text { al. } 2009^{117}\end{array}$ & Perspective study & 183 patients & $\begin{array}{l}54 \text { months of follow-up } \\
\text { Incidence of TKR }\end{array}$ & Incidence of TKR of $28,4 \%$ & II \\
\hline $\begin{array}{l}\text { Waddell } \\
\text { \& Joseph } \\
2016^{118}\end{array}$ & Review & 1342 patients & $\begin{array}{l}13 \text { years of follow-up } \\
\text { Incidence of TKR }\end{array}$ & $\begin{array}{l}\text { TKR delayed of } 3 \text { years in } \\
25 \% \text { of patients } \\
\text { TKR delayed of } 7 \text { years in } \\
75 \% \text { of patients }\end{array}$ & I \\
\hline
\end{tabular}

\section{Keypoints}

- Knee infiltration with HA is strongly recommended for pain relief and potential disease-modifying effects.

- Evidence is greater for patients with mild to moderate osteoarthritis (K/L II-III).

- HA injections may delay the need for prosthetic knee replacement.

KEY WORDS: hyaluronic acid, molecular weight, knee, osteoarthritis, intra-articular injection, viscosupplementation, pain, tolerability, safety, meta-analysis, adverse events, total knee replacement.

\section{Hyaluronic acid in ankle disorders}

Hyaluronic acid is frequently used to reduce symptoms in early stages of ankle osteoarthritis. Many methods of treatment have been proposed, but actually no precise algorithm has been defined. HA is typically used when first-level analgesics have not determined adequate benefit and it could represent an option to postpone surgery ${ }^{121,122}$.

In selected studies (7 studies; 5 RCTs) response to treat- ment was moderate even a large share of the samples respond to the treatment (Tab. VII) ${ }^{123-129}$. It remains unclear which patients (age, degree of ankle osteoarthritis) may have greater improvement from HA injections and the number of injections to perform per patient.

Level of recommendation: $B$.

Keypoints

- HA is safe in ankle joint, although improvements in clinical scores appear to be slightly significant in higher quality trials.

- HA can be recommended in patients who respond inadequately to common analgesics.

- It remains unclear which patients may have greater improvement from $\mathrm{HA}$ injections and the number of injections to perform per patient .

KEY WORDS: viscosupplementation, hyaluronic acid, ankle, arthritis.

\section{Hyaluronic acid in small joints}

The role of HA in small joints is not well established yet. Few studies investigated HA injections trape- 
Table VII. Selected studies on ankle pathologies

\begin{tabular}{|c|c|c|c|c|c|c|}
\hline $\begin{array}{l}\text { Author } \\
\text { and year }\end{array}$ & $\begin{array}{l}\text { Study } \\
\text { design }\end{array}$ & Protocol & $\begin{array}{l}\text { Follow-up } \\
\text { (weeks) }\end{array}$ & $\begin{array}{l}\text { Outcome } \\
\text { measures }\end{array}$ & Results & $\begin{array}{l}\text { Level of } \\
\text { evidence }\end{array}$ \\
\hline $\begin{array}{l}\text { Salk et al. } \\
2006^{123}\end{array}$ & RCT & $\begin{array}{l}5 \text { injections of Hyalgan }{ }^{\circledR} \\
\text { (10 patients) } \\
5 \text { injections of placebo } \\
\text { (10 patients) }\end{array}$ & 24 & AOS & $\begin{array}{l}\text { Significant improvement in } \\
\text { both groups }(p<0,001)\end{array}$ & \\
\hline $\begin{array}{l}\text { Cohen et al. } \\
2008^{124}\end{array}$ & RCT & $\begin{array}{l}5 \text { injections of Hyalgan }{ }^{\circledR} \\
\text { (15 patients) } \\
5 \text { injections of placebo } \\
\text { (15 patients) }\end{array}$ & 12 & AOS & $\begin{array}{l}\text { Significant improvement in } \\
\text { HA group compared to } \\
\text { control group }\end{array}$ & \\
\hline $\begin{array}{l}\text { Karatosun et } \\
\text { al. } \\
2008^{125}\end{array}$ & $\begin{array}{l}\text { Perspective, } \\
\text { randomized }\end{array}$ & $\begin{array}{l}3 \text { injections of Adant }{ }^{\circledR} \\
\text { (15 patients) } \\
\text { Exercise ( } 15 \text { patients) }\end{array}$ & 52 & $\begin{array}{l}\text { AOFAS } \\
\text { score, } \\
\text { VAS pain }\end{array}$ & $\begin{array}{l}\text { Significant improvement in } \\
\text { both groups }(p<0,001)\end{array}$ & II \\
\hline $\begin{array}{l}\text { Carpenter } \\
\text { et al. } 2008^{126}\end{array}$ & $\begin{array}{l}\text { Perspective, } \\
\text { non } \\
\text { randomized }\end{array}$ & $\begin{array}{l}\text { Ankle arthroscopy }+3 \\
\text { injections of Synvisc }{ }^{\circledR} \\
\text { (14 patients) } \\
\text { Ankle arthroscopy } \\
\text { (12 patients) }\end{array}$ & 48 & $\begin{array}{l}10 \text { points } \\
\text { pain score } \\
\text { scale }\end{array}$ & $\begin{array}{l}\text { Significant pain reduction } \\
\text { in comparison to controls }\end{array}$ & IV \\
\hline $\begin{array}{l}\text { Mei-Dan } \\
\text { et al. } 2012^{127}\end{array}$ & $\mathrm{RCT}$ & $\begin{array}{l}3 \text { injections of Euflexxa }{ }^{\circledR} \\
\text { (15 patients) } \\
3 \text { injections of PRP } \\
\text { (14 patients) }\end{array}$ & 28 & AOFAS & $\begin{array}{l}\text { Significant improvement in } \\
\text { both groups }(p<0,001) \text {, } \\
\text { higher for PRP group } \\
(p<0,05)\end{array}$ & II \\
\hline $\begin{array}{l}\text { DeGroot } \\
\text { et al. } 2012^{128}\end{array}$ & $\mathrm{RCT}$ & $\begin{array}{l}1 \text { injection of Supartz }{ }^{\circledR} \\
\text { ( } 32 \text { patients) } \\
1 \text { injection of placebo } \\
\text { (32 patients) }\end{array}$ & 12 & AOFAS & $\begin{array}{l}\text { Significant improvement in } \\
\text { both groups }(p<0,001)\end{array}$ & \\
\hline $\begin{array}{l}\text { Sun et al. } \\
2014^{129}\end{array}$ & $\mathrm{RCT}$ & $\begin{array}{l}1 \text { injection of Hyalgan }{ }^{\circledR}+ \\
\text { exercise ( } 37 \text { patients) } \\
1 \text { injection of botulinum } \\
\text { toxin ( } 38 \text { patients) }\end{array}$ & 24 & AOS & $\begin{array}{l}\text { Significant improvement in } \\
\text { both groups }(p<0,001)\end{array}$ & \\
\hline
\end{tabular}

ziometacarpal (TMC) and first metatarsophalangeal joint (MTPJ) OA, while other small joints were not studied.

\section{Trapeziometacarpal joint osteoarthritis}

Studies selected have heterogeneous protocols and only two RCTs were found (Tab. VIII) ${ }^{130-139}$. Although some studies demonstrate a significant decrease in pain at a medium-term follow-up, no significant superiority compared to corticosteroid or placebo is emerged. A volume of $0.3 \mathrm{~cm}^{3}$ injected for each injection seems to be ideal in order to reduce volume effect and postinjection pain ${ }^{15}$.

Level of recommendation: $B$.

First metatarsophalangeal joint osteoarthritis

Only few studies were conducted, while a high quality RCT showed that an intra-articular injection of hylan $\mathrm{G}-\mathrm{F} 20$ is no more effective than placebo in reducing symptoms in people with symptomatic first MTPJ OA (Tab. IX) ${ }^{140-142}$.

Level of recommendation: $C$.

\section{Keypoints}

- In TMC OA a significant superiority compared to corticosteroids or placebo is not emerged, while $\mathrm{HA}$ seems to lead to higher improvements in long- term follow-up.

- In first metatarsophalangeal joint, no high-quality study demonstrate the superiority of HA in comparison to corticosteroids or placebo.

KEY WORDS: carpometacarpal joint, trapeziometacarpal, thumb, hallux rigidus, rhizarthrosis, metatarsophalangeal joint, golfer's toe and or viscosupplementation, hyaluronic acid, intra-articular injection.

\section{Hyaluronic acid in tendon and bursa}

$H A$ after flexor tendon repair surgery

HA has been widely used for topical application and injections after surgical repair of flexor tendons of the hand with the aim of promoting tendon sliding and preventing post-surgical adhesions. Many Authors have showed a lower granulation tissue formation with reduction of post-surgical adhesions, in part for reduced peritendinous inflammation. Four high-quality RCTs were found (Tab. X) ${ }^{143-146}$. HA products with higher molecular weight and longer half-life favor a greater permanence of HA into intrasynovial peritendinous space compared to native $\mathrm{HA}$ and low molecular weight formulations, ensuring greater clinical efficacy.

Level of recommendation: $A$. 
Table VIII. Selected studies on injections in trapeziometacarpal joint.

\begin{tabular}{|c|c|c|c|c|c|c|}
\hline $\begin{array}{l}\text { Author } \\
\text { and year }\end{array}$ & $\begin{array}{l}\text { Study } \\
\text { design }\end{array}$ & Protocol & $\begin{array}{l}\text { Follow-up } \\
\text { (weeks) }\end{array}$ & $\begin{array}{l}\text { Outcome } \\
\text { measures }\end{array}$ & Results & $\begin{array}{l}\text { Level of } \\
\text { evidence }\end{array}$ \\
\hline $\begin{array}{l}\text { Figen } \\
\text { Ayhan et } \\
\text { al. } 2009^{130}\end{array}$ & $\mathrm{RCT}$ & $\begin{array}{l}1 \text { injection of Hylan G-F } 20 \\
\text { (33 patients) } \\
1 \text { injection of saline solution } \\
\text { (33 patients) }\end{array}$ & 24 & $\begin{array}{l}\text { VAS, gripping } \\
\text { force, Dreiser }\end{array}$ & $\begin{array}{l}\text { Significant improvement in } \\
\text { function }(p=0,001) \text {, VAS } \\
\text { pain }(p=0,002) \text {, gripping } \\
\text { force }(p=0,004) \text { for HA } \\
\text { group }\end{array}$ & I \\
\hline $\begin{array}{l}\text { Salini et al. } \\
2009^{131}\end{array}$ & $\begin{array}{l}\text { Perspective } \\
\text { non } \\
\text { randomized }\end{array}$ & $\begin{array}{l}1 \text { injection of HA } 800-1200 \\
\mathrm{kDa}(18 \text { patients) }\end{array}$ & 4 & $\begin{array}{l}\text { VAS, FANS } \\
\text { consumpion, } \\
\text { Dreiser, } \\
\text { gripping force }\end{array}$ & $\begin{array}{l}\text { Significant improvement in } \\
\text { pain }(p<0,001) \text {, function } \\
(p<0,004) \text {, force }(p<0,001)\end{array}$ & III \\
\hline $\begin{array}{l}\text { Di Sante et } \\
\text { al. } 2011^{132}\end{array}$ & $\begin{array}{l}\text { Perspective } \\
\text { non } \\
\text { randomized }\end{array}$ & $\begin{array}{l}3 \text { weekly injections of } \mathrm{HA} \\
\mathrm{ND}(31 \text { patients) }\end{array}$ & 24 & $\begin{array}{l}\text { VAS, Duruöz } \\
\text { Hand Index }\end{array}$ & $\begin{array}{l}\text { Significant improvement } \\
\text { only in pain at } 1 \text { and } 3 \\
\text { months, but no } \\
\text { improvement at } 6 \text { months } \\
\text { nor in function }\end{array}$ & III \\
\hline $\begin{array}{l}\text { Frizziero et } \\
\text { al. } 2014^{133}\end{array}$ & $\begin{array}{l}\text { Retrospective } \\
\text { non } \\
\text { randomized }\end{array}$ & $\begin{array}{l}3 \text { weekly injections of } \\
\text { Hyalgan }{ }^{\circledR} \text { (58 patients) }\end{array}$ & 24 & $\begin{array}{l}\text { VAS, FANS } \\
\text { consumpion, } \\
\text { gripping force }\end{array}$ & $\begin{array}{l}\text { Significant improvement in } \\
\text { pain }(p<0,001) \text { and } \\
\text { reduced FANS } \\
\text { consumption }(p<0,017)\end{array}$ & IV \\
\hline $\begin{array}{l}\text { Roux et al. } \\
2007^{134}\end{array}$ & $\begin{array}{l}\text { Perspective } \\
\text { randomized }\end{array}$ & $\begin{array}{l}\text { Sinovial }{ }^{\circledR} \\
1 \text { injection (14 patients) } \\
2 \text { injections (14 patients) } \\
3 \text { injections (14 patients) }\end{array}$ & 12 & VAS, Dreiser & $\begin{array}{l}\text { Significant improvement in } \\
\text { pain and function, without } \\
\text { significant differences } \\
\text { between groups }\end{array}$ & II \\
\hline $\begin{array}{l}\text { Heyworth } \\
\text { et al. } \\
2007^{135}\end{array}$ & $\mathrm{RCT}$ & $\begin{array}{l}2 \text { injections Synvisc }{ }^{\circledR}(20) \\
1 \text { injection of placebo }+1 \\
\text { injection of betamethasone } \\
\text { acetate ( } 22 \text { patients) } \\
2 \text { injections of placebo (18) }\end{array}$ & 26 & $\begin{array}{l}\text { VAS, gripping } \\
\text { force, DASH }\end{array}$ & $\begin{array}{l}\text { No significant differences } \\
\text { between groups, even if } \\
\text { there is a postitive trend } \\
\text { for HA group after } 4 \text { weeks }\end{array}$ & I \\
\hline $\begin{array}{l}\text { Fuchs et } \\
\text { al. } 2005^{136}\end{array}$ & $\begin{array}{l}\text { Perspective } \\
\text { randomized }\end{array}$ & $\begin{array}{l}3 \text { injections of Ostenil Mini }{ }^{\circledR} \\
\text { (28 patients) } \\
3 \text { injections of triamcinolone } \\
\text { acetonide ( } 28 \text { patients) }\end{array}$ & 26 & $\begin{array}{l}\text { VAS, gripping } \\
\text { force }\end{array}$ & $\begin{array}{l}\text { Pain resolution, } \\
\text { improvement in articular } \\
\text { movement more lasting for } \\
\text { HA group }\end{array}$ & II \\
\hline $\begin{array}{l}\text { Ingenoli et } \\
\text { al. } 2010^{137}\end{array}$ & Case series & $\begin{array}{l}3 \text { injections of Hyalubrix }{ }^{\circledR} \\
\text { (32 patients) }\end{array}$ & 24 & $\begin{array}{l}\text { VAS, Dreiser, } \\
\text { gripping force }\end{array}$ & $\begin{array}{l}\text { Significant improvement in } \\
\text { pain and local } \\
\text { inflammation at short and } \\
\text { medium term }\end{array}$ & IV \\
\hline $\begin{array}{l}\text { Bahadir et } \\
\text { al. } 2009^{138}\end{array}$ & $\begin{array}{l}\text { Perspective } \\
\text { randomized }\end{array}$ & $\begin{array}{l}3 \text { injections of Ostenil® (20 } \\
\text { patients) } \\
1 \text { injection of triamcinolone } \\
\text { acetonide ( } 20 \text { patients) }\end{array}$ & 48 & $\begin{array}{l}\text { VAS, Duruöz } \\
\text { Hand Index, } \\
\text { gripping force }\end{array}$ & $\begin{array}{l}\text { No significant differences } \\
\text { between groups at all } \\
\text { follow-up }\end{array}$ & II \\
\hline $\begin{array}{l}\text { Stahl et al. } \\
2005^{139}\end{array}$ & $\begin{array}{l}\text { Perspective } \\
\text { randomized }\end{array}$ & $\begin{array}{l}3 \text { injections of Ostenil Mini® } \\
\text { ( } 26 \text { patients) } \\
3 \text { injections of methyl- } \\
\text { prednisolone ( } 26 \text { patients) }\end{array}$ & 24 & $\begin{array}{l}\text { Pain, gripper, } \\
\text { gripping force, } \\
\text { Purdue } \\
\text { Pegboard Test }\end{array}$ & $\begin{array}{l}\text { Both treatment are } \\
\text { effective, HA gruop shows } \\
\text { higher improvement in } \\
\text { gripping force and PPT }\end{array}$ & II \\
\hline
\end{tabular}

$H A$ in trigger finger, entesopathies and bursitis

In two recent randomized clinical trials, ultrasoundguided infiltration of medium molecular weight HA has been proposed for the treatment of stenosing tenosynovitis of finger flexor tendons, with encouraging results ${ }^{147-148}$.
Evidence on clinical efficacy for HA in human insertional tendon disorders is limited at four studies, although results are promising68,94,149,150 (Tab. XI).

$\mathrm{HA}$ injections have also been proposed for the treatment of bursitis. Actually only two prospective studies without a control group are available, respectively on 
Table IX. Selected studies on first metatarsophalangeal joint injections.

\begin{tabular}{|c|c|c|c|c|c|c|}
\hline $\begin{array}{l}\text { Author } \\
\text { and year }\end{array}$ & $\begin{array}{l}\text { Study } \\
\text { design }\end{array}$ & Protocol & $\begin{array}{l}\text { Follow-up } \\
\text { (weeks) }\end{array}$ & $\begin{array}{l}\text { Outcome } \\
\text { measures }\end{array}$ & Results & $\begin{array}{l}\text { Level of } \\
\text { evidence }\end{array}$ \\
\hline $\begin{array}{l}\text { Munteanu et } \\
\text { al. } 2011^{140}\end{array}$ & $\mathrm{RCT}$ & $\begin{array}{l}1 \text { injection of Hylan G-F } \\
20 \text { ( } 75 \text { patients) } \\
1 \text { injection of placebo (76 } \\
\text { patients) }\end{array}$ & 24 & $\begin{array}{l}\text { Foot Health } \\
\text { Status } \\
\text { Questionaire }\end{array}$ & $\begin{array}{l}\text { No significant differences } \\
\text { between groups at all } \\
\text { follow-up }\end{array}$ & I \\
\hline $\begin{array}{l}\text { Pons et al. } \\
2007^{141}\end{array}$ & $\begin{array}{l}\text { Perspective } \\
\text { randomized }\end{array}$ & $\begin{array}{l}1 \text { injection of Ostenil } \\
\text { Mini® }(20 \text { joints }) \\
1 \text { injection of } \\
\text { triamcinolone acetonide } \\
\text { (20 joints) }\end{array}$ & 11 & $\begin{array}{l}\text { VAS, AOFAS } \\
\text { score }\end{array}$ & $\begin{array}{l}\text { Significant difference in } \\
\text { pain during movement } \\
\text { and AOFAS score for HA } \\
\text { group }(p<0,05)\end{array}$ & II \\
\hline $\begin{array}{l}\text { Petrella \& } \\
\text { Cogliano } \\
2004^{142}\end{array}$ & $\begin{array}{l}\text { Perspective } \\
\text { non } \\
\text { randomized }\end{array}$ & $\begin{array}{l}8 \text { injections of HA ND (47 } \\
\text { patients) }\end{array}$ & 16 & $\begin{array}{l}\text { VAS, tiptoe } \\
\text { walking pain, } \\
\text { ROM, global } \\
\text { patient } \\
\text { satisfaction }\end{array}$ & $\begin{array}{l}\text { Significant improvement } \\
\text { in all outcome measures }\end{array}$ & III \\
\hline
\end{tabular}

Table X. Selected studies on flexor tendons tendon pathology.

\begin{tabular}{|c|c|c|c|c|c|c|c|}
\hline $\begin{array}{l}\text { Author } \\
\text { and year }\end{array}$ & $\begin{array}{l}\text { Study } \\
\text { design }\end{array}$ & $\begin{array}{l}\text { Experimental } \\
\text { groups }\end{array}$ & Protocol/pathology & Follow-up & $\begin{array}{l}\text { Outcome } \\
\text { measures }\end{array}$ & Results & $\begin{array}{l}\text { Level of } \\
\text { evidence }\end{array}$ \\
\hline $\begin{array}{l}\text { Wiig et al. } \\
2014^{143}\end{array}$ & $\mathrm{RCT}$ & $\begin{array}{l}\text { PXL01 in (46 } \\
\text { patients) }(1,5-8,1 \\
\text { MDa, } 15 \mathrm{mg} / \mathrm{ml}) \\
\text { Placebo (49 patients) }\end{array}$ & $\begin{array}{l}\text { Injection between } \\
\text { tendon and sheath and } \\
\text { around sheath during } \\
\text { surgery } \\
\text { Surgical repair of hand } \\
\text { areas I-II flexor } \\
\text { tendons: adhesion } \\
\text { prevention }\end{array}$ & $\begin{array}{l}\text { Until } 12 \\
\text { months }\end{array}$ & $\begin{array}{l}\text { TAM, tip-bend } \\
\text { distance, } \\
\text { sensitivity, } \\
\text { degree of } \\
\text { tenolysis, } \\
\text { gripping force }\end{array}$ & $\begin{array}{l}\text { HA improves } \\
\text { post-surgical } \\
\text { recovery, with } \\
\text { more } \\
\text { pronounced } \\
\text { difference } 6 \\
\text { months after } \\
\text { surgery }\end{array}$ & I \\
\hline $\begin{array}{l}\text { Özgenel } \\
\text { \& Etöz } \\
2012^{144}\end{array}$ & $\mathrm{RCT}$ & $\begin{array}{l}\text { High molecular } \\
\text { weight } \mathrm{HA}(11 \\
\text { patiens) }(1,0-2,9 \\
\text { MDa, } 15 \mathrm{mg} / \mathrm{ml}) \\
\text { Placebo (11 patients) }\end{array}$ & $\begin{array}{l}1 \text { injection during } \\
\text { surgery, } 2 \text { injections at } \\
\text { weekly intervals } \\
\text { Hand area II flexor } \\
\text { tendon injury: adhesion } \\
\text { prevention }\end{array}$ & $\begin{array}{l}3 \text { weeks, } 3 \\
\text { months, } \\
\text { long-term }\end{array}$ & $\begin{array}{l}\text { TAM, TPM, } \\
\text { functional } \\
\text { outcome with } \\
\text { Strickland } \\
\text { grading } \\
\text { system }\end{array}$ & $\begin{array}{l}\text { No differences } \\
\text { at } 3 \text { weeks, } \\
\text { improvement } \\
\text { in HA group at } \\
3 \text { months and } \\
\text { long-term }\end{array}$ & I \\
\hline $\begin{array}{l}\text { Riccio } \\
\text { et al. } \\
2010^{145}\end{array}$ & $\mathrm{RCT}$ & $\begin{array}{l}\text { Hyaloglide } \mathbb{} \\
\text { ( } 26 \text { patients) } \\
\text { Standard surgical } \\
\text { release ( } 19 \text { patients) }\end{array}$ & $\begin{array}{l}\text { Application of } \\
\text { Hyaloglide } \AA \text { along the } \\
\text { exposed tendon } \\
\text { surface and in digital } \\
\text { canal } \\
\text { Adhesions recurrence } \\
\text { after tenolysis of flexor } \\
\text { tendons in hand zone II }\end{array}$ & $\begin{array}{l}30-60-90- \\
180 \text { days } \\
\text { after } \\
\text { surgery }\end{array}$ & $\begin{array}{l}\text { TAM, } \\
\text { QuickDASH, } \\
\text { working days } \\
\text { lost after } \\
\text { surgery }\end{array}$ & $\begin{array}{l}\text { Better } \\
\text { recovery of } \\
\text { TAM and } \\
\text { faster return to } \\
\text { work and daily } \\
\text { life activities in } \\
\text { HA group }\end{array}$ & I \\
\hline $\begin{array}{l}\text { Hagberg } \\
\text { et al. } \\
1992^{146}\end{array}$ & $\mathrm{RCT}$ & $\begin{array}{l}\text { High molecular } \\
\text { weight HA ( } 4.0 \mathrm{Mda}) \\
\text { Placebo ( } 120 \text { cases } \\
\text { stratified in } 6 \text { classes) }\end{array}$ & $\begin{array}{l}\text { Injection in tendon } \\
\text { sheath after } \\
\text { tenorraphia or tendon } \\
\text { graft } \\
\text { Adhesions after } \\
\text { surgical repair of flexor } \\
\text { tendons in hand zone II }\end{array}$ & 4 months & $\begin{array}{l}\text { TAM, } \\
\text { extension } \\
\text { deficit, DIPAM } \\
\text { (active motion) }\end{array}$ & $\begin{array}{l}\text { No significant } \\
\text { effects of HA } \\
\text { on recovery of } \\
\text { TAM }\end{array}$ & I \\
\hline
\end{tabular}


Table XI. Selected studies on tendon and bursal pathologies.

\begin{tabular}{|c|c|c|c|c|c|c|c|}
\hline $\begin{array}{l}\text { Author } \\
\text { and year }\end{array}$ & $\begin{array}{l}\text { Study } \\
\text { design }\end{array}$ & $\begin{array}{l}\text { Experimental } \\
\text { groups }\end{array}$ & Protocol/pathology & Follow-up & $\begin{array}{l}\text { Outcome } \\
\text { measures }\end{array}$ & Results & $\begin{array}{l}\text { Level of } \\
\text { evidence }\end{array}$ \\
\hline $\begin{array}{l}\text { Liu et al. } \\
2015^{147}\end{array}$ & $\mathrm{RCT}$ & $\begin{array}{l}\text { Medium molecular } \\
\text { weight HA (18 cases) } \\
(0,8-1,17 \mathrm{Mda}) \\
\text { cortisone (19 cases) }\end{array}$ & $\begin{array}{l}1 \text { US-guided } \\
\text { injection of HA } \\
1 \text { US-guided } \\
\text { injection of cortisone } \\
\text { Trigger finger } \\
\text { (stenosing } \\
\text { tenosynovitis) }\end{array}$ & $\begin{array}{l}3 \text { weeks, } 3 \\
\text { months }\end{array}$ & $\begin{array}{l}\text { Quinnell scale } \\
\text { Michigan scale } \\
\text { (MHQ), VAS, } \\
\text { TAM, gripping } \\
\text { force }\end{array}$ & $\begin{array}{l}\text { Better outcomes } \\
\text { for both groups, } \\
\text { different trend } \\
\text { for } \mathrm{MHQ} \\
\text { (progressive } \\
\text { increase for } \mathrm{HA} \text {; } \\
\text { increase at } 3 \\
\text { weeks, } \\
\text { decrease at } 3 \\
\text { months for } \\
\text { steroid) }\end{array}$ & I \\
\hline $\begin{array}{l}\text { Callegari } \\
\text { et al. } \\
2011^{148}\end{array}$ & $\mathrm{RCT}$ & $\begin{array}{l}\text { Cortisone/lidocaine }+ \\
\text { medium molecular } \\
\text { weight HA }(0,8-1,2 \\
\text { MDa) (15 patients) } \\
\text { Open surgical release } \\
\text { (15 patients) }\end{array}$ & $\begin{array}{l}\text { US-guided injection } \\
\text { of } \\
\text { cortisone/lidocaine } \\
\text { and after } 10 \text { days of } \\
\text { HA }\end{array}$ & $\begin{array}{l}3 \text { weeks, } \\
3-6-12 \\
\text { months }\end{array}$ & $\begin{array}{l}\text { DASH, } \\
\text { Satisfaction } \\
\text { Visual Analog } \\
\text { Scale (SVAS), } \\
\text { VAS }\end{array}$ & $\begin{array}{l}\text { Similar results } \\
\text { between groups }\end{array}$ & I \\
\hline $\begin{array}{l}\text { Tosun et } \\
\text { al. } 2015^{149}\end{array}$ & $\mathrm{RCT}$ & $\begin{array}{l}\mathrm{HA}+\text { chondroitin } \\
\text { sulphate + prilocaine } \\
\text { ( } 25 \text { patients) } \\
\text { Triamcinolone + } \\
\text { prilocaine ( } 32 \\
\text { patients) } \\
\text { No control group }\end{array}$ & $\begin{array}{l}\text { Single injection of } \\
1.6 \mathrm{~mL} \text { in an area of } \\
\text { about } 2 \mathrm{~cm}^{2} \\
\text { immediately anterior } \\
\text { and distal to the } \\
\text { lateral epicondyle } \\
\text { Lateral epicondylitis }\end{array}$ & $\begin{array}{l}\text { 3-6 } \\
\text { months } \\
\text { after } \\
\text { injection }\end{array}$ & $\begin{array}{l}\text { Pain and } \\
\text { function with } \\
\text { PatientRated } \\
\text { Tennis Elbow } \\
\text { Evaluation } \\
\text { (PRTEE) }\end{array}$ & $\begin{array}{l}\text { Pain and } \\
\text { function } \\
\text { significantly } \\
\text { improved at } 3 \\
\text { and } 6 \text { months in } \\
\text { both groups, but } \\
\text { better results for } \\
\text { HA+CS group }\end{array}$ & II \\
\hline $\begin{array}{l}\text { Kumai et } \\
\text { al. } 201468\end{array}$ & $\begin{array}{l}\text { Pilot } \\
\text { study }\end{array}$ & $\begin{array}{l}\text { High molecular weight } \\
\text { HA ( } 2.7 \mathrm{Mda})(61 \\
\text { patients) } \\
\text { No control group }\end{array}$ & $\begin{array}{l}\text { Single injection of } \\
\text { HMW-HA near } \\
\text { affected } \\
\text { tendon/insertion } \\
\text { Entheopathy } \\
\text { (epicondylitis, } \\
\text { patellar } \\
\text { tendinopathy, } \\
\text { insertional Achilles } \\
\text { tendinopathy, plantar } \\
\text { fasciitis) }\end{array}$ & $\begin{array}{l}1 \text { week } \\
\text { after } \\
\text { injection }\end{array}$ & $\begin{array}{l}\text { Spontaneous } \\
\text { pain (VAS), } 5 \\
\text { categories of } \\
\text { local } \\
\text { symptoms, } \\
\text { caused pain }\end{array}$ & $\begin{array}{l}\text { VAS reduction } \\
\text { for all infiltrated } \\
\text { sites and } \\
\text { improvement of } \\
\text { local caused } \\
\text { pain }\end{array}$ & IV \\
\hline $\begin{array}{l}\text { Muneta et } \\
\text { al. } 2012^{150}\end{array}$ & $\begin{array}{l}\text { Cohort } \\
\text { study }\end{array}$ & $\begin{array}{l}\text { - Low molecular } \\
\text { weight HA+ lidocaine } \\
\text { ( } 50 \text { patients) }(9.0 \mathrm{Mda}) \\
\text { No control group }\end{array}$ & $\begin{array}{l}\text { Injection between } \\
\text { posterior tendon } \\
\text { surface and } \\
\text { infrapatellar fat } \\
\text { (patellar } \\
\text { tendinopathy) or } \\
\text { more painful point } \\
\text { around tendon; } \\
\text { repeated from } 1 \text { to } \\
11 \text { times spaced at } \\
\text { least } 1 \text { week } \\
\text { Patellar } \\
\text { tendinopathy and } \\
\text { anterior knee pain } \\
\text { syndrome in athletes }\end{array}$ & $\begin{array}{l}\text { 6-88 } \\
\text { months }\end{array}$ & $\begin{array}{l}\text { Roles and } \\
\text { Maudsley } \\
\text { modified score } \\
\text { (pain and } \\
\text { practice of } \\
\text { sport) }\end{array}$ & $\begin{array}{l}\text { Slight increase } \\
\text { in pain } 1-2 \text { days } \\
\text { after injection, } \\
\text { then } \\
\text { improvement } \\
\text { compared to } \\
\text { previous } \\
\text { condition. Most } \\
\text { effective in } \\
\text { patellar } \\
\text { tendinopathy } \\
\text { compared to } \\
\text { other types of } \\
\text { anterior knee } \\
\text { pain }\end{array}$ & II \\
\hline
\end{tabular}


Continue from Table XI.

\begin{tabular}{|c|c|c|c|c|c|c|}
\hline $\begin{array}{l}\text { Petrella et } \\
\text { al. } 2010^{94}\end{array}$ & RCT & $\begin{array}{l}\text { - HA (165 patients) } \\
\text { (molecular weight not } \\
\text { specified) } \\
\text { - saline solution (166 } \\
\text { patients) }\end{array}$ & $\begin{array}{l}2 \text { weekly injections } \\
\text { in subcutaneous and } \\
\text { muscular tissue } 1 \\
\mathrm{~cm} \text { from lateral } \\
\text { epicondyle } \\
\text { Lateral epicondylitis }\end{array}$ & $\begin{array}{l}7-14-30- \\
90-365 \\
\text { days }\end{array}$ & $\begin{array}{l}\text { VAS, gripping } \\
\text { force, global } \\
\text { satisfaction, } \\
\text { return to ADL } \\
\text { and sport }\end{array}$ & $\begin{array}{l}\text { Better results in I } \\
\text { HA group }\end{array}$ \\
\hline $\begin{array}{l}\text { Chen } \\
\text { et al. } \\
2014{ }^{152}\end{array}$ & $\begin{array}{l}\text { Cohort } \\
\text { study }\end{array}$ & $\begin{array}{l}\text { High molecular weight } \\
\text { HA(6000 kDa) (10 } \\
\text { patients) } \\
\text { Low molecular weight } \\
\text { HA (500-730 kDa) (10 } \\
\text { patients) } \\
\text { No control group }\end{array}$ & $\begin{array}{l}3 \text { intrabursal } \\
\text { injections after } \\
\text { aspiration with } \\
\text { lateral access, on } \\
\text { a weekly basis } \\
\text { Knee suprapatellar } \\
\text { bursitis }\end{array}$ & $\begin{array}{l}1-2-3-4 \\
\text { weeks } \\
\text { after first } \\
\text { injection }\end{array}$ & $\begin{array}{l}\text { Difference in } \\
\text { protein } \\
\text { concentration } \\
\text { in synovial fluid } \\
\text { before and } \\
\text { after injection }\end{array}$ & $\begin{array}{l}\text { Similar results in II } \\
\text { both groups }\end{array}$ \\
\hline $\begin{array}{l}\text { Chang } \\
\text { et al. } \\
2009^{151}\end{array}$ & $\begin{array}{l}\text { Pilot } \\
\text { study }\end{array}$ & $\begin{array}{l}\text { Cortisone + medium } \\
\text { molecular weight } \mathrm{HA} \\
(22 \text { patients })(940- \\
1020 \mathrm{kDa}) \\
\text { No control group }\end{array}$ & $\begin{array}{l}3 \text { non-guided weekly } \\
\text { injections with } \\
\text { access at vertebral } \\
\text { margin of the } \\
\text { scapula between } \\
\text { serratus anterior } \\
\text { muscle and lateral } \\
\text { thoracic wall } \\
\text { Scapulothoracic } \\
\text { bursitis }\end{array}$ & $\begin{array}{l}1-2-3 \\
\text { weeks and } \\
3 \text { months } \\
\text { after first } \\
\text { injection }\end{array}$ & $\begin{array}{l}\text { VAS, Rubin } \\
\text { scale }\end{array}$ & $\begin{array}{l}\text { Pain reduction, } \\
\text { no significant } \\
\text { adverse events }\end{array}$ \\
\hline
\end{tabular}

scapulo-thoracic bursitis ${ }^{151}$ and on suprapatellar bursitis ${ }^{152}$; both studies reported significant improvements and Authors seem to encourage the use of HA in such conditions.

Level of recommendation: $C$.

\section{Keypoints}

- HMW-HA into intrasynovial peritendinous space should be proposed after surgical repair of flexor tendons of the hand with the aim of preventing adhesions and optimize recovery of motility and function.

- Currently, the use of HA in insertional tendon disease, trigger finger and bursitis is not strongly support by evidences, even reporting encouraging results without major side effects.

KEY WORDS: tendon, periarticular, tendinopathy and or hyaluronic acid, injection.

\section{Combination therapy with HA}

Association with corticosteroids

Several studies investigated combined therapy with corticosteroids in various pathologies, as knee osteoarthritis, stenosing tenosynovitis of fingers flexor tendons, internal derangement of temporomandibular joint, adhesive capsulitis and lateral epicondylitis (Tab. XII) ${ }^{89,148,153-157}$. Despite the different indications and protocols, all these studies suggested the superiority of the therapeutic association in terms of efficacy (pain reduction) compared to the use of each treatment alone.
Level of recommendation: $B$.

Association with local anesthetics

In the selected studies HA and local anesthetics have been used in association to other drugs, so it is difficult to establish the clinical efficacy of this combined therapy, whether the outcome was favorable for combined treatment groups ${ }^{148,149,157}$.

Level of recommendation: $C$.

\section{Association with NSAIDs}

Only two RCTs analyzed the association between HA and NSAIDs. Both demonstrated a superiority in terms of pain reduction for combined intra-articular therapy compared to $\mathrm{HA}$ alone in subjects suffering of knee $\mathrm{OA}^{158,159}$

Level of recommendation: $C$.

\section{Association with PRP}

A retrospective non-randomized clinical trial on patients affected by Kellgren-Lawrence grade III-IV knee OA showed better outcome for the group treated with association between HA and PRP compared to $\mathrm{HA}$ alone ${ }^{160}$.

Level of recommendation: $C$.

\section{Association with MSCs}

A recent RCT showed an increased quality of articular cartilage tissue after associative treatment with $\mathrm{HA}$ and peripheral blood stem cells compared to HA alone in patients with chondral lesions of the knee ${ }^{161}$. Level of recommendation: $C$. 
Table XII. Selected studies on combination therapies.

\begin{tabular}{|c|c|c|c|c|c|c|c|}
\hline $\begin{array}{l}\text { Author } \\
\text { and year }\end{array}$ & $\begin{array}{l}\text { Study } \\
\text { design }\end{array}$ & Population & Treatments & Type of HA & Type of cotherapy & $\begin{array}{l}\text { Follow- } \\
\text { up period }\end{array}$ & $\begin{array}{l}\text { Level of } \\
\text { evidence }\end{array}$ \\
\hline $\begin{array}{l}\text { Callegari } \\
\text { et al. } \\
2011^{148}\end{array}$ & $\mathrm{RCT}$ & $\begin{array}{l}30 \text { patients with } \\
\text { stenosing } \\
\text { tenosynovitis of } \\
\text { fingers flexor } \\
\text { tendons }\end{array}$ & $\begin{array}{l}2 \text { groups: } \\
\text { - corticosteroids + HA } \\
\text { (group A) } \\
\text { - open surgery (group B) }\end{array}$ & $\begin{array}{l}1 \mathrm{ml} 0.8 \% \text { of } \\
\mathrm{HA} \text { (Sinovial } \\
\text { Mini) }\end{array}$ & $\begin{array}{l}\text { Methylpredni- } \\
\text { solone acetate } \\
40 \mathrm{mg} / 1 \mathrm{ml} \\
\text { (Depo-medrol) }\end{array}$ & $\begin{array}{l}6 \text { weeks, } \\
3,6,12 \\
\text { months }\end{array}$ & II \\
\hline $\begin{array}{l}\text { De } \\
\text { Campos } \\
\text { et al. } \\
2013^{153}\end{array}$ & $\mathrm{RCT}$ & $\begin{array}{l}104 \text { patients with } \\
\text { gonarthrosis }\end{array}$ & $\begin{array}{l}2 \text { groups: } \\
-1 \text { injection of HA (VS } \\
\text { group); } \\
-1 \text { injection of } \mathrm{HA}+ \\
\text { triamcinolone (VS+T } \\
\text { group). }\end{array}$ & $\begin{array}{l}6 \mathrm{ml} \text { of Hylan } \\
\text { GF-20 }\end{array}$ & $\begin{array}{l}1 \mathrm{ml} / 20 \mathrm{mg} \text { of } \\
\text { triamcinolone } \\
\text { hexacetonide }\end{array}$ & $\begin{array}{l}1,4,12, \\
24 \text { weeks }\end{array}$ & \\
\hline $\begin{array}{l}\text { Giombini } \\
\text { et al. } \\
2016^{162}\end{array}$ & RCT & $\begin{array}{l}70 \text { subjects with } \\
\text { gonarthrosis }\end{array}$ & $\begin{array}{l}3 \text { groups ( } 1 \text { injection/ } \\
\text { week for } 5 \text { weeks): } \\
\text { - HA only }(n=23) \text {; } \\
\text { - only } \mathrm{O}^{2} \mathrm{O}^{3}(n=23) \text {; } \\
\text { - } \mathrm{HA}+\mathrm{O}^{2} \mathrm{O}^{3}(n=24)\end{array}$ & $\begin{array}{l}20 \mathrm{mg} / 2 \mathrm{ml} \text { of } \\
\mathrm{HA} \\
\text { (Hyalgan } \AA)\end{array}$ & $\begin{array}{l}\text { mixture of } \mathrm{O}^{2} \mathrm{O}^{3}(15 \\
\mathrm{ml}) \text { with }[\mathrm{O} 3 \text { ] of } 15 \\
\mu \mathrm{g} / \mathrm{ml} \text {, obtained } \\
\text { through an ozone } \\
\text { generator }\end{array}$ & $\begin{array}{l}2 \text { months } \\
\text { from } \\
\text { end of } \\
\text { treatment }\end{array}$ & II \\
\hline $\begin{array}{l}\text { Giraddi } \\
\text { et al. } \\
2015^{154}\end{array}$ & $\mathrm{RCT}$ & $\begin{array}{l}14 \text { patients with } \\
\text { internal } \\
\text { derangement of } \\
\text { temporomandibular } \\
\text { joint }\end{array}$ & $\begin{array}{l}2 \text { groups (arthrocentesis } \\
+ \text { injection): } \\
\text { - betamethasone + HA } \\
\text { - only betamethasone }\end{array}$ & $0.5 \mathrm{ml}$ of $\mathrm{HA}$ & $\begin{array}{l}\text { - group I: } 0.5 \mathrm{ml} \text { of } \\
\text { betamethasone; } \\
\text { - group II: } 1 \mathrm{ml} \text { of } \\
\text { betamethasone }\end{array}$ & $\begin{array}{l}2 \text { days, } 1 \\
2 \text { weeks, } \\
1,2,6 \\
\text { months }\end{array}$ & II \\
\hline $\begin{array}{l}\text { Lee et al. } \\
2011158\end{array}$ & $\mathrm{RCT}$ & $\begin{array}{l}43 \text { subjects with } \\
\text { gonarthrosis }\end{array}$ & $\begin{array}{l}2 \text { groups: } \\
- \text { HA+30 mg of ketorolac } \\
\text { ( } 3 \text { weeks), followed by } \\
\text { HA alone ( } 2 \text { weeks) } \\
\text { - only HA for } 5 \text { weeks }\end{array}$ & $\begin{array}{l}2.5 \mathrm{ml}(1 \%) \\
\text { of Hyal (940- } \\
1020 \mathrm{kDa})\end{array}$ & $30 \mathrm{mg}$ of ketorolac & $\begin{array}{l}1,3,5,16 \\
\text { weeks } \\
\text { after } \\
\text { beginning } \\
\text { of therapy }\end{array}$ & II \\
\hline $\begin{array}{l}\text { Ozturk } \\
\text { et al. } \\
2006^{155}\end{array}$ & $\mathrm{RCT}$ & $\begin{array}{l}40 \text { patients with } \\
\text { gonarthrosis }\end{array}$ & $\begin{array}{l}2 \text { groups ( } 3 \text { weekly } \\
\text { injections for } 3 \text { weeks }+3 \\
\text { injections at } 6^{\text {th }} \text { month): } \\
-\mathrm{HA}(n=24, \text { group } A) ; \\
-\mathrm{HA}+\text { triamcinolone at I } \\
\text { and IV injection }\end{array}$ & $\begin{array}{l}2 \mathrm{ml} \text { of HA } \\
\text { (Orthovisc): } \\
15 \mathrm{mg} \\
\text { sodium } \\
\text { hyaluronate } \\
+9 \mathrm{mg} \\
\text { sodium } \\
\text { chloride } / 1 \mathrm{ml}\end{array}$ & $\begin{array}{l}1 \mathrm{ml} \text { triamcinolone } \\
\text { acetonide } \\
\text { (Kenacort-A) }\end{array}$ & $\begin{array}{l}1-3,6,7 \\
9,12 \\
\text { months }\end{array}$ & II \\
\hline $\begin{array}{l}\text { Palmieri } \\
\text { et al. } \\
2013^{159}\end{array}$ & $\mathrm{RCT}$ & $\begin{array}{l}62 \text { patients with } \\
\text { bilateral } \\
\text { gonarthrosis }\end{array}$ & $\begin{array}{l}3 \text { groups: } \\
\text { - } 66 \mathrm{mg} \text { of } \mathrm{HA} \\
-49.5 \mathrm{mg} \text { of } \mathrm{HA}+5 \mathrm{mg} \\
\text { of diclofenac } \\
-49.5 \mathrm{mg} \text { of } \mathrm{HA}+5 \mathrm{mg} \\
\text { of sodium clodronate }\end{array}$ & $\begin{array}{l}-66 \mathrm{mg} / 2 \mathrm{ml} \\
\text { of } \mathrm{HA} \\
\text { (Variofillß) } \\
-49.5 \mathrm{mg} / 1.5 \\
\mathrm{ml} \text { of } \mathrm{HA} \\
\text { (Variofill囚) }\end{array}$ & $\begin{array}{l}\text { - } 5 \mathrm{mg} / 0.5 \mathrm{ml} \text { of } \\
\text { sodium diclofenac; } \\
\text { - } 5 \mathrm{mg} / 0.5 \mathrm{ml} \text { of } \\
\text { sodium clodronate }\end{array}$ & $\begin{array}{l}3 \text { and } 6 \\
\text { months }\end{array}$ & II \\
\hline $\begin{array}{l}\text { Petrella } \\
\text { et al. } \\
2015^{156}\end{array}$ & $\mathrm{RCT}$ & $\begin{array}{l}98 \text { subjects with } \\
\text { gonarthrosis }\end{array}$ & $\begin{array}{l}3 \text { groups: } \\
\text { - HA (Hydros) } \\
\text { - HA }+10 \mathrm{mg} \text { of } \\
\text { triamcinolone acetonide } \\
\text { (Hydros TA) } \\
\text { - HA (Synvisc-One) }\end{array}$ & $\begin{array}{l}\text {-Hydros } \\
\text {-Hydros TA } \\
\text { (HA + } 10 \mathrm{mg} \\
\text { triamcinolone } \\
\text { acetonide) } \\
\text {-Synvisc- } \\
\text { One (hylan } \\
\text { G-F 20) }\end{array}$ & $\begin{array}{l}10 \mathrm{mg} \text { of } \\
\text { triamcinolone } \\
\text { acetonide }\end{array}$ & $\begin{array}{l}2,6,13, \\
26 \text { weeks }\end{array}$ & II \\
\hline $\begin{array}{l}\text { Rovetta \& } \\
\text { Monteforte } \\
1998^{89}\end{array}$ & RCT & $\begin{array}{l}30 \text { subjects with } \\
\text { adhesive capsulitis }\end{array}$ & $\begin{array}{l}2 \text { groups (injections } \\
\text { every } 15 \text { days in first } \\
\text { month, then monthly } \\
\text { for } 6 \text { months): } \\
\text { - injection of HA + } \\
\text { steroids + physiotherapy } \\
\text { - injection of steroids + } \\
\text { physiotherapy }\end{array}$ & $\begin{array}{l}20 \mathrm{mg} \text { of } \\
\text { sodium } \\
\text { hyaluronate }\end{array}$ & $\begin{array}{l}20 \mathrm{mg} \text { of } \\
\text { triamcinolone } \\
\text { acetonide (both } \\
\text { groups) }\end{array}$ & 6 months & II \\
\hline
\end{tabular}


Continue from Table XII.

\begin{tabular}{|c|c|c|c|c|c|c|c|}
\hline $\begin{array}{l}\text { Saw et al. } \\
2013^{161}\end{array}$ & RCT & $\begin{array}{l}50 \text { patients with } \\
\text { chondral lesions of } \\
\text { the knee (grade 3-4 } \\
\text { ICRS } \\
\text { International } \\
\text { Cartilage Repair } \\
\text { Society) }\end{array}$ & $\begin{array}{l}2 \text { groups ( } 5 \text { weekly } \\
\text { injections, started } 1 \\
\text { week after arthroscopy } \\
+3 \text { weekly injections } \\
\text { after } 6 \text { months): } \\
\text { - HA only } \\
\text { - HA + peripheral blood } \\
\text { stem cells (PBSC) }\end{array}$ & $\begin{array}{l}2 \mathrm{ml} \text { of } \mathrm{HA} \text { for } \\
\text { each injection }\end{array}$ & $\begin{array}{l}8 \mathrm{ml} \text { injection of } \\
\text { PBSC }\end{array}$ & $\begin{array}{l}\text {-IKDC: } 6 \text {, } \\
\text { 12,18,24 } \\
\text { months } \\
\text {-MRI: } 6 \text {, } \\
12,18 \\
\text { months } \\
\text {-biopsy: } \\
\text { 18 months }\end{array}$ & II \\
\hline $\begin{array}{l}\text { Tosun } \\
\text { et al. } \\
2015^{149}\end{array}$ & RCT & $\begin{array}{l}57 \text { patients with } \\
\text { clinical diagnosis of } \\
\text { lateral epicondylitis }\end{array}$ & $\begin{array}{l}2 \text { groups ( } 1 \text { single } \\
\text { injection): } \\
-\mathrm{HA}+\text { chondroitin } \\
\text { sulfate }(C S)+\text { prilocaine } \\
\text { - triamcinolone + } \\
\text { prilocaine }\end{array}$ & $\begin{array}{l}1 \mathrm{ml} \text { of laluril } \\
(800 \mathrm{mg} \text { of } \\
\mathrm{HA}+1 \mathrm{~g} \text { of } \\
\text { chondroitin } \\
\text { sulphate } / 50 \\
\mathrm{ml})+0.6 \mathrm{ml} \text { of } \\
\text { prilocaine } \\
\mathrm{HCl} \\
\text { (Citanest) }\end{array}$ & $\begin{array}{l}1 \mathrm{ml} \text { triamcinolone } \\
\text { acetonide }(40 \mathrm{mg} / \\
\mathrm{ml}, \text { Kenacort- } \mathrm{A} \\
\text { Retard })+0.6 \mathrm{ml} \text { of } \\
\text { prilocaine } \mathrm{HCl} \\
\text { (Citanest) }\end{array}$ & $\begin{array}{l}3 \text { and } 6 \\
\text { months } \\
\text { after } \\
\text { injection }\end{array}$ & II \\
\hline $\begin{array}{l}\text { Saturveith } \\
\text { an et al. } \\
2016 \text { v }\end{array}$ & $\begin{array}{l}\text { Retros } \\
\text { pective } \\
\text { non } \\
\text { rando } \\
\text { mized }\end{array}$ & $\begin{array}{l}64 \text { patients (101 } \\
\text { knees) with } \\
\text { gonarthrosis }\end{array}$ & $\begin{array}{l}2 \text { groups: } \\
\text { - HA + PRP (56 knees) } \\
\text { - HA only (45 knees) }\end{array}$ & $\begin{array}{l}4 \mathrm{ml} \text { of high- } \\
\mathrm{MW} \mathrm{HA} \\
(1476 \times 106 \\
\text { Da) with a } \\
\text { concentration } \\
\text { of } 22 \mathrm{mg} / \mathrm{ml}\end{array}$ & $\begin{array}{l}2.5-3 \mathrm{ml} \text { of PRP } \\
\text { with an average } \\
\text { [PLTs] of 1.4-1.6 } \\
\text { million/ } \mu \mathrm{l}\end{array}$ & $\begin{array}{l}2 \text { and } 6 \\
\text { months } \\
\text { after } \\
\text { injection }\end{array}$ & II \\
\hline $\begin{array}{l}\text { Briggs } \\
\text { et al. } \\
2012^{157}\end{array}$ & $\begin{array}{l}\text { Clinical } \\
\text { trial } \\
\text { without } \\
\text { control }\end{array}$ & $\begin{array}{l}47 \text { patients ( } 27 \\
\text { females) } \\
\text { with diagnosis of } \\
\text { gonarthrosis }\end{array}$ & $\begin{array}{l}\text { Cycle of } 3 \text { injections: } \\
\text { - at I injection brand+ } \\
\text { HA+Kenalog+lidocaine } \\
\text { - at II and III injection } \\
\text { only HA }\end{array}$ & Hylan G-F & $\begin{array}{l}-2 \mathrm{ml} \text { of Kenalog- } \\
10 \text { (triamcinolone } \\
\text { acetonide); } \\
-3 \mathrm{ml} \text { of brand } \\
\text { (Bupivacaine) } \\
-3 \mathrm{ml} \text { of lidocaine }\end{array}$ & $\begin{array}{l}3,6,12 \\
\text { weeks } \\
\text { and } 6 \\
\text { months }\end{array}$ & II \\
\hline $\begin{array}{l}\text { Conrozier } \\
\text { et al. } \\
2016^{163}\end{array}$ & $\begin{array}{l}\text { Retrosp } \\
\text { ective } \\
\text { clinical } \\
\text { trial } \\
\text { without } \\
\text { control }\end{array}$ & $\begin{array}{l}40 \text { patients with } \\
\text { gonarthrosis }\end{array}$ & $\begin{array}{l}1 \text { single injection of } \\
\text { HAnox-M-XL (4.4 ml) }\end{array}$ & $\begin{array}{l}\text { HAnox-M-XL } \\
4.4 \mathrm{ml}: \text { cross- } \\
\text { linked HA } \\
(16 \mathrm{mg} / \mathrm{ml})+ \\
\text { mannitol } \\
(35 \mathrm{mg} / \mathrm{ml})\end{array}$ & $\begin{array}{l}35 \mathrm{mg} / \mathrm{ml} \text { of } \\
\text { mannitol }\end{array}$ & $\begin{array}{l}3 \text { and } 6 \\
\text { months }\end{array}$ & II \\
\hline $\begin{array}{l}\text { Henrotin } \\
\text { et al. } \\
2012^{164}\end{array}$ & $\begin{array}{l}\text { Clinical } \\
\text { trial } \\
\text { without } \\
\text { control }\end{array}$ & $\begin{array}{l}30 \text { patients } \\
\text { with gonarthrosis }\end{array}$ & $\begin{array}{l}3 \text { weekly injections of } \\
\text { sterile solution }(2 \mathrm{ml}) \text { of } \\
\mathrm{HA}+\text { chondroitin sulphate } \\
\text { (CS) }\end{array}$ & $24 \mathrm{mg}$ of $\mathrm{HA}$ & $\begin{array}{l}60 \mathrm{mg} \text { chondroitin } \\
\text { sulfate (Structovial } \\
\text { CS) }\end{array}$ & $\begin{array}{l}6 \text { and } 12 \\
\text { weeks }\end{array}$ & II \\
\hline
\end{tabular}

Association with other drugs/medical devices

Three different studies reported significant clinical benefits with the use of HA in association to oxygenozone therapy, mannitol and chondroitin sulfate, respectively, in patients with knee osteoarthritis ${ }^{162-164}$. Level of recommendation: $C$.

Keypoints

- The association of HA with other drugs or devices could have advantages in comparison to HA alone.

- Dosage and frequency of association with HA in osteoarticular and myotendinous diseases are not defined.

- Future high quality RCTs are needed in order to improve the knowledge about mechanism of action and efficacy of combined therapies.

KEY WORDS: hyaluronic acid, musculoskeletal, injection, intra-articular, sodium hyaluronate, anesthet- ic, corticosteroid, NSAIDS, PRP, mesenchymal stem cells, ozon.

\section{Ultrasound guidance for HA injection in musculoskeletal disorders}

The advantages of ultrasound (US) imaging (realtime execution, absence of ionizing radiation, low cost and availability of device) are responsible of the large diffusion of US-guidance.

\section{US-guidance in shoulder pathologies}

Three studies were selected. Two studies investigated the outcome in patients with adhesive capsulitis ${ }^{84,165}$, while one study in subacromial pain syndrome (Tab. XIII) ${ }^{166}$. All studies reported good clinical results after US-guided injections of HA, at least in the short term.

US-guidance in hand pathologies

Four different studies shave reported that US-guided injections of HA appear to be a safe and suitable tool 
Table XIII. Selected studies for on US-guided injections.

\begin{tabular}{|c|c|c|c|c|c|}
\hline $\begin{array}{l}\text { Author } \\
\text { and year }\end{array}$ & Population & Type of HA & Injection frequency & $\begin{array}{l}\text { Follow-up } \\
\text { period }\end{array}$ & $\begin{array}{l}\text { Level of } \\
\text { evidence }\end{array}$ \\
\hline $\begin{array}{l}\text { Atchia et al. } \\
2011^{104}\end{array}$ & $\begin{array}{l}77 \text { patients with unilateral } \\
\text { coxarthrosis waiting for surgical } \\
\text { total hip replacement }\end{array}$ & $3 \mathrm{ml} / 60 \mathrm{mg}$ of Durolane & Not specified & $\begin{array}{l}1,4,8 \\
\text { weeks }\end{array}$ & II \\
\hline $\begin{array}{l}\text { Battaglia et } \\
\text { al. } 2013^{105}\end{array}$ & $\begin{array}{l}100 \text { patients with unilateral } \\
\text { coxarthrosis }\end{array}$ & $\begin{array}{l}\text { High molecular weight } \mathrm{HA} \\
(1500 \mathrm{Kd} \text {, Hyalubrix })\end{array}$ & $\begin{array}{l}3 \text { consecutive } \\
\text { injections } \\
\text { (every } 2 \text { weeks) }\end{array}$ & $\begin{array}{l}1,3,6,12 \\
\text { months }\end{array}$ & I \\
\hline $\begin{array}{l}\text { Bum Park et } \\
\text { al. } 2012^{169}\end{array}$ & 99 subjects with gonarthrosis & $\begin{array}{l}2 \mathrm{ml} 1 \% \text { high molecular } \\
\text { weight } \mathrm{HA}(940-1020 \mathrm{kDa})\end{array}$ & $\begin{array}{l}3 \text { weekly intra- } \\
\text { articular injections }\end{array}$ & $\nabla$ & II \\
\hline $\begin{array}{l}\text { Callegari et } \\
\text { al. } 2011^{148}\end{array}$ & $\begin{array}{l}30 \text { subjects with stenosing } \\
\text { tenosynovitis of finger flexors }\end{array}$ & $\begin{array}{l}1 \mathrm{ml} \mathrm{0.8 \%} \mathrm{HA} \mathrm{(Sinovial} \mathrm{Mini)} \\
\text { +methylprednisolone acetate } \\
40 \mathrm{mg} / 1 \mathrm{ml} \text { (Depo-medrol) }\end{array}$ & $\begin{array}{l}2 \text { injections ( } 10 \text { days } \\
\text { between them) }\end{array}$ & $\begin{array}{l}6 \text { weeks, } 3 \\
6,12 \\
\text { months }\end{array}$ & II \\
\hline $\begin{array}{l}\text { Kim et al. } \\
2012^{166}\end{array}$ & $\begin{array}{l}80 \text { patients with subacromial } \\
\text { conflict syndrome }\end{array}$ & $\begin{array}{l}2 \mathrm{ml} / 20 \mathrm{mg} \text { of Hyruan plus } \\
\text { (average molecular weight } \\
300,000,000 \mathrm{Da} \text { ) }\end{array}$ & $\begin{array}{l}3 \text { weekly injections } \\
\text { (Al group); } \\
1 \text { injection } \\
\text { (corticosteroid } \\
\text { group) }\end{array}$ & $\begin{array}{l}3,6,12 \\
\text { weeks }\end{array}$ & II \\
\hline $\begin{array}{l}\text { Lee et al. } \\
2009165\end{array}$ & $\begin{array}{l}43 \text { patients with shoulder } \\
\text { adhesive capsulitis }\end{array}$ & $\begin{array}{l}2.5 \mathrm{ml} / 25 \mathrm{mg} \text { of low } \\
\text { molecular weight HA }\end{array}$ & $\begin{array}{l}\text { I week: } 0.5 \mathrm{ml} / 20 \mathrm{mg} \\
\text { of triamcinolone with } \\
1.5 \mathrm{ml} \text { of } 2 \% \\
\text { lidocaine and } 3 \mathrm{ml} \\
\text { of saline solution; } \\
\text { II-VI week: HA }\end{array}$ & $\begin{array}{l}\text { Weekly } \\
\text { follow-up }\end{array}$ & II \\
\hline $\begin{array}{l}\text { Liu et al. } \\
2015^{147}\end{array}$ & $\begin{array}{l}36 \text { subjects ( } 39 \text { fingers) with } \\
\text { clinical diagnosis of trigger } \\
\text { finger }\end{array}$ & $\begin{array}{l}1 \mathrm{ml} \text { medium molecular } \\
\text { weight } \mathrm{HA}(1000-1200 \mathrm{kDa} \text {, } \\
\text { Artz) }\end{array}$ & 1 injection & $\begin{array}{l}3 \text { weeks, } \\
3 \text { months }\end{array}$ & II \\
\hline $\begin{array}{l}\text { Monfort et al. } \\
2015^{168}\end{array}$ & 88 patients with rhizoartrosis & $\begin{array}{l}0.5 \mathrm{~cm} 3 / 5 \mathrm{mg} \text { of } 500- \\
1000 \mathrm{kDa} \mathrm{HA} \text { produced by } \\
\text { bacterial fermentation } \\
\text { (Suplasyn } \AA \text { ) }\end{array}$ & 3 weekly injections & $\begin{array}{l}7,14,30,90 \\
180 \text { days }\end{array}$ & II \\
\hline $\begin{array}{l}\text { Orlandi et al. } \\
2015^{167}\end{array}$ & $\begin{array}{l}75 \text { patients with unilateral de } \\
\text { Quervain's disease }\end{array}$ & $\begin{array}{l}16 \mathrm{mg} / 2 \mathrm{ml} \text { of low molecular } \\
\text { weight } \mathrm{HA}(0.8 \% \text {, Sinovial) }\end{array}$ & $\begin{array}{l}2 \text { injections ( } 15 \text { days } \\
\text { between them): } \\
\text { I injection: steroid; } \\
\text { II injection: HA }\end{array}$ & $\begin{array}{l}1,3,6 \\
\text { months }\end{array}$ & 1 \\
\hline $\begin{array}{l}\text { Park et al. } \\
2013^{84}\end{array}$ & $\begin{array}{l}90 \text { patients with shoulder } \\
\text { adhesive capsulitis }\end{array}$ & $\begin{array}{l}18 \mathrm{ml} \text { of lidocaine } 0.5 \% \text { for } \\
\text { capsular distention }+2 \mathrm{ml} \\
\text { high } \mathrm{MW} \mathrm{HA}(10 \mathrm{mg} / \mathrm{ml})\end{array}$ & 3 biweekly injections & $\begin{array}{l}2 \text { and } 6 \\
\text { weeks }\end{array}$ & II \\
\hline $\begin{array}{l}\text { Qvistgaard et } \\
\text { al. } 2006^{99}\end{array}$ & 101 patients with coxarthrosis & $2 \mathrm{ml}$ of HA (Hyalgan $\AA)$ & $\begin{array}{l}3 \text { injections every } 14 \\
\text { days }\end{array}$ & $\begin{array}{l}14,28,90 \\
\text { days }\end{array}$ & II \\
\hline
\end{tabular}

for the treatment of trigger finger, de Quervain's disease and rhizarthrosis $147,148,167,168$.

\section{US-guidance in hip}

US-guided injections of HA have shown good results in three studies on patient with hip osteoarthritis $^{99,104,105}$. Authors suggested that US could be useful not only as a guide, but also as a biomarker of response to therapy.

US-guidance in knee

One level II study reported that the precision of injection is better for US-guided procedure in comparison to anatomical landmark injections in suprapatellar bursitis $^{169}$.

Level of recommendation for US-guided injection in hip joint: $A$.

Level of recommendation for US-guided injection in trigger finger: $B$.

Level of recommendation for US-guided injection in rhizarthrosis, glenohumeral joint and subacromial space: $C$.

Level of recommendation for US-guided injection in other anatomical sites: $D$. 


\section{Keypoints}

- Ultrasound imaging is an effective tool for intra-articular injections guidance in several musculoskeletal disorders, in absence of contraindications and severe side effects.

- While US offers various advantages (cost/benefit ratio, availability, real time acquisition), there is still lack of strong evidence regarding the impact of $\mathrm{HA}$ injections with ultrasound guidance in terms of accuracy and benefits in comparison to blinded procedures.

KEY WORDS: hyaluronic acid guided injection as mesh term.

\section{Hyaluronic acid and exercise therapy}

Four RCTs ${ }^{125,170-172}$ and one review ${ }^{174}$ compared the effectiveness of intra-articular injections of $\mathrm{HA}$ to a specific rehabilitative protocol in the treatment of patients with knee and ankle osteoarthritis; only one RCT investigated the combination to each treatment in alone (Tab. XIV).

The results lead Authors to conclude that both treatments improve pain and function, although combined treatment seems to guarantee greater efficacy, at least in the short term.

Level of recommendation: $B$.

\section{Keypoints}

- Both HA injections and exercise therapy alone and in combination should improve pain e function in patients affected by OA.

- A single RCT suggested a possible greater efficacy of combined treatment in the short term.

- More studies are needed to strongly support this recommendation.

KEY WORDS: hyaluronic acid injection, physical exercises, exercise therapy, viscosupplementation, rehabilitation protocol and/or randomized controlled trial, systematic review.

\section{Hyaluronic acid and physical therapies}

In clinical practice the association between HA injection and physical therapies is common. Indeed, the effects of these therapies seem to be complementary and synergistic: in particular, physical therapies show beneficial actions in the acute phase reducing pain and inflammation through thermal, biochemical, mechanical and electrical effects, while HA acts mainly by facilitating and maintaining functional recovery over time.

However, the real effectiveness of physical therapies in musculoskeletal pathologies is controversial and only few scientific studies are aimed at validating the association between them and $\mathrm{HA}$.

\section{Osteoarthritis}

Three studies ${ }^{6,23,25}$ show better results with the association of HA and physical therapies compared to physical therapies alone in patients with shoulder and knee osteoarthritis ${ }^{174-176}$ (Tab. XV). One pilot study did not show any significant difference, even both short-term (3 weeks) and long-term (3 months) evaluations, index of severity for osteoarthritis of the knee scores were reduced in all three groups ${ }^{177}$.

\section{Adhesive capsulitis}

Two studies ${ }^{26,27}$ agree that the addition of HA to conventional treatments (including physical therapies) does not add significant benefits in patient suffering from adhesive capsulitis.

Level of recommendation: $C$.

Keypoints

- HA and physical therapies are commonly used for the treatment of musculoskeletal pathologies.

- Evidence on the effectiveness of physical therapies in joint and tendon disorders is controversial, mainly because of the lack of high quality RCTs.

- Only few studies demonstrated the effectiveness of association between physical therapies and $\mathrm{HA}$, especially in knee and shoulder osteoarthritis, while there is no evidence on shoulder adhesive capsulitis.

KEY WORDS: hyaluronic acid injection, physical therapy, lasertherapy, viscosupplementation, rehabilitation protocol, shockwaves, ultrasound, electrotherapy and/or randomized controlled trial, systematic review.

\section{Hyaluronic acid in post-surgical management}

The promising results obtained in the conservative treatment of various musculoskeletal diseases have led many surgeons to propose HA also in post-surgical management, especially after shoulder, knee and ankle arthroscopy (Tab. XVI).

\section{HA after knee arthroscopy}

Early viscosupplementation in arthroscopic partial meniscectomy was found to have conflicting results and a possible improvement in short-term pain is not showed in all level I studies ${ }^{178-180}$

Different studies on viscosupplementation after ACL reconstruction evidenced inflammation, swelling and pain reduction only in the immediate post-operative period, without any difference in the longterm ${ }^{69,181,182}$.

Conversely, three RCTs showed significant pain and clinical scores improvement for HMW HA after knee arthroscopy in knee $\mathrm{OA}^{183-185}$

\section{HA after shoulder arthroscopy}

Postoperative capsular stiffness is the main complication after shoulder arthroscopy and may determine prolonged rehabilitation period. HA could be used in postsurgery with the aim of decreasing adhesions and thus facilitating rehabilitation.

However, a recent RCT has not showed significant difference in pain VAS, internal rotation, external rotation and functional scores between two groups at each follow-up period ${ }^{186}$. 


\section{A. Frizziero et al.}

Table XIV. Selected studies on HA and exercise.

\begin{tabular}{|c|c|c|c|c|c|c|}
\hline $\begin{array}{l}\text { Author } \\
\text { and year }\end{array}$ & $\begin{array}{l}\text { Study } \\
\text { design }\end{array}$ & Protocol & $\begin{array}{l}\text { Follow-up } \\
\text { (weeks) }\end{array}$ & Outcome measures & Results & $\begin{array}{l}\text { Level of } \\
\text { evidence }\end{array}$ \\
\hline $\begin{array}{l}\text { Karatosun } \\
\text { et al. } 2006170\end{array}$ & Randomized & $\begin{array}{l}3 \text { injections of Hylan G- } \\
\text { F20 (52 patients) } \\
\text { Exercise ( } 53 \text { patients) }\end{array}$ & $12,24,48,72$ & $\begin{array}{l}\text { Hospital for Special } \\
\text { Surgery (HSS) Knee } \\
\text { Score }\end{array}$ & $\begin{array}{l}\text { No differences } \\
\text { between groups }\end{array}$ & II \\
\hline $\begin{array}{l}\text { Karatosun } \\
\text { et al. } 2008^{125}\end{array}$ & $\begin{array}{l}\text { Randomized } \\
\text { perspective }\end{array}$ & $\begin{array}{l}3 \text { injections of Hylan G-F } \\
20 \text { ( } 19 \text { patients) } \\
\text { Exercise ( } 24 \text { patients) }\end{array}$ & $8,12,24,48$ & $\begin{array}{l}\text { American Orthopedic } \\
\text { Foot and Ankle } \\
\text { Society (AOFAS) } \\
\text { score, VAS score }\end{array}$ & $\begin{array}{l}\text { No differences } \\
\text { between groups }\end{array}$ & II \\
\hline $\begin{array}{l}\text { Kawasaki } \\
\text { et al. } 2009^{171}\end{array}$ & $\begin{array}{l}\text { Randomized } \\
\text { perspective }\end{array}$ & $\begin{array}{l}1 \text { injection of ND device } \\
\text { (42 patients) } \\
\text { Exercise ( } 45 \text { patients) }\end{array}$ & 24 & $\begin{array}{l}\text { VAS, Japanese Knee } \\
\text { Osteoarthritis } \\
\text { Measure (JKOM) }\end{array}$ & $\begin{array}{l}\text { No differences } \\
\text { between groups }\end{array}$ & II \\
\hline $\begin{array}{l}\text { Saccomanno } \\
\text { et al. } 2016^{172}\end{array}$ & Randomized & $\begin{array}{l}3 \text { injections of Orthovisc } \\
\text { (55 patients) } \\
\text { Exercise ( } 55 \text { patients) } \\
3 \text { injections of Orthovisc } \\
+ \text { Exercise (55 patients) }\end{array}$ & $4,12,24$ & $\begin{array}{l}\text { Western Ontario and } \\
\text { McMaster Universities } \\
\text { (WOMAC) Index, } \\
\text { Active Range of } \\
\text { Movement (AROM) }\end{array}$ & $\begin{array}{l}\text { Significant } \\
\text { improvement } \\
\text { in pain at } 1 \\
\text { month in } \mathrm{HA}+ \\
\text { exercise group }\end{array}$ & 1 \\
\hline
\end{tabular}

Table XV. Selected studies on combined HA and physical therapies.

\begin{tabular}{|c|c|c|c|c|c|c|}
\hline $\begin{array}{l}\text { Author } \\
\text { and year }\end{array}$ & $\begin{array}{l}\text { Study } \\
\text { design }\end{array}$ & Protocol/pathology & $\begin{array}{l}\text { Follow-up } \\
\text { (weeks) }\end{array}$ & $\begin{array}{l}\text { Outcome } \\
\text { measures }\end{array}$ & Results & $\begin{array}{l}\text { Level of } \\
\text { evidence }\end{array}$ \\
\hline $\begin{array}{l}\text { Di Giacomo \& } \\
\text { De Gasperis } \\
2015^{174}\end{array}$ & $\begin{array}{l}\text { Randomized } \\
\text { perspective }\end{array}$ & $\begin{array}{l}5 \text { injections of Hyalgan } 20+ \\
\text { exercise ( } 31 \text { patients) } \\
\text { Physical therapies } \\
\text { (30 patients) } \\
\text { Glenohumeral osteoarthritis }\end{array}$ & 16,24 & Constant scale & $\begin{array}{l}\text { First group (HA+PT) } \\
\text { had statistically better } \\
\text { results on disability } \\
\text { and pain compared to } \\
\text { second group (PT) }\end{array}$ & II \\
\hline $\begin{array}{l}\text { Huang et al., } \\
2005^{175}\end{array}$ & Randomized & $\begin{array}{l}\text { Injection of ND device + } \\
\text { exercises + US (32) } \\
\text { Exercises (26) } \\
\text { Exercises + US (29) } \\
\text { Control (31) } \\
\text { Gonarthrosis }\end{array}$ & 8,1 year & $\begin{array}{l}\text { Lequesne } \\
\text { scale, } \\
\text { VAS, ROM, } \\
\text { walking speed, } \\
\text { peak of } \\
\text { strength }\end{array}$ & $\begin{array}{l}\text { Combined treatment } \\
\text { with } \mathrm{HA} \text {, isokinetic } \\
\text { exercises and US } \\
\text { gave better results on } \\
\text { disability and pain } \\
\text { compared to exercises } \\
\text { alone or exercises + } \\
\text { US at } 1 \text { year }\end{array}$ & II \\
\hline $\begin{array}{l}\text { Bayramoğlu } \\
\text { et al., 2003177 }\end{array}$ & Randomized & $\begin{array}{l}3 \text { injections of Synvisc } ® \\
+ \text { exercise ( } 12 \text { patients) } \\
3 \text { injections of Orthovisc } ®+ \\
\text { exercise ( } 16 \text { patients) } \\
\text { Exercise ( } 9 \text { patients) } \\
\text { Gonarthrosis }\end{array}$ & 3,12 & $\begin{array}{l}\text { Lequesne } \\
\text { scale, } \\
\text { isokinetic } \\
\text { strength }\end{array}$ & $\begin{array}{l}\text { No significant } \\
\text { differences in } \\
\text { function at } 3 \text { weeks } \\
\text { and } 3 \text { months } \\
\text { between treatment } \\
\text { with HA+PT (TENS + } \\
\text { diathermy) and PT } \\
\text { alone }\end{array}$ & II \\
\hline $\begin{array}{l}\text { Ip \& Fu } \\
2015^{176}\end{array}$ & $\begin{array}{l}\text { Randomized } \\
\text { perspective }\end{array}$ & $\begin{array}{l}\text { Exercise }+ \text { fake irradiation }+5 \\
\text { injections of saline solution } \\
\text { (70 patients) } \\
\text { Exercise }+5 \text { injections of } \\
\text { Hyalgan } \AA+\text { LLLT } \\
\text { (70 patients) } \\
\text { Gonarthrosis }\end{array}$ & 7 years & $\begin{array}{l}\text { WOMAC } \\
\text { scale, use of } \\
\text { prosthesis }\end{array}$ & $\begin{array}{l}\text { Group B treated with } \\
\text { LLLT + low molecular } \\
\text { weight HA had greater } \\
\text { reduction of pain and } \\
\text { minor recourse to } \\
\text { prosthetic surgery } \\
\text { compared to group A } \\
\text { treated with traditional } \\
\text { physical therapies like } \\
\text { US, ET and diathermy }\end{array}$ & II \\
\hline
\end{tabular}


Table XVI. Selected studies on post-surgical management.

\begin{tabular}{|c|c|c|c|c|c|c|}
\hline $\begin{array}{l}\text { Author } \\
\text { and year }\end{array}$ & $\begin{array}{l}\text { Study } \\
\text { design }\end{array}$ & Protocol/pathology & $\begin{array}{l}\text { Follow-up } \\
\text { (weeks) }\end{array}$ & $\begin{array}{l}\text { Outcome } \\
\text { measures }\end{array}$ & Results & $\begin{array}{l}\text { Level of } \\
\text { evidence }\end{array}$ \\
\hline $\begin{array}{l}\text { Mathies } \\
2006^{178}\end{array}$ & $\mathrm{RCT}$ & $\begin{array}{l}25 \text { patients: treatment } \\
25 \text { patients: control } \\
\text { Arthroscopic } \\
\text { meniscectomy }\end{array}$ & 4 & VAS, circumference & $\begin{array}{l}\text { Less pain and swelling in } \\
\text { the first } 30 \text { days }\end{array}$ & I \\
\hline $\begin{array}{l}\text { Thein et al. } \\
2010^{179}\end{array}$ & $\mathrm{RCT}$ & $\begin{array}{l}28 \text { patients: treatment } \\
28 \text { patients: control } \\
\text { Arthroscopic } \\
\text { meniscectomy }\end{array}$ & 12 & VAS, circumference & $\begin{array}{l}\text { Less pain, less swelling, } \\
\text { equal functional scores }\end{array}$ & 1 \\
\hline $\begin{array}{l}\text { Filardo et al. } \\
2016^{180}\end{array}$ & $\mathrm{RCT}$ & $\begin{array}{l}45 \text { patients: treatment } \\
45 \text { patients: control } \\
\text { Arthroscopic } \\
\text { meniscectomy }\end{array}$ & 24 & $\begin{array}{l}\text { IKDC, KOOS, VAS, } \\
\text { Tegner scores }\end{array}$ & No difference & 1 \\
\hline $\begin{array}{l}\text { Heybeli et al. } \\
2008^{183}\end{array}$ & $\mathrm{RCT}$ & $\begin{array}{l}33 \text { patients: treatment } \\
34 \text { patients: control } \\
\text { Gonarthrosis }\end{array}$ & 24 & WOMAC, VAS & $\begin{array}{l}\text { Better clinical scores at } 6 \\
\text { weeks } \\
\text { No difference at } 24 \\
\text { weeks }\end{array}$ & I \\
\hline $\begin{array}{l}\text { Westrich et al. } \\
2009^{184}\end{array}$ & $\mathrm{RCT}$ & $\begin{array}{l}23 \text { patients: treatment } \\
23 \text { patients: control } \\
\text { Gonarthrosis }\end{array}$ & 24 & $\begin{array}{l}\text { VAS, functional } \\
\text { results }\end{array}$ & $\begin{array}{l}\text { Better results for } \\
\text { treatment group }\end{array}$ & 1 \\
\hline $\begin{array}{l}\text { Hempfling } \\
2007^{185}\end{array}$ & $\mathrm{RCT}$ & $\begin{array}{l}40 \text { patients: treatment } \\
40 \text { patients: control } \\
\text { Gonarthrosis }\end{array}$ & 2 years & $\begin{array}{l}\text { VAS, walking ability, } \\
\text { functional results }\end{array}$ & $\begin{array}{l}\text { Better results in treatment } \\
\text { group }\end{array}$ & I \\
\hline $\begin{array}{l}\text { Huang et al. } \\
200769\end{array}$ & $\mathrm{RCT}$ & $\begin{array}{l}90 \text { patients: treatment } \\
30 \text { patients: control } \\
\text { LCA reconstruction }\end{array}$ & 16 & $\begin{array}{l}\text { Lysholm scale, } \\
\text { ROM, walking } \\
\text { speed }\end{array}$ & $\begin{array}{l}\text { Better results in treatment } \\
\text { group }\end{array}$ & I \\
\hline $\begin{array}{l}\text { Chau et al. } \\
2012^{181}\end{array}$ & $\mathrm{RCT}$ & $\begin{array}{l}16 \text { patients: treatment } \\
16 \text { patients: control } \\
\text { LCA reconstruction }\end{array}$ & 12 & $\begin{array}{l}\text { KOOS, ROM, } \\
\text { circumference, use } \\
\text { of analgesics }\end{array}$ & $\begin{array}{l}\text { Improvement in pain and } \\
\text { swelling at } 2 \text { days }\end{array}$ & 1 \\
\hline $\begin{array}{l}\text { Di Martino } \\
\text { et al. } 2016^{182}\end{array}$ & $\mathrm{RCT}$ & $\begin{array}{l}30 \text { patients: treatment } \\
30 \text { patients: control } \\
\text { LCA reconstruction }\end{array}$ & 1 year & $\begin{array}{l}\text { ROM, VAS, } \\
\text { circumference, SF- } \\
36, \text { IKDC, Tegner } \\
\text { score }\end{array}$ & $\begin{array}{l}\text { Improvement in ROM and } \\
\text { swelling at } 30 \text { and } 60 \\
\text { days }\end{array}$ & 1 \\
\hline $\begin{array}{l}\text { Oh et al. } \\
2011^{186}\end{array}$ & RCT & $\begin{array}{l}40 \text { patients: treatment } \\
40 \text { patients: control } \\
\text { Rotator cuff suture }\end{array}$ & 1 year & $\begin{array}{l}\text { VAS, ROM, } \\
\text { CONSTANT, ASES }\end{array}$ & No difference & 1 \\
\hline $\begin{array}{l}\text { Doral et al. } \\
2012^{187}\end{array}$ & $\mathrm{RCT}$ & $\begin{array}{l}41 \text { patients: treatment } \\
16 \text { patients: control } \\
\text { Chondral lesions of } \\
\text { astragalus }\end{array}$ & 2 years & $\begin{array}{l}\text { Freiburg, AOFAS } \\
\text { score }\end{array}$ & $\begin{array}{l}\text { Better results for } \\
\text { treatment group }\end{array}$ & 1 \\
\hline $\begin{array}{l}\text { Görmeli et al. } \\
2015^{188}\end{array}$ & $\mathrm{RCT}$ & $\begin{array}{l}13 \text { patients: PRP } \\
14 \text { patients: HA } \\
13 \text { patients: control } \\
\text { Chondral lesions of } \\
\text { astragalus }\end{array}$ & 60 & AOFAS score, VAS & $\begin{array}{l}\text { Better results in PRP and } \\
\text { HA groups compared to } \\
\text { controls }\end{array}$ & I \\
\hline
\end{tabular}


HA after foot and ankle surgery

Two different level I RCTs showed that HA in addition to microfractures could offer better clinical results in osteochondral lesions of the talus ${ }^{187,188}$.

Level of recommendation: A after knee arthroscopy in knee OA patients.

Level of recommendation: $D$ after knee arthroscopic meniscectomy and ACL surgery.

Level of recommendation: $A$ in post-surgical pain management.

Level of recommendation: $C$ after shoulder arthroscopy and foot and ankle surgery.

\section{Keypoints}

- HA may determine improve in pain in the early postoperative period after knee artrhoscopy.

- HA does not appear to offer any long-term clinical benefit after arthroscopic meniscectomy and LCA surgery.

- Further studies are needed to recommend the use of HA after shoulder and ankle surgery.

KEY WORDS: hyaluronic acid, viscosupplementation, sodium hyaluronate, knee arthroscopy, knee surgery, shoulder arthroscopy, shoulder surgery, ankle arthroscopy, ankle surgery, ligaments and tendons, tendon surgery.

\section{Contraindications and adverse effects}

Fifty-seven studies (40 RCTs and 17 systematic reviews) were selected65,78,98,99,101,102,104,107,108, 114,136,139, 140,148,156,158,159,189-227.

Absolute contraindications are represented by hypersensitivity to products, suspect or presence of infections at injection skin site or selected joint, joint inflammatory states.

As intra-articular injection represents an invasive procedure, should be carefully considered in patients suffering from hematological disorders.

Hepatic pathologies and venous and/or lymphatic stasis could affect HA metabolism.

Considering the lack of scientific evidence regarding HA safety in pregnancy, breast-feeding and in the pediatric population, viscosupplementation is contraindicated in these conditions (Tab. XVII).

Adverse effects are of minor entity, as usually not limit daily life activities and disappear in a few hours or days (Tab. XVIII).

Minor adverse effects include local superficial or articular pain and/or swelling, myalgia, upper respiratory tract disorders, headache, paresthesia, lipothymia, gastrointestinal minor disorders, general fatigue, skin rash, local pruritus, urticaria, allergic manifestations, phlebitis and other minor events.

Only few studies reported more serious adverse events that however concerned a negligible percentage of included subjects and were considered improbable and unrelated to the treatment.

Level of recommendation: A for safety and tolerability of HA products.

\section{Keypoints}

- HA injections are well tolerated.

- Adverse effects due to HA injections are not frequent, minor and transient; serious adverse events recorded were not related to treatment.

KEY WORDS: hyaluronic acid injection, side effects, contraindication.

\section{Authors contributions}

I.S.MU.L.T. - ITALIAN SOCIETY OF MUSCLES LIGAMENTS \& TENDONS. Italian version of the Guidelines: "Linee Guida I.S.Mu.L.T. Trattamento infiltrativo con acido ialuronico nelle patologie dell'apparato muscolo-scheletrico" IBSA Farmaceutici Italia, Edra Editore, 2017.

\section{Coordinators}

Filippo Vittadini, Antonio Frizziero, Francesco Oliva.

\section{Group of the experts}

Giovanni Abatangelo, Asmaa Mahmoud, Daniela Buonocore, Roberto Buda, Maurizia Dossena, Luigi Frizziero, Stefano Galletti, Alessio Giai Via, Giovanni Merolla, Alberto Migliore, Simone Nicoletti, Antonello Padolino, Marco Terreni, Alessandro Valent, Manuela Verri, Mario Vetrano.

\section{Overseeing group}

Anna C Berardi, Francesco Ceccarelli, Cosimo Costantino, Cesare Faldini, Calogero Foti, Nicola Maffulli, Giuseppe Porcellini, Maria Chiara Vulpiani.

\section{Group of preparation and evaluation of the literature}

Serenella Bacciu, Michela Bossa, Filippo Calderazzi, Antonio Carolla, Paolo Finotti, Giuseppe Gasparre, Simone Natali, Leonardo Pellicciari, Eleonora Piccirilli, Eleonora Pintus, Davide Romiti, Antonella Vertuccio. 
Table XVII. Contraindications reported on leaflets of each HA formulation considered.

\begin{tabular}{|c|c|c|c|c|c|c|c|c|c|}
\hline Trade name & $\begin{array}{l}\text { Hyper- } \\
\text { sensitivity } \\
\text { to HA }\end{array}$ & $\begin{array}{l}\text { Skin } \\
\text { infections }\end{array}$ & $\begin{array}{l}\text { Joint } \\
\text { infections }\end{array}$ & $\begin{array}{l}\text { Joint } \\
\text { phlogosis }\end{array}$ & $\begin{array}{l}\text { Pregnancy } \\
\text { /lactation }\end{array}$ & $\begin{array}{l}\text { Lymphatic/ } \\
\text { venous } \\
\text { stasis }\end{array}$ & $\begin{array}{l}\text { Liver patho- } \\
\text { logies }\end{array}$ & $\begin{array}{l}\text { Pediatric } \\
\text { age }\end{array}$ & $\begin{array}{l}\text { Blood } \\
\text { disorders }\end{array}$ \\
\hline Artrhum & 0 & 0 & 0 & 0 & 0 & 0 & 0 & 0 & 0 \\
\hline Arthrum $2.5 \%$ & 0 & 0 & 0 & 0 & 0 & 0 & 0 & 0 & 0 \\
\hline Artrosulfur HA & 0 & 1 & 1 & 1 & 0 & 0 & 0 & 0 & 0 \\
\hline Artz/Supartz & 1 & 0 & 0 & 0 & 1 & 0 & 1 & 1 & 0 \\
\hline Condrovisc & 0 & 1 & 1 & 1 & 1 & 0 & 0 & $\nabla$ & 0 \\
\hline Coxarthrum & 1 & 0 & 1 & 1 & 0 & 0 & 0 & 0 & 0 \\
\hline Durolane (AF) & 0 & 1 & 0 & 0 & 1 & 0 & 0 & 1 & 0 \\
\hline Euflexxa & 1 & 1 & 1 & 0 & 1 & 0 & 0 & 0 & 0 \\
\hline Fermathron (AF) & 1 & 1 & 1 & 0 & 0 & 0 & 0 & 0 & 0 \\
\hline Go-on & 1 & 0 & 0 & 1 & 0 & 0 & 0 & 0 & 0 \\
\hline Go-on Mini & 1 & 0 & 0 & 1 & 0 & 0 & 0 & 0 & 0 \\
\hline Go-on matrix & 1 & 1 & 1 & 1 & 0 & 1 & 0 & 0 & 0 \\
\hline Hyalart & 1 & 0 & 0 & 0 & 0 & 0 & 1 & 0 & 0 \\
\hline Hyalgan & 1 & 0 & 0 & 0 & 0 & 0 & 1 & 0 & 0 \\
\hline Hyalubrix & 1 & 1 & 0 & 0 & 0 & 0 & 0 & 0 & 0 \\
\hline Hyalubrix $60^{*}$ & 1 & 1 & 0 & 0 & 0 & 0 & 0 & 0 & 0 \\
\hline Hymovis & 1 & 1 & 0 & 0 & 0 & 0 & 0 & 0 & 0 \\
\hline Inartral & 1 & 1 & 0 & 0 & 0 & 0 & 0 & 0 & 0 \\
\hline Intragel (AF) & 0 & 1 & 1 & 1 & 0 & 0 & 0 & 0 & 0 \\
\hline Jointex (AF) & 0 & 1 & 1 & 1 & 0 & 0 & 0 & 0 & 0 \\
\hline Jonexa & 1 & 1 & 1 & 0 & 0 & 1 & 0 & 0 & 0 \\
\hline Kartilage (AF) & 1 & 0 & 0 & 1 & 0 & 0 & 0 & 0 & 0 \\
\hline MonoVisc & 1 & 1 & 0 & 0 & 0 & 0 & 0 & 0 & 1 \\
\hline OrthoVisc (AF) & 1 & 0 & 0 & 0 & 1 & 0 & 0 & 0 & 0 \\
\hline Ostenil (AF) & 1 & j & 0 & 0 & 0 & 0 & 0 & 0 & 0 \\
\hline Proial & 1 & 1 & 1 & 0 & 0 & 0 & 0 & 0 & 0 \\
\hline Promovia & 0 & 1 & 0 & 0 & 0 & 0 & 0 & 0 & 0 \\
\hline RenehaVis & 1 & 0 & 0 & 0 & 0 & 0 & 0 & 0 & 0 \\
\hline Rhizarthrum & 1 & 0 & 1 & 1 & 0 & 0 & 0 & 0 & 0 \\
\hline Sinovial (AF) & 0 & 1 & 1 & 1 & 0 & 0 & 0 & 0 & 0 \\
\hline SportVis & 1 & 1 & 0 & 0 & 0 & 0 & 0 & 0 & 0 \\
\hline Structovial & 1 & 0 & 1 & 0 & 0 & 0 & 0 & 0 & 0 \\
\hline Synocrom (AF) & 1 & 0 & 1 & 0 & 0 & 0 & 0 & 0 & 0 \\
\hline Synolis V-A & 1 & 1 & 1 & 0 & 1 & 0 & 0 & 1 & 0 \\
\hline Synvisc (AF) & 0 & 1 & 1 & 1 & 0 & 1 & 0 & 0 & 0 \\
\hline Yaral (AF) & 0 & 1 & 1 & 1 & 0 & 0 & 0 & 0 & 0 \\
\hline Viscoplus (AF) & 0 & 0 & 0 & 0 & 0 & 0 & 0 & 0 & 0 \\
\hline
\end{tabular}

Notes: * also Hyalone; AF: all formulations of the same brand. 
Table XVIII. Adverse events reported in selected studies after HA injection.

\begin{tabular}{|c|c|c|c|c|c|c|}
\hline $\begin{array}{l}\text { Author } \\
\text { and year }\end{array}$ & $\begin{array}{l}\text { Study } \\
\text { design }\end{array}$ & Population & Treatments & Type of HA & Adverse events & $\begin{array}{l}\text { Level of } \\
\text { evidence }\end{array}$ \\
\hline $\begin{array}{l}\text { Abate } \\
\text { et al. } \\
2008^{189}\end{array}$ & $\begin{array}{l}\text { Systematic } \\
\text { review }\end{array}$ & $\begin{array}{l}17 \text { clinical trials } \\
\text { (coxarthrosis) }\end{array}$ & & $\begin{array}{l}\text { No difference between } \\
\text { HA formulations } \\
\text { (data not shown) }\end{array}$ & $\begin{array}{l}\text { - pain at injection site } \\
\text { - heaviness at injection } \\
\text { site }\end{array}$ & I \\
\hline $\begin{array}{l}\text { Altman } \\
\text { et al. } \\
1998^{192}\end{array}$ & $\begin{array}{l}\text { RCT } \\
\text { multicenter }\end{array}$ & $\begin{array}{l}495 \text { patients } \\
\text { with } \\
\text { idiopathic } \\
\text { gonarthrosis }\end{array}$ & $\begin{array}{l}3 \text { treatment groups: } \\
\text { - HA } \\
\text { - placebo } \\
\text { - naproxen }\end{array}$ & & $\begin{array}{l}\text { - pain at injection site } \\
\text { - gastrointestinal } \\
\text { disorders } \\
\text { - swelling/effusion } \\
\text { - death (pre-existing } \\
\text { cardiovascular disorders) }\end{array}$ & I \\
\hline $\begin{array}{l}\text { Altman } \\
\text { et al. } \\
2009^{193}\end{array}$ & $\mathrm{RCT}$ & $\begin{array}{l}588 \text { subjects } \\
\text { with } \\
\text { gonarthrosis }\end{array}$ & $\begin{array}{l}2 \text { groups: } \\
\text { - Phosphate } \\
\text { Buffered } \\
\text { Saline (PBS) } \\
\text { - BioHA }\end{array}$ & $\begin{array}{l}20 \mathrm{mg} / 2 \mathrm{ml} \text { of } \\
\text { EUFLEXXA® } \\
\text { (1\% bio-engineered } \\
\text { sodium hyaluronate) }\end{array}$ & $\begin{array}{l}\text { - pain at injection site } \\
\text { - arthralgia } \\
\text { - pneumonia } \\
\text { - TIA }\end{array}$ & I \\
\hline $\begin{array}{l}\text { Altman } \\
\text { et al. } \\
2011^{194}\end{array}$ & $\mathrm{RCT}$ & $\begin{array}{l}433 \text { subjects } \\
\text { with } \\
\text { gonarthrosis }\end{array}$ & $\begin{array}{l}2 \text { groups: } \\
\text { - PBS } \\
\text { - BioHA }\end{array}$ & $\begin{array}{l}20 \mathrm{mg} / 2 \mathrm{ml} \text { of } \\
\text { EUFLEXXA® } \\
\text { (1\% bio-engineered } \\
\text { sodium hyaluronate) }\end{array}$ & $\begin{array}{l}\text { - pain at injection site } \\
\text { - arthralgia } \\
\text { - rhinopharyngitis } \\
\text { - other upper airways } \\
\text { infections } \\
\text { - soft tissue edema } \\
\text { adjacent to injection site } \\
\text { - joint swelling } \\
\text { - peripheral edema }\end{array}$ & 1 \\
\hline $\begin{array}{l}\text { Arden } \\
\text { et al. } \\
2014195\end{array}$ & $\mathrm{RCT}$ & $\begin{array}{l}208 \text { patients } \\
\text { with } \\
\text { gonarthrosis }\end{array}$ & $\begin{array}{l}2 \text { groups: } \\
-3 \mathrm{ml} \text { of NASHA } \\
\text { (Not Animal } \\
\text { Stabilized HA) } \\
-3 \mathrm{ml} \text { of saline } \\
\text { solution } \\
\text { buffered at } \mathrm{pH} 7\end{array}$ & $\begin{array}{l}60 \mathrm{mg} / 3 \mathrm{ml} \text { of Durolane } \\
\text { (NASHA with unique } \\
\text { cross-linked molecular } \\
\text { structure) }\end{array}$ & pain at injection site & 1 \\
\hline $\begin{array}{l}\text { Arrich } \\
\text { et al. } \\
2005^{196}\end{array}$ & $\begin{array}{l}\text { Systematic } \\
\text { review }\end{array}$ & $\begin{array}{l}22 \text { studies } \\
\text { (gonarthrosis) }\end{array}$ & & $\begin{array}{l}\text { Hyalgan } 500-730 \mathrm{kDa} \\
\text { Orthovisc } 1000-2900 \mathrm{kDa} \\
\text { HA nms } 600-1200 \mathrm{kDa} \\
\text { Artz } 600-1200 \mathrm{kDa} \\
\text { Artzal } \sim 1000 \mathrm{kDa} \\
\text { Synvisc } \sim 7000 \mathrm{kDa} \\
\text { Suplasyn } 500-730 \mathrm{kDa} \\
\text { BioHy } 2400-3600 \mathrm{kDa}\end{array}$ & pain at injection site & 1 \\
\hline $\begin{array}{l}\text { Atchia } \\
\text { et al. } \\
2011^{104}\end{array}$ & $\mathrm{RCT}$ & $\begin{array}{l}77 \text { patients } \\
\text { with unilateral } \\
\text { coxarthrosis } \\
\text { waiting for total } \\
\text { hip arthroplasty }\end{array}$ & $\begin{array}{l}\text { 4 groups: } \\
\text { - standard treatment } \\
\text { (without infiltrations) } \\
\text { - - saline solution } \\
\text { - NASHA } \\
\text { - methylpre-dnisolone } \\
\text { acetate (Depomedrol) }\end{array}$ & $3 \mathrm{ml} / 60 \mathrm{mg}$ of Durolane & post-arthroplasty infection & 1 \\
\hline $\begin{array}{l}\text { Bannuru } \\
\text { et al. } \\
2014197\end{array}$ & $\begin{array}{l}\text { Systematic } \\
\text { review }\end{array}$ & $\begin{array}{l}5 \text { studies } \\
\text { (gonarthrosis) }\end{array}$ & & $\begin{array}{l}\text { Synvisc, Hyalgan, } \\
\text { Suplasyn, Suvenyl }\end{array}$ & $\begin{array}{l}\text { - pain at injection site } \\
\text { - TIA } \\
\text { - myocardial infarction }\end{array}$ & I \\
\hline $\begin{array}{l}\text { Bellamy } \\
\text { et al. } \\
2005^{198}\end{array}$ & $\begin{array}{l}\text { Cochrane } \\
\text { review }\end{array}$ & $\begin{array}{l}63 \text { trials } \\
\text { (gonarthrosis) }\end{array}$ & & $\begin{array}{l}\text { Hyaluronate and hylan } \\
\text { derivates (Adant, } \\
\text { ArthrumH, Artz: Artzal, } \\
\text { Supartz), BioHy } \\
\text { (Arthrease), Durolane, } \\
\text { Fermathron, Go-On, } \\
\text { Hyalgan, Hylan G-F 20 } \\
\text { (Synvisc Hylan G-F 20), } \\
\text { NRD-101, Orthovisc, } \\
\text { Ostenil, Replasyn, SLM- } \\
\text { 10, Suplasyn, Synject } \\
\text { and Zeel compositum }\end{array}$ & $\begin{array}{l}\text { - pain at injection site } \\
\text { - joint swelling } \\
\text { - gastrointestinal } \\
\text { disorders } \\
\text { - hemarthrosis } \\
\text { - phlebitis } \\
\text { - skin rash } \\
\text { - pruritus }\end{array}$ & I \\
\hline
\end{tabular}


Continue from Table XVIII.

\begin{tabular}{|c|c|c|c|c|c|c|}
\hline $\begin{array}{l}\text { Blaine } \\
\text { et al. } \\
200665\end{array}$ & $\mathrm{RCT}$ & $\begin{array}{l}660 \text { subjects } \\
\text { with shoulder } \\
\text { pain }\end{array}$ & $\begin{array}{l}3 \text { groups: } \\
-5 \text { infiltrations of } \\
H A \\
-3 \text { infiltrations of } \\
\mathrm{HA}+2 \text { of saline } \\
\text { solution } \\
-5 \text { infiltrations of } \\
\text { saline solution }\end{array}$ & $2 \mathrm{ml}$ Hyalgan (10 mg/ml) & $\begin{array}{l}\text { - pain at injection site } \\
\text { - arthralgia } \\
\text { - rhinopharyngitis } \\
\text { - headache } \\
\text { - vertebral pain }\end{array}$ & I \\
\hline $\begin{array}{l}\text { Brandt } \\
\text { et al. } \\
2001^{200}\end{array}$ & $\mathrm{RCT}$ & $\begin{array}{l}226 \text { patients } \\
\text { with } \\
\text { gonarthrosis }\end{array}$ & $\begin{array}{l}2 \text { groups: } \\
\text { - HA } \\
\text { - salin solution }\end{array}$ & $\begin{array}{l}2 \mathrm{ml}(15 \mathrm{mg} / \mathrm{ml}) \text { of } \\
\text { ORTHOVISC, high MW } \\
\text { hyaluronic acid, extract } \\
\text { from cock's crests }\end{array}$ & $\begin{array}{l}\text { - pain at injection site } \\
\text { - arthralgia } \\
\text { - local inflammation } \\
\text { - bruising } \\
\text { - generalized fatigue } \\
\text { - gastrointestinal diseases }\end{array}$ & I \\
\hline $\begin{array}{l}\text { Brzusek } \\
\text { et al. } \\
2008^{201}\end{array}$ & $\begin{array}{l}\text { Systematic } \\
\text { review }\end{array}$ & $\begin{array}{l}16 \text { studies } \\
\text { (gonarthrosis) }\end{array}$ & & $\begin{array}{l}\text { Euflexxa, Orthovisc, } \\
\text { Hyalgan,Supartz,Synvisc }\end{array}$ & $\begin{array}{l}\text { - pain at injection site } \\
\text { - joint swelling }\end{array}$ & I \\
\hline $\begin{array}{l}\text { Callegari } \\
\text { et al. } \\
2011^{148}\end{array}$ & $\mathrm{RCT}$ & $\begin{array}{l}30 \text { subjects } \\
\text { with stenosing } \\
\text { tenosynovitis } \\
\text { of finger flexor }\end{array}$ & $\begin{array}{l}2 \text { groups: } \\
\text { - group A: } \\
\text { corticosteroids + } \\
\text { HA } \\
\text { - group B: open } \\
\text { surgery }\end{array}$ & $\begin{array}{l}1 \mathrm{ml} 0.8 \% \mathrm{HA} \text { (Sinovial } \\
\text { Mini) }+ \text { methyl } \\
\text { prednisolone acetate } 40 \\
\mathrm{mg} / 1 \mathrm{ml} \text { (Depo-medrol) }\end{array}$ & No adverse events & I \\
\hline $\begin{array}{l}\text { Chang } \\
\text { et al. } \\
2013^{216}\end{array}$ & $\begin{array}{l}\text { Systematic } \\
\text { review }\end{array}$ & $\begin{array}{l}9 \text { studies } \\
\text { (ankle } \\
\text { osteoarthritis) }\end{array}$ & & Not specified & $\begin{array}{l}\text { - post-injection pain } \\
\text { - increase in volume of } \\
\text { inguinal lymph nodes } \\
\text { - localized pruritus } \\
\text { - dissecans } \\
\text { osteochondritis ( } 4 \text { months } \\
\text { after treatment) }\end{array}$ & I \\
\hline $\begin{array}{l}\text { Chevalier } \\
\text { et al. } \\
2010^{202}\end{array}$ & $\mathrm{RCT}$ & $\begin{array}{l}253 \text { patients } \\
\text { with } \\
\text { gonarthrosis }\end{array}$ & $\begin{array}{l}2 \text { groups: } \\
\text { - arthrocentesis + } \\
\text { infiltration of } \mathrm{HA} \\
\text { - arthrocentesis + } \\
\text { injection saline } \\
\text { solution }\end{array}$ & $\begin{array}{l}6 \mathrm{ml} \text { of Hylan G-F } 20 \\
\text { (Synvisc-One) }\end{array}$ & $\begin{array}{l}\text { - pain at injection site } \\
\text { - joint stiffness } \\
\text { - intraarticular effusion } \\
\text { - joint swelling }\end{array}$ & 1 \\
\hline $\begin{array}{l}\text { Lee } \\
\text { et al. } \\
2011^{158}\end{array}$ & $\mathrm{RCT}$ & $\begin{array}{l}43 \text { subjects } \\
\text { with } \\
\text { gonarthrosis }\end{array}$ & $\begin{array}{l}2 \text { groups: } \\
- \text { HA }+30 \mathrm{mg} \\
\text { ketorolac ( } 3 \\
\text { weeks), followed by } \\
\text { HA alone ( } 2 \text { weeks) } \\
\text { - HA alone for } 5 \\
\text { weeks }\end{array}$ & $\begin{array}{l}2.5 \mathrm{ml}(1 \%) \text { of Hyal (MW: } \\
940-1020 \mathrm{kDa})\end{array}$ & $\begin{array}{l}\text { - pain at injection site } \\
\text { (HA+ketorolac group) }\end{array}$ & I \\
\hline $\begin{array}{l}\text { Day } \\
\text { et al. } \\
2004^{108}\end{array}$ & $\begin{array}{l}\text { RCT } \\
\text { multicentric } \\
\text { study }\end{array}$ & $\begin{array}{l}223 \text { patients } \\
\text { with } \\
\text { gonarthrosis }\end{array}$ & $\begin{array}{l}2 \text { groups: } \\
\text { - HA in saline } \\
\text { solution } \\
\text { - only saline } \\
\text { solution }\end{array}$ & $\begin{array}{l}25 \mathrm{mg} \text { of ARTZ } \\
\text { (extract from cock's } \\
\text { crest, MW } 6.2 \times 105- \\
11.7 \times 105 \mathrm{Da})\end{array}$ & pain at injection site & I \\
\hline $\begin{array}{l}\text { Diracoglu } \\
\text { et al. } \\
2009^{222}\end{array}$ & $\mathrm{RCT}$ & $\begin{array}{l}63 \text { patients } \\
\text { with } \\
\text { bilateral } \\
\text { gonarthrosis }\end{array}$ & $\begin{array}{l}2 \text { groups: } \\
\text { - HA } \\
\text { - placebo }\end{array}$ & Hylan G-F 20 (Synvisc) & No adverse events & 1 \\
\hline
\end{tabular}




\section{A. Frizziero et al.}

Continue from Table XVIII.

\begin{tabular}{|c|c|c|c|c|c|c|}
\hline $\begin{array}{l}\text { Espal- } \\
\text { largues } \\
\text { et al. } \\
2003^{203}\end{array}$ & $\begin{array}{l}\text { Systematic } \\
\text { review }\end{array}$ & $\begin{array}{l}14 \text { studies } \\
\text { (gonarthrosis) }\end{array}$ & & Hylan G-F 20 & $\begin{array}{l}\text { - pain at injection site } \\
\text { - muscle cramps } \\
\text { - hemorrhoids } \\
\text { - impatience }\end{array}$ & I \\
\hline $\begin{array}{l}\text { Fernández } \\
\text { López } \\
\text { et al. } \\
2006^{224}\end{array}$ & $\begin{array}{l}\text { Systematic } \\
\text { review }\end{array}$ & $\begin{array}{l}8 \text { studies } \\
\text { (coxarthrosis) }\end{array}$ & & Not specified & No adverse events & I \\
\hline $\begin{array}{l}\text { Filardo } \\
\text { et al. } \\
2012^{204}\end{array}$ & $\mathrm{RCT}$ & $\begin{array}{l}109 \text { patients } \\
\text { with knee } \\
\text { chondropathy } \\
\text { or gonarthrosis }\end{array}$ & $\begin{array}{l}2 \text { groups: } \\
\text { - PRP } \\
\text { - HA }\end{array}$ & $\begin{array}{l}\text { Hyalubrix (HA with MW } \\
>1500 \mathrm{KDa})\end{array}$ & pain at injection site & I \\
\hline $\begin{array}{l}\text { Fuchs } \\
\text { et al. } \\
2005^{223}\end{array}$ & RCT & $\begin{array}{l}60 \text { patients } \\
\text { with } \\
\text { chronic non } \\
\text { radicular } \\
\text { lumbar pain }\end{array}$ & $\begin{array}{l}2 \text { groups: } \\
\text { - HA } \\
\text { - triamcinolone } \\
\text { acetonide }\end{array}$ & $\begin{array}{l}10 \mathrm{mg} \text { of Ostenil }{ }^{\circledR} \text { mini, } \\
\text { highly purified } \mathrm{HA} \text {, from } \\
\text { bacterial fermentation, } \\
\text { in } 1 \mathrm{ml} \text { of saline solution }\end{array}$ & No adverse events & I \\
\hline $\begin{array}{l}\text { Fuchs } \\
\text { et al. } \\
2006^{136}\end{array}$ & $\mathrm{RCT}$ & $\begin{array}{l}56 \text { patients } \\
\text { with } \\
\text { rhizarthrosis }\end{array}$ & $\begin{array}{l}2 \text { groups: } \\
\text { - HA } \\
\text { - triamcinolone } \\
\text { acetonide }\end{array}$ & $\begin{array}{l}10 \mathrm{mg} / 1 \mathrm{ml} \text { of } \\
\text { Ostenilß } \\
\text { mini }(1,2 \mathrm{MDa})\end{array}$ & $\begin{array}{l}\text { - lipotimia } \\
\text { - pain at index finger } \\
\text { - sciatica } \\
\text { - pulmonary carcinoma }\end{array}$ & I \\
\hline $\begin{array}{l}\text { Oh } \\
\text { et al. } \\
2011^{186}\end{array}$ & $\mathrm{RCT}$ & $\begin{array}{l}80 \text { subjects } \\
\text { submitted } \\
\text { to rotator cuff } \\
\text { surgical } \\
\text { repair }\end{array}$ & $\begin{array}{l}2 \text { groups: } \\
\text { Al/carboxymethylat } \\
\text { ed } \\
\text { cellulose } \\
\text { no treatment }\end{array}$ & $\begin{array}{l}5 \mathrm{~g} \text { of } \mathrm{HA} / \\
\text { carboxymethylated } \\
\text { cellulose }(\mathrm{CMC}): \\
\text { Guardix-Sol }{ }^{\circledR}\end{array}$ & No adverse events & I \\
\hline $\begin{array}{l}\text { Ishijima } \\
\text { et al. } \\
2014^{218}\end{array}$ & $\mathrm{RCT}$ & $\begin{array}{l}200 \text { patients } \\
\text { with } \\
\text { gonarthrosis }\end{array}$ & $\begin{array}{l}2 \text { groups: } \\
\text { - NSAIDs } \\
\text { - HA }\end{array}$ & $\begin{array}{l}25 \mathrm{mg} \text { of high MW HA } \\
(2700 \mathrm{kDa}) \text {, Chugai } \\
\text { Pharmaceutical Co. }\end{array}$ & joint stiffness & I \\
\hline $\begin{array}{l}\text { Jørgensen } \\
\text { et al. } \\
2010^{205}\end{array}$ & $\mathrm{RCT}$ & $\begin{array}{l}337 \text { patients } \\
\text { with } \\
\text { gonarthrosis }\end{array}$ & $\begin{array}{l}2 \text { groups: } \\
\text { - HA } \\
\text { - saline solution }\end{array}$ & $\begin{array}{l}2 \mathrm{ml} \text { of sodium } \\
\text { hyaluronate (Hyalgan, } \\
10 \mathrm{mg} / \mathrm{ml})\end{array}$ & pain at injection site & I \\
\hline $\begin{array}{l}\text { Jüni et al. } \\
2007^{219}\end{array}$ & $\mathrm{RCT}$ & $\begin{array}{l}660 \text { patients } \\
\text { with } \\
\text { gonarthrosis }\end{array}$ & $\begin{array}{l}3 \text { groups: } \\
\text { - High MW } \\
\text { crosslinked HA } \\
\text { derived from cock's } \\
\text { crest (Synvisc) } \\
\text { - Medium-MW non- } \\
\text { crosslinked HA } \\
\text { derived from cock's } \\
\text { crest (Orthovisc) } \\
\text { - Low MW non } \\
\text { cross-linked HA } \\
\text { obtained through } \\
\text { bacterial } \\
\text { fermentation } \\
\text { (Ostenil) }\end{array}$ & $\begin{array}{l}2 \mathrm{ml} \text { of Synvisc, } \\
\text { Orthovisc and Ostenil }\end{array}$ & $\begin{array}{l}\text { - joint effusion } \\
\text { - redness at injection site } \\
\text { - septic arthritis } \\
\text { - anaphylactic shock }\end{array}$ & I \\
\hline $\begin{array}{l}\text { Lee et al. } \\
2006^{206}\end{array}$ & RCT & $\begin{array}{l}146 \text { subjects } \\
\text { with } \\
\text { gonarthrosis }\end{array}$ & $\begin{array}{l}2 \text { groups: } \\
\text { - High MW HA } \\
\text { - Low MW HA }\end{array}$ & $\begin{array}{l}\text { Hyruan Plus (high MW } \\
3000 \text { kD), Hyal (medium } \\
\text { MW } 750 \text { kD) }\end{array}$ & $\begin{array}{l}\text { - pain at injection site } \\
\text { - localized pruritus } \\
\text { - urticaria } \\
\text { - myalgia } \\
\text { - paresthesias }\end{array}$ & I \\
\hline $\begin{array}{l}\text { Leighton } \\
\text { et al. } \\
2014^{207}\end{array}$ & $\mathrm{RCT}$ & $\begin{array}{l}442 \text { subjects } \\
\text { with } \\
\text { gonarthrosis }\end{array}$ & $\begin{array}{l}2 \text { groups: } \\
\text { NASHA } \\
\text { Methylpredni- } \\
\text { solone } \\
\text { acetate (MPA) }\end{array}$ & $60 \mathrm{mg} / 3 \mathrm{ml}$ of Durolane & $\begin{array}{l}\text { - pain at injection site } \\
\text { - arthralgia } \\
\text { - joint stiffness } \\
\text { - joint swelling }\end{array}$ & I \\
\hline
\end{tabular}


Continue from Table XVIII.

\begin{tabular}{|c|c|c|c|c|c|c|}
\hline $\begin{array}{l}\text { Lund- } \\
\text { sgaard } \\
\text { et al. } \\
2008^{225}\end{array}$ & $\mathrm{RCT}$ & $\begin{array}{l}251 \text { subjects } \\
\text { with } \\
\text { gonarthrosis }\end{array}$ & $\begin{array}{l}3 \text { groups: } \\
-2 \mathrm{ml} \text { of HA } \\
-20 \mathrm{ml} \text { saline } \\
\text { solution } \\
-2 \mathrm{ml} \text { saline } \\
\text { solution }\end{array}$ & $\begin{array}{l}2 \mathrm{ml} \text { of Hyalgan (10.3 } \\
\mathrm{mg} / \mathrm{ml})\end{array}$ & No adverse events & 1 \\
\hline $\begin{array}{l}\text { Maheu } \\
\text { et al. } \\
2011^{208}\end{array}$ & $\mathrm{RCT}$ & $\begin{array}{l}276 \text { patients } \\
\text { with } \\
\text { gonarthrosis }\end{array}$ & $\begin{array}{l}2 \text { groups: } \\
-20 \mathrm{mg} \text { of medium } \\
\text { MW HA (F60027) } \\
-16 \mathrm{mg} \text { of high MW } \\
\text { HA (Hylan G-F20) }\end{array}$ & $\begin{array}{l}20 \text { mg of F60027 } \\
\text { (Structorial) } \\
16 \text { mg of Hylan G-F20 } \\
\text { (Synvisc) }\end{array}$ & pain at injection site & 1 \\
\hline $\begin{array}{l}\text { Medina } \\
\text { et al. } \\
2006^{220}\end{array}$ & $\begin{array}{l}\text { Systematic } \\
\text { review }\end{array}$ & $\begin{array}{l}7 \text { studies } \\
\text { (gonarthrosis) }\end{array}$ & - & $\begin{array}{l}\text { Artzal, Synvisc, Hyalgan, } \\
\text { Durolane, Suplasyn, } \\
\text { NRD101 }\end{array}$ & $\begin{array}{l}\text { allergic manifestations: } \\
\text { - sweating } \\
\text { - pallor } \\
\text { - feeling of thoracic or } \\
\text { epigastric oppression } \\
\text { - cyanotic skin } \\
\text { - hypotension }\end{array}$ & I \\
\hline $\begin{array}{l}\text { Migliore et } \\
\text { al. } \\
2009^{102}\end{array}$ & RCT & $\begin{array}{l}42 \text { subjects } \\
\text { with } \\
\text { coxarthrosis }\end{array}$ & $\begin{array}{l}2 \text { groups: - } 4 \mathrm{ml} \mathrm{HA} \\
\text { derived from } \\
\text { bacterial } \\
\text { fermentation } \\
-4 \mathrm{ml} \text { mepivacaine } \\
2 \%\end{array}$ & $\begin{array}{l}4 \mathrm{ml} \text { of Hyalubrix } \\
(60 \mathrm{mg})\end{array}$ & pain at injection site & I \\
\hline $\begin{array}{l}\text { Munteanu } \\
\text { et al. } \\
2011^{140}\end{array}$ & RCT & $\begin{array}{l}151 \text { patients } \\
\text { with } \\
\text { osteoarthritis of } \\
\text { first metatarso- } \\
\text { phalangeal } \\
\text { joint }\end{array}$ & $\begin{array}{l}\text { Participants } \\
\text { randomly allocated } \\
\text { to receive up to } 1 \\
\text { ml intraarticular } \\
\text { injection of both } \\
\text { Hylan G-F20 or } \\
\text { placebo }\end{array}$ & Hylan G-F 20 (Synvisc) & cellulitis at injection site & I \\
\hline $\begin{array}{l}\text { Navarro- } \\
\text { Sarabia } \\
\text { et al. } \\
2011114\end{array}$ & $\mathrm{RCT}$ & $\begin{array}{l}306 \text { subjects } \\
\text { with } \\
\text { gonarthrosis }\end{array}$ & $\begin{array}{l}2 \text { groups: } \\
\text { - HA } \\
\text { - saline solution }\end{array}$ & $\begin{array}{l}2.5 \mathrm{ml}(1 \%) \text { of medium } \\
\mathrm{MW}(900000 \mathrm{Da}) \text { sodium } \\
\text { hyaluronate, obtained } \\
\text { from fermentation of } \\
\text { Streptococcus } \\
\text { zoopidemicus (Adant) }\end{array}$ & $\begin{array}{l}\text { allergic reaction not } \\
\text { specified }\end{array}$ & I \\
\hline $\begin{array}{l}\text { Neustadt } \\
\text { et al. } \\
2005^{209}\end{array}$ & $\begin{array}{l}\text { RCT } \\
\text { multicenter }\end{array}$ & $\begin{array}{l}327 \text { patients } \\
\text { with } \\
\text { gonarthrosis }\end{array}$ & $\begin{array}{l}3 \text { groups: } \\
-4 \text { injections of } \\
\text { high MW HA (O4) } \\
-3 \mathrm{HA} \text { and } 1 \\
\text { arthrocentesis } \\
\text { (O3A1) } \\
-4 \text { arthrocentesis } \\
\text { (A4) }\end{array}$ & $\begin{array}{l}2 \mathrm{ml} / 30 \mathrm{mg} \text { of highly } \\
\text { purified high MW HA } \\
\text { (Orthovisc, } 1-2,9 \mathrm{MDa} \text { ) }\end{array}$ & $\begin{array}{l}\text { - pain at injection site } \\
\text { - arthralgia } \\
\text { - hematoma/ecchymosis } \\
\text { at injection site } \\
\text { - rhinopharyngitis } \\
\text { - headache } \\
\text { - vertebral pain } \\
\text { - heart attack } \\
\text {-gastrointestinal bleeding }\end{array}$ & 1 \\
\hline $\begin{array}{l}\text { Oliveras- } \\
\text { Moreno } \\
\text { et al. } \\
2008^{226}\end{array}$ & $\mathrm{RCT}$ & $\begin{array}{l}41 \text { subjects } \\
\text { with pain at } \\
\text { temporo- } \\
\text { mandibular } \\
\text { joint (Wilkes } \\
\text { stage II) }\end{array}$ & $\begin{array}{l}2 \text { groups: } \\
\text { - HA } \\
\text { - methocarbamol } \\
\text { + paracetamol }\end{array}$ & $\begin{array}{l}1 \mathrm{ml} \text { of sodium } \\
\text { hyaluronate } 1 \% \text { (Ostenil } \\
\text { mini) }\end{array}$ & No adverse events & I \\
\hline $\begin{array}{l}\text { Özgen } \\
\text { et al. } \\
2012^{78}\end{array}$ & $\mathrm{RCT}$ & $\begin{array}{l}24 \text { subjects } \\
\text { with tendinitis } \\
\text { of } \\
\text { supraspinatus }\end{array}$ & $\begin{array}{l}2 \text { groups: } \\
\text { - HA } \\
\text { - physical means }\end{array}$ & $\begin{array}{l}2 \mathrm{ml} / 16 \mathrm{mg} \text { of } \mathrm{G}-\mathrm{F} 20 \\
\text { with a } \mathrm{MW} \text { of } 6 \times 106\end{array}$ & No adverse events & I \\
\hline $\begin{array}{l}\text { Palmieri } \\
\text { et al. } \\
2013^{159}\end{array}$ & $\mathrm{RCT}$ & $\begin{array}{l}62 \text { patients } \\
\text { with } \\
\text { bilateral } \\
\text { gonarthrosis }\end{array}$ & $\begin{array}{l}3 \text { groups: } \\
-66 \mathrm{mg} \text { of } \mathrm{HA} \\
-49.5 \mathrm{mg} \text { of } \mathrm{HA}+ \\
5 \mathrm{mg} \text { of diclofenac }\end{array}$ & $\begin{array}{l}66 \mathrm{mg} / 2 \mathrm{ml} \text { of } \mathrm{HA} \\
\text { (Variofillß) }\end{array}$ & No adverse events & I \\
\hline
\end{tabular}




\begin{tabular}{|c|c|c|c|c|c|c|}
\hline & & & $\begin{array}{l}\text { sodium } \\
-49.5 \mathrm{mg} \text { of } \mathrm{HA}+ \\
5 \mathrm{mg} \text { of sodium } \\
\text { clodronate }\end{array}$ & & & \\
\hline $\begin{array}{l}\text { Petrella } \\
\text { et al. } \\
2015^{156}\end{array}$ & $\begin{array}{l}\mathrm{RCT} \\
\text { multicenter }\end{array}$ & $\begin{array}{l}98 \text { subjects } \\
\text { with } \\
\text { gonarthrosis }\end{array}$ & $\begin{array}{l}3 \text { groups: } \\
\text { - HA (Hydros) } \\
- \text { HA + } \\
\text { triamcinolone } \\
\text { acetonide } 10 \mathrm{mg} \\
\text { (Hydros TA) } \\
\text { - HA (Synvisc-One) }\end{array}$ & $\begin{array}{l}\text { - Hydros (hydrogel with } \\
\text { HA suspended in HA } \\
\text { solution) } \\
\text { - Hydros TA (HA+10 mg } \\
\text { triamcinolone acetonide) } \\
\text { - Synvisc-One } ® \text { (hylan } \\
\text { G-F 20) }\end{array}$ & $\begin{array}{l}\text { - arthralgia } \\
\text { - joint swelling } \\
\text { - joint stiffness } \\
\text { - vertebral pain } \\
\text { - colitis } \\
\text { - bronchopneumonia } \\
\text { - meniscal lesion }\end{array}$ & I \\
\hline $\begin{array}{l}\text { Qvistgaard } \\
\text { et al. } \\
2006^{99}\end{array}$ & $\mathrm{RCT}$ & $\begin{array}{l}101 \text { patients } \\
\text { with } \\
\text { coxarthrosis }\end{array}$ & $\begin{array}{l}3 \text { groups: } \\
-1 \mathrm{ml} / 40 \mathrm{mg} \\
\text { methylpredni-solone } \\
+2 \text { fake injections } \\
-3 \text { injections } \mathrm{HA} \\
(2 \mathrm{ml})-3 \text { injections of } \\
\text { saline solution } \\
(2 \mathrm{ml})\end{array}$ & $2 \mathrm{ml}$ of HA (Hyalgan $\AA)$ & pain at injection site & 1 \\
\hline $\begin{array}{l}\text { Reichen- } \\
\text { bach } \\
\text { et al. } \\
2007^{211}\end{array}$ & $\begin{array}{l}\text { Systematic } \\
\text { review }\end{array}$ & $\begin{array}{l}13 \text { studies } \\
\text { (gonarthrosis) }\end{array}$ & & $\begin{array}{l}\text { Artzal, Orthovisc, } \\
\text { Hyalgan, Ostenil, Bio-Hy }\end{array}$ & $\begin{array}{l}\text { - pain at injection site } \\
\text { - joint swelling }\end{array}$ & I \\
\hline $\begin{array}{l}\text { Richette } \\
\text { et al. } \\
2009^{101}\end{array}$ & $\mathrm{RCT}$ & $\begin{array}{l}122 \text { patients } \\
\text { with } \\
\text { symptomatic } \\
\text { coxarthrosis }\end{array}$ & $\begin{array}{l}2 \text { groups: } \\
\text { - HA } \\
\text { - saline solution }\end{array}$ & $\begin{array}{l}2.5 \mathrm{ml} \text { of HA (Adant) } \\
\text { obtained from } \\
\text { Streptococcus } \\
\text { fermentation with } \\
\text { average MW } 900000 \mathrm{Da}\end{array}$ & $\begin{array}{l}\text { - pain at injection site } \\
\text { - hematoma at injection } \\
\text { site } \\
\text { - pruritus }\end{array}$ & I \\
\hline $\begin{array}{l}\text { Saito } \\
\text { et al. } \\
2009^{212}\end{array}$ & $\begin{array}{l}\text { Systematic } \\
\text { review }\end{array}$ & $\begin{array}{l}5 \text { studies (knee } \\
\text { rheumatoid } \\
\text { arthritis) }\end{array}$ & & Not specified & pain at injection site & I \\
\hline $\begin{array}{l}\text { Saito } \\
\text { et al. } \\
2010^{191}\end{array}$ & $\begin{array}{l}\text { Systematic } \\
\text { review }\end{array}$ & $\begin{array}{l}19 \text { studies } \\
\text { (chronic } \\
\text { shoulder pain) }\end{array}$ & & $\begin{array}{l}\text { NRD 101, Artz (900 kD), } \\
\text { SLM-10 (1900 kD), } \\
\text { Hyalart, Subenyl (1900 } \\
\text { kD), Orthovisc (1000- } \\
2900 \text { kD), Hyalgan (500- } \\
730 \text { kD) }\end{array}$ & $\begin{array}{l}\text { - pain at injection site } \\
\text { - joint swelling }\end{array}$ & I \\
\hline $\begin{array}{l}\text { Shi } \\
\text { et al. } \\
2003^{190}\end{array}$ & $\begin{array}{l}\text { Cochrane } \\
\text { review }\end{array}$ & $\begin{array}{l}11 \text { studies } \\
\text { (temporo- } \\
\text { mandibular } \\
\text { joint disorders) }\end{array}$ & & & $\begin{array}{l}\text { - discomfort at injection } \\
\text { site } \\
\text { - joint swelling }\end{array}$ & 1 \\
\hline $\begin{array}{l}\text { Stahl } \\
\text { et al. } \\
2005^{139}\end{array}$ & $\mathrm{RCT}$ & $\begin{array}{l}52 \text { patients } \\
\text { with } \\
\text { grade II } \\
\text { rhizoartrosis }\end{array}$ & $\begin{array}{l}2 \text { groups: } \\
\text { - methyl- } \\
\text { prednisolone } \\
\text { acetate } \\
\text { - HA }\end{array}$ & $\begin{array}{l}15 \text { mg of sodium } \\
\text { hyaluronate (Ortho-Visc) }\end{array}$ & No adverse events & I \\
\hline $\begin{array}{l}\text { Strand } \\
\text { et al. } \\
2012^{227}\end{array}$ & $\mathrm{RCT}$ & $\begin{array}{l}379 \text { patients } \\
\text { with } \\
\text { gonarthrosis }\end{array}$ & $\begin{array}{l}2 \text { groups: } \\
\text { - HA } \\
\text { - PBS }\end{array}$ & $\begin{array}{l}30 \mathrm{mg} / 3 \mathrm{ml} \text { crosslinked } \\
\mathrm{HA}(\mathrm{Gel}-200)\end{array}$ & No adverse events & I \\
\hline $\begin{array}{l}\text { Tang } \\
2012^{221}\end{array}$ & RCT & $\begin{array}{l}162 \text { patients } \\
\text { with knee } \\
\text { Kashin-Beck } \\
\text { disease }\end{array}$ & $\begin{array}{l}2 \text { groups: } \\
\text { - Intra-articular } \\
\text { HA - meloxicam } \\
\text { per os }\end{array}$ & $\begin{array}{l}25 \mathrm{mg} \text { of } \mathrm{HA}(10 \mathrm{~g} / \mathrm{ml},> \\
800 \mathrm{kDa})\end{array}$ & $\begin{array}{l}\text { local reactions at injection } \\
\text { site }\end{array}$ & \\
\hline $\begin{array}{l}\text { Tikiz } \\
\text { et al. } \\
2005^{98}\end{array}$ & RCT & $\begin{array}{l}43 \text { patients } \\
\text { with } \\
\text { coxarthrosis }\end{array}$ & $\begin{array}{l}2 \text { groups: } \\
\text { - Low MW HA } \\
\text { - High MW HA }\end{array}$ & $\begin{array}{l}\text { - Low MW HA (Ostenil, } \\
\text { 1,2-1,4x106 Da; 1\%) } \\
\text { - High MW HA(hylan G-F } \\
20, \text { Synvisc, 7x106Da) }\end{array}$ & $\begin{array}{l}\text { - pain at injection site } \\
\text { - joint swelling }\end{array}$ & $\mathrm{I}$ \\
\hline
\end{tabular}


Continue from Table XVIII.

\begin{tabular}{|c|c|c|c|c|c|c|}
\hline $\begin{array}{l}\text { Waddell } \\
\text { et al. } \\
2007^{107}\end{array}$ & $\begin{array}{l}\text { Systematic } \\
\text { review }\end{array}$ & (gonarthrosis) & & $\begin{array}{l}\text { Synvisc (hylan G-F 20), } \\
\text { Hyalgan (sodium } \\
\text { hyaluronate), Supartz } \\
\text { (sodium hyaluronate), } \\
\text { Orthovisc (high MW HA) } \\
\text { and Euflexxa ( } 1 \% \\
\text { sodium hyaluronate) }\end{array}$ & $\begin{array}{l}\text { - pain at injection site } \\
\text { - joint swelling }\end{array}$ & I \\
\hline $\begin{array}{l}\text { Wang } \\
\text { et al. } \\
2004^{213}\end{array}$ & $\begin{array}{l}\text { Systematic } \\
\text { review }\end{array}$ & $\begin{array}{l}20 \text { studies } \\
\text { (gonarthrosis) }\end{array}$ & & $\begin{array}{l}\text { Cross-linked HA } \\
\text { (Synvisc), non-cross- } \\
\text { linked HA (Hyalgan, } \\
\text { Orthovisc, Artz) and bio- } \\
\text { engineered HA }\end{array}$ & $\begin{array}{l}\text { - pain at injection site } \\
\text { - joint swelling } \\
\text { - vasculitis } \\
\text { - hypersensitivity } \\
\text { reactions }\end{array}$ & I \\
\hline $\begin{array}{l}\text { Wobig } \\
\text { et al. } \\
1998^{217}\end{array}$ & RCT & $\begin{array}{l}110 \text { patients } \\
\text { with } \\
\text { gonarthrosis }\end{array}$ & $\begin{array}{l}2 \text { groups: } \\
\text { - HA } \\
\text { - saline solution }\end{array}$ & $2 \mathrm{ml}$ of hylan G-F 20 & $\begin{array}{l}\text { - muscle cramps } \\
\text { - hemorrhoids } \\
\text { - impatience }\end{array}$ & I \\
\hline $\begin{array}{l}\text { Wobig } \\
\text { et al. } \\
1999^{214}\end{array}$ & RCT & $\begin{array}{l}70 \text { patients } \\
\text { with } \\
\text { gonarthrosis }\end{array}$ & $\begin{array}{l}2 \text { groups: } \\
\text { - High MW HA } \\
\text { - Low MW HA }\end{array}$ & $\begin{array}{l}\text { - High MW HA (hylan G- } \\
\text { F 20, } 0.8 \% \text { ) } \\
\text { - Low MW HA (1\%) }\end{array}$ & $\begin{array}{l}\text { - pain at injection site } \\
\text { - joint swelling } \\
\text { - intraarticular effusion }\end{array}$ & I \\
\hline $\begin{array}{l}\text { Yu et al. } \\
2014215\end{array}$ & $\begin{array}{l}\text { Systematic } \\
\text { review }\end{array}$ & $\begin{array}{l}7 \text { studies } \\
\text { (gonartrosis in } \\
\text { KBD) }\end{array}$ & - & - & $\begin{array}{l}\text { - pain at injection site } \\
\text { - joint swelling } \\
\text { - intraarticular effusion } \\
\text {-bleeding at injection site }\end{array}$ & I \\
\hline
\end{tabular}

\section{References}

1. Balazs EA, Laurent TC, Jeanloz RW. Nomenclature of hyaluronic acid. Biochem J. 1986;235:903.

2. Turley EA, Noble PW, Bourguignon LY. Signaling properties of hyaluronan receptors. J Bio Chem. 2002;277:4589-4592.

3. Toole BP, Wight TN, Tammi MI. Hyaluronan-cell interactions in cancer and vascular disease. J Biol Chem. 2002;277:45934596.

4. Hascall VC, Majors AK, de la Motte CA, Evanko SP, Wang A, Drazba JA, et al. Intracellular hyaluronan: a new frontier for inflammation? Biochim Biophys Acta. 2004;1673:3-12.

5. Kogan G, Soltes L, Stern R, Gemeiner P. Hyaluronic acid: a natural biopolymer with a broad range of biomedical and industrial applications. Biotechnol Lett. 2007;29:17-25.

6. Darke A, Finer EG, Moorhouse R, Rees DA. Studies of hyaluronate solutions by nuclear magnetic relaxation measurements. Detection of covalently defined, stiff segments within the flexible chains. J Mol Biol. 1975;99:477-486.

7. Ribitsch G, Schurz J, Ribitsch V. Investigation of the solution structure of hyaluronic acid by light-scattering, SAXS and viscosity measurements. Colloid Polym Sci. 1980;258:13221334.

8. Faga A, Nicoletti G, Brenta F, Scevola S, Abatangelo G, Brun $P$. Hyaluronic acid three-dimensional scaffold for surgical revision of retracting scars: a human experimental study. Int Wound J. 2013;10:329-335.

9. Nicoletti G, Brenta F, Bleve M, Pellegatta T, Malovini A, Faga A, Perugini P.Long-term in vivo assessment of bioengineered skin substitutes: a clinical study. J Tissue Eng Regen Med. 2015;9:460-468.

10. Necas J, Bartosikova L, Brauner P, Kolar J. Hyaluronic acid (hyaluronan): a review. Veterinarni Medicina 2008; 53: 397411.

11. Chen WYJ and Abatangelo G. Functions of hyaluronan in wound repair. Wound Repair Regen. 1999;7:79-89.

12. Entwistle J, Hall CL, Turley EA. Receptors: regulators of signalling to the cytoskeleton. J Cell Biochem. 1996;61:569-577.

13. Stephens MB, Beutler Al, O'Connor FG. Musculoskeletal in- jections: a review of the evidence. Am Fam Physician. 2008 Oct;78(8):971-976.

14. Sala DR. Manuale di infiltrazione. Edizione Italiana a cura di D'Avola G, Morelli A, Zoppi U. Torino, Italy: Ed. Minerva Medica. 1997:96.

15. Douglas $L$ and PCRS Members. The Primary Care Rheumatology Society Joint and Soft Tissue Injection Guidelines. The Primary Care Rheumatology Society. 2014 Jan:12.

16. Hawker GA, Grigoriadis E, Fam AG. Principles of joint and periarticular aspirations and injections. In: Lawry GV, Kreder HJ, Hawker GA, Jerome D, editors. Fam's musculoskeletal examination and joint injection techniques, 2nd edition. Philadelphia, PA: Mosby Elsevier. 2010:127-130.

17. Pfenninger JL. Injections of joints and soft tissue: Part I. General guidelines. Am Fam Physician. 1991 Oct;44(4):11961202.

18. Falco FJE, Onyewu CO, Irwin Jr FL, Kim DW, Zhu J . Peripheral Joint, Soft Tissue and Splnal Injection Techniques. In Braddom RL, editor. Physical Medicine and Rehabilitation. 3rd edition. Elsevier Health Science. 2006:541-562.

19. Courtney $\mathrm{P}$, Doherty M. Joint aspiration and injection. Best Pract Res Clin Rheumatol. 2005;19(3):345-369.

20. Hamburger MI, Lakhanpal S, Mooar PA, Oster D. Intra-articular hyaluronans: a review of product-specific safety profiles. Semin Arthritis Rheum. 2003 Apr;32(5):296-309.

21. Hirota W. Intra-articular injection of hyaluronic acid reduces total amounts of leukotriene C4, 6-keto-prostaglandin F1a, prostaglandin $\mathrm{F} 2 \mathrm{a}$ and IL-1 $\beta$ in synovial fluid of patients with internal derangement in disorders of the temporomandibular joint. Br J Oral Maxillofac Surg. 1998;36:35-38.

22. Campo GM, Avenosa A, Nastasi G, Prestipino V, Vaccaro M, D'Ascola A, et al. Hyaluronan reduces inflammation in experimental arthritis by modulating TLR-2 and TLR-4 cartilage expression. Biochim Biophys Acta. 2011 Sep;1812(9):11701181.

23. Kaneko S, Satoh T. Interleukin-6 and interleukin-8 levels in serum and synovial fluid of pathients with osteoarthritis. Cytokines Cell Mol Ther. 2000;6:71-79.

24. Goto M, Hanyu T. Intra-articular injection of hyaluronate (SI- 
6601D) improves joint pain and synovial fluid prostaglandin E2 levels in rheumatoid arthritis: a multicenter clinical trial. Clin Exp Rheumatol. 2001;19:377-383.

25. Yasui T, Akatsuka M, Tobetto K, Hayaishi M, Ando T. The effect of hyaluronan on interleukin-1 alpha-induced prostaglandin E2 production in human osteoarthritic synovial cells. Agents Actions Sep. 1992;37(1e2):155e6.

26. Takahashi K, Goomer RS. The effect of hyaluronan on matrix metalloproteinase-3 (MMP-3), interleukin-1 $\beta$ (IL-1 $\beta$ ), and tissue inibitor of metalloproteinase-1 (TIMP-1) gene expression during the development of osteoarthritis. Osteoarthritis Cartilage. 1999;7:182-190.

27. Punzi L, Schiavon F, Cavasin F, Ramonda R, Gambari PF, Todesco $\mathrm{S}$. The influence of intra-articular hyaluronic acid on PGE-2 and cAMP of synovial fluid. Clin Exp Rheumatol. 1989;7:247-250.

28. Punzi L. The complexity of the mechanisms of action of hyaluronan in joint diseases. Clin Exp Rheumatol. 2001;19: 242-246.

29. Oliviero F, Scanu A, Ramonda R, Frallonardo P, Sfriso P, Dayer JM, Punzi L. IL-1B and IL-8 are scavenged by the hexadecylamide derivative of hyaluronic acid: a new mechanism. J Biomed Mater Res A. 2015 Sep;103(9):2823-2829.

30. Schiraldi C, Stellavato A, de Novellis F, La Gatta A, De Rosa $M$. Hyaluronan viscosupplementation: state of the art and insight into the novel cooperative hybrid complexes based on high and low molecular weight HA of potential interest in osteoarthritis treatment. Clin Cases Miner Bone Metab. 2016 Jan-Apr;13(1):36-37.

31. Kang Y, Eger W, Koepp H, Williams JM, Kuettner KE, Homandberg GA. Hyaluronan suppresses fibronectin fragment-mediated damage to human cartilage ex- plant cultures by enhancing proteoglycan synthesis. J Orthop Res. Nov 1999;17(6):858e869.

32. Fukuda K, Dan H, Takayama M, Kumano F, Saitoh M, Tanaka S. Hyaluronic acid increases proteoglycan synthesis in bovine articular cartilage in the presence of interleukin-1. J Pharmacol Exp Ther Jun. 1996;277(3):1672e1675.

33. Greenberg DD, Stoker A, Kane S, Cockrell M, Cook JL. Biochemical effects of two different hyaluronic acid products in a co-culture model of osteoarthritis. Osteoarthritis Cartilage. 2006 Aug;14(8):814-822.

34. Oliveira MZ, Albano MB, Namba MM, da Cunha LA, de Lima Gonçalves RR, Trindade ES, et al. Effect of hyaluronic acids as chondroprotective in experimental model of osteoarthrosis. Rev Bras Ortop. 2014 Feb 12;49(1):62-68.

35. Yatabe T, Mochizuki S, Takizawa M, Chijiiwa M, Okada A, Kimura T, et al. Hyaluronan inhibits expression of ADAMTS4 (aggrecanase-1) in human osteoarthritic chondrocytes. Ann Rheum Dis. 2009;68:1051-1058.

36. Koga H. Effects of hyaluronic acid on arthritic articular cartilage. Connect Tissue Res. 2012;53(1):48-93.

37. Li J, Gorski DJ, Anemaet W, Velasco J, Takeuchi J, Sandy JD, et al. Hyaluronan injection in murine osteoarthritis prevents TGFbeta 1-induced synovial neovascularization and fibrosis and maintains articular cartilage integrity by a CD44-dependent mechanism. Arthritis Res Ther. 2012;14(3):R151.

38. Mihara M, Hashizume M. The effect of high molecular hyaluronic acid on the induction of matrix degradation enzymes By IL-6, IL-1 $\beta$ and TNF-a. Osteoarthr Cartil. 2012;20: S134-135.

39. Hashimoto S, Setareh M, Ochs RL, Lotz M. Fas/Fas ligand expression and induction of apoptosis in condrocytes. Arthritis Rheum. 1997;40:1749-1755.

40. Hashimoto S, Ochs RL, Komiya S, Lotz M. Linkage of condrocyte apoptosis and cartilage degradation in human osteoarthritis. Arthritis Rheum. 1998;41:1632-1638.

41. Grishko V, Xu M, Ho R, Mates A, Watson S, Kim JT, et al. Ef- fects of hyaluronic acid on mitochondrial function and mitochondria-driven apoptosis following oxidative stress in human chondrocytes. J Biol Chem. 2009 Apr 3;284(14):9132-9139.

42. Peng H, Zhou JL, Liu SQ, Hu QJ, Ming JH, Qiu B. Hyaluronic acid inhibits nitric oxide-induced apoptosis and dedifferentiation of articular chondrocytes in vitro. Inflamm Res. 2010 Jul;59(7):519-530.

43. Kobayashi $\mathrm{K}$. The suppressive effect of hyaluronan on nitric oxide production and cell apoptosis in the central region of meniscus following partial meniscectomy. lowa Orthop J. 2002;22:39-41.

44. Takahashi K, Hashimoto S, Kubo T, Hirasawa Y, Lotz M, Amiel D. Hyaluronan suppressed nitric oxid production in the meniscus and synovium of rabbit osteoarthritis model. $\mathrm{J} \mathrm{Or-}$ thop Res. 2001;19(3):500-503.

45. Balasz EA. Analgesic effects of elastoviscous hyaluronan solutions and the treatment of osteoarthritic pain. Cell Tissue Organs. 2003;174:49-72.

46. Natura G, Bär KJ, Eitner A, Boettger MK, Richter F, Hensellek $\mathrm{S}$, et al. Neuronal prostaglandin E2 receptor subtype EP3 mediates antinociception during inflammation. Proc Natl Acad Sci USA. 2013 Aug 13;110(33):13648-13653.

47. Caires R, Luis E, Taberner FJ, Fernandez-Ballester G, FerrerMontiel A, Balazs EA, et al. Hyaluronan modulates TRPV1 channel opening, reducing peripheral nociceptor activity and pain. Nat Commun. 2015 Aug 27;6:8095.

48. Gomis A, Pawlak M, Balazs EA, Schmidt RF, Belmonte C. Effects of different molecular weight elastoviscous hyaluronan solutions on articular nociceptions afferents. Arthritis Rheum. 2004:50:314-326.

49. Gomis A, Miralles A, Schmidt RF, Belmonte C. Nociceptive nerve activity in an experimental model of knee joint osteoarthritis of the Guinea pig: effects of intra-articular hyaluronan application. Pain. 2007;130:126-136.

50. Gomis A, Miralles A, Schmidt RF, Belmonte C. Intra-articular injections of hyaluronan solutions of different elastoviscosity reduce nociceptive nerve activity in a model of osteoarthritic knee joint of the Guinea pig. Osteoarthritis Cartilage. 2008;17:798-804.

51. Grubb BD. Models of inflammation used to study the properties of articular nociceptors. Pain in osteoarthritis. Edited by Felson DT and Schaible HG; Wiley-Blackwell. 2009.

52. Boettger MK, Kümmel D, Harrison A, Schaible HG. Evaluation of long-term antinociceptive properties of stabilized hyaluronic acid preparation (NASHA) in an animal model of repetitive joint pain. Arthritis Res Ther. 2011;13:R110.

53. Zavan B, Ferroni L, Giorgi C, Calò G, Brun P, Cortivo R, et al. Hyaluronic acid induces activation of the k-opioid receptor. Plos One 2013;8:e55510. Epub. 2013 Jan 28.

54. Hiraoka N, Takahashi KA, Arai Y, Sakao K, Mazda O, Kishida $T$, et al. Intra-articular injection of hyaluronan restores the aberrant expression of matrix metalloproteinase-13 in osteoarthritic subchondral bone. J Orthop Res. 2011 Mar;29 (3):354-360.

55. Mladenovic Z, Saurel AS, Berenbaum F, Jacques C. Potential role of hyaluronic acid on bone in osteoarthritis: matrix metalloproteinases, aggrecanases, and RANKL expression are partially prevented by hyaluronic acid in interleukin 1-stimulated osteoblasts. J Rheumatol. 2014 May;41(5):945-954.

56. Theoleyre S, Wittrant $Y$, Tat SK, Fortun Y, Redini F, Heymann D. The molecular triad OPG/RANK/RANKL: involvement in the orchestration of pathophysiological bone remodeling. Cytokine Growth Factor Rev. 2004 Dec;15(6):457-475.

57. Ghosh P, Smith MM. The syntesis of hyaluronic acid by human synovial fibroblasts is influenced by the nature of te hyaluronan in the extracellular enviroment. Reumathol Int. 1987;7(3):113122.

58. Peyron JG, Balazs EA. Preliminary clinical assessment of 
Nahyaluronate injection of the human knee. Pathol Biol. 1974;22:731-736.

59. Bagga $H$, Burkhardt $D$, Sambrook $P$, March $L$. Longterm effects of intraarticular hyaluronan on synovial fluid in osteoarthritis of the knee. J Rheumatol. 2006;33:946-950.

60. Kusayama Y, Akamatsu Y, Kumagai K, Kobayashi H, Aratake $\mathrm{M}$, Saito T. Changes in synovial fluid biomarkers and clinical efficacy of intra-articular injections of hyaluronic acid for patients with knee osteoarthritis. J Exp Orthop. 2014 Dec;1(1):16.

61. Shimizu M, Higuchi H, Takagishi K, Shinozaki T, Kobayashi T Clinical and biochemical characteristics after intra-articular injection for the treatment of osteoarthritis of the knee: prospective randomized study of sodium hyaluronate and corticosteroid. J Orthop Sci. 2010 Jan;15(1):51-56.

62. Wiig M, Abrahamsson SO, Lundborg G. Effects of hyaluronan on cell proliferation and collagen synthesis: a study of rabbit flexor tendons in vitro. J Hand Surg Am. 1997;22:818-825.

63. Tomonaga A, Hamada K, Gotoh M, Yamakawa H, Kobayashi $\mathrm{K}$, Fukuda $\mathrm{H}$. Expression of procollagen alpha 1 type III mRNA in rotator cuff tears. Tokai J Exp Clin Med. 2000;25(3):125134.

64. Osti L, Berardocco M, di Giacomo V, Di Bernardo G, Oliva F, Berardi AC. Hyaluronic acid increases tendon derived cell viability and collagen type I expression in vitro: Comparative study of four different Hyaluronic acid preparations by molecular weight. BMC Musculoskelet Disord. 2015;16(1):284.

65. Halici M, Karaoglu S, Canoz O, Kabak S, Baktir A. Sodium hyaluronate regulating angiogenesis during Achilles tendon healing. Knee Surg Sports Traumatol Arthrosc. 2004;12(6): 562-567.

66. Goto M, Hanyu T, Yoshio T, et al. Intra-articular injection of hyaluronate (SI-6601D) improves joint pain and synovial fluid prostaglandin E2 levels in rheumatoid arthritis: a multicenter clinical trial. Clin Exp Rheumatol. 2001;19:377-383.

67. Salamanna F, Frizziero A, Pagani S, et al. Metabolic and cytoprotective effects of in vivo peri-patellar hyaluronic acid injections in cultured tenocytes. Connect Tissue Res. 2015;56:35-43.

68. Kumai T, Muneta T, Tsuchiya A, et al. The short-term effect after a single injection of high-molecular-weight hyaluronic acid in patients with enthesopathies (lateral epicondylitis, patellar tendinopathy, insertional Achilles tendinopathy, and plantar fasciitis): a preliminary study. J Orthop Sci. 2014;19(4):603-611.

69. Huang MH, Yang RC, Chou PH, Preliminary effects of hyaluronic acid on early rehabilitation of patients with isolated anterior cruciate ligament reconstruction. Clin J Sport Med. 2007 Jul;17(4):242-250.

70. Messina C, Banfi G, Orlandi D, et al. Ultrasound-guided interventional procedures around the shoulder. $\mathrm{Br} \mathrm{J}$ Radiol. 2016;89(1057):20150372.

71. Chen CP, Hsu CC, Pei YC. Changes of synovial fluid protein concentrations in supra-patellar bursitis patients after the injection of different molecular weights of hyaluronic acid. Exp Gerontol. 2014 Apr;52:30-35.

72. Greving K, Dorrestijn O, Winters JC, Groenhof F, van der Meer $\mathrm{K}$, Stevens M, et al. Incidence, prevalence, and consultation rates of shoulder complaints in general practice. Scand $\mathrm{J}$ of Rheumatol. 2012;41:150-155.

73. Michener LA, McClure PW, Karduna AR. Anatomical and biomechanical mechanisms of subacromial impingement syndrome. Clin Biomech (Bristol, Avon). 2003;18:369-379.

74. Tekavec E, Jöud A, Rittner R, Mikoczy Z, Nordander C, Petersson IF, et al. Population-based consultation patterns in patients with shoulder pain diagnoses. BMC Musculoskeletal Disorders. 2012;13:238.

75. Blaine T, Moskowitz R, Udell J, Skyhar M, Levin R, Friedlander $\mathrm{J}$, et al. Treatment of persistent shoulder pain with sodium hyaluronate: a randomized, controlled trial. A multicenter study. J Bone Joint Surg Am. 2008;90:970-979.
76. Kwon YW, Eisenberg G, Zuckerman JD. Sodium hyaluronate for the treatment of chronic shoulder pain associated with glenohumeral osteoarthritis: a multicenter, randomized, double-blind, placebo-controlled trial. J Shoulder Elbow Surg. 2013;22:584-594.

77. Merolla G, Sperling JW, Paladini P, Porcellini G. Efficacy of Hylan $\mathrm{G}-\mathrm{F} 20$ versus 6-methylprednisolone acetate in painful shoulder osteoarthritis: a retrospective controlled trial. Musculoskeletal Surgery. 2011;95:215-224.

78. Ozgen M, Fırat S, Sarsan A, Topuz O, Ardıç F, Baydemir C Short- and long-term results of clinical effectiveness of sodium hyaluronate injection in supraspinatus tendinitis. Rheumatol Int. 2012;32:137-144.

79. Costantino C, Olvirri S. Rehabilitative and infiltrative treatment with hyaluronic acid in elderly patients with rotator cuff tears. Acta Bio-Medica: Atenei Parmensis. 2009;80:225-229.

80. Porcellini G, Merolla G, Giordan N, Paladini P, Burini A, Cesari $E$, et al. Intra-articular glenohumeral injections of HYADD®4-G for the treatment of painful shoulder osteoarthritis: a prospective multicenter, open-label trial. Joints 2016.;3:116-121.

81. Brander VA, Gomberawalla A, Chambers M, Bowen M, Nuber G. Efficacy and safety of hylan G-F 20 for symptomatic glenohumeral osteoarthritis: a prospective, pilot study. PM R. 2010;2:259-267.

82. Silverstein E, Leger R, Shea KP. The use of intra-articular hylan G-F 20 in the treatment of symptomatic osteoarthritis of the shoulder: a preliminary study. Am J Sports Medicine. 2007;35:979-985.

83. Noël E, Hardy P, Hagena FW, Laprelle E, Goebel F, Faure C, et al. Efficacy and safety of Hylan G-F 20 in shoulder osteoarthritis with an intact rotator cuff. Open-label prospective multicenter study. Joint Bone Spine. 2009;76:670-673.

84. Park KD, Nam H-S, Lee JK, Kim YJ, Park Y. Treatment effects of ultrasound-guided capsular distension with hyaluronic acid in adhesive capsulitis of the shoulder. Archives of Physical Medicine and Rehabilitation. 2013;94:264-270.

85. Porcellini G, Merolla G, Giordan N, Paladini P, Burini A, Cesari $E$, et al. Intra-articular glenohumeral injections of HYADD ${ }^{8} 4-G$ for the treatment of painful shoulder osteoarthritis: a prospective multicenter, open-label trial. Joints n.d.;3:116-121

86. Osti L, Buda M, Buono AD, Osti R, Massari L. Clinical evidence in the treatment of rotator cuff tears with hyaluronic acid.MLTJ. 2016 Feb 13;5(4):270-275.

87. Itokazu M, Matsunaga T. Clinical evaluation of high-molecularweight sodium hyaluronate for the treatment of patients with periarthritis of the shoulder. Clin Ther. 1995.:17:946-955.

88. Tamai K, Mashitori H, Ohno W, Hamada J, Sakai H, Saotome K. Synovial response to intraarticular injections of hyaluronate in frozen shoulder: a quantitative assessment with dynamic magnetic resonance imaging. J Orthop Sci: Official Journal of the Japanese Orthopaedic Association. 2004;9:230-234.

89. Rovetta G, Monteforte P. Intraarticular injection of sodium hyaluronate plus steroid versus steroid in adhesive capsulitis of the shoulder. Intern J of Tissue Reactions. 1998;20:125130.

90. Hsieh L-F, Hsu W-C, Lin Y-J, Chang H-L, Chen C-C, Huang V Addition of intra-articular hyaluronate injection to physical therapy program produces no extra benefits in patients with adhesive capsulitis of the shoulder: a randomized controlled trial. Arch of Phys Med Rehabil. 2012;93:957-964.

91. Meloni F, Milia F, Cavazzuti M, Doria C, Lisai P, Profili S, et al. Clinical evaluation of sodium hyaluronate in the treatment of patients with sopraspinatus tendinosis under echographic guide: experimental study of periarticular injections. Eur $\mathrm{J} \mathrm{Ra-}$ diol. 2008:68:170-173.

92. Chou WY, Ko JY, Wang FS, Huang CC, Wong T, Wang C-J, et al. Effect of sodium hyaluronate treatment on rotator cuff lesions without complete tears: a randomized, double-blind, 
placebo-controlled study. Journal of Shoulder and Elbow Surgery. 2010;19:557-563.

93. Tagliafico A, Serafini G, Sconfienza LM, Lacelli F, Perrone N, Succio G, et al. Ultrasound-guided viscosupplementation of subacromial space in elderly patients with cuff tear arthropathy using a high weight hyaluronic acid: prospective open-label non-randomized trial. Europ Radiol. 2011;21:182-187.

94. Petrella RJ, Cogliano A, Decaria J, Mohamed N, Lee R. Management of Tennis Elbowwith sodium hyaluronate periarticular injections. Sports Med Arthrosc Rehab Ther Technol. 2010 Feb 2;2:4.

95. Tosun HB, Gurmustas S, Agir I, Uludag A, Serbest S, Pepele D, Ertem K. Comparison of the effects of sodium hyaluronatechondroitin sulphate and corticosteroid in the treatment of lateral epicondylitis: a prospective randomized trial. J Orthop Sci. 2015 Sep;20(5):837-843.

96. van Brakel RW, Eygendaal D. Intra-articular injection of hyaluronic acid is not effective for the treatment of post-traumatic osteoarthritis of the elbow. Arthroscopy. 2006 Nov;22 (11):1199-1203.

97. Pederzini LA, Milandri L, Tosi M, Prandini M, Nicoletta F. Preliminary clinical experience with hyaluronan anti-adhesion gel in arthroscopic arthrolysis for posttraumatic elbow stiffness. J Orthop Traumatol. 2013 Jun;14(2):109-114

98. Tikiz C, Unlü Z, Sener A, Efe M, Tüzün C. Comparison of the efficacy of lower and higher molecular weight viscosupplementation in the treatment of hip osteoarthritis. Clin Rheumatol. 2005;24(3)244-250.

99. Qvistgaard E, Christensen R, Torp-Pedersen S, Biddal H. Intra-articular treatment of hip osteoarthritis: a randomized trial of hyaluronic acid, corticosteroid, and isotonic saline. Osteoarhtritis Cart. 2006;14(2):163-170.

100. Van der Bekerom MPJ, Rys B, Mulier M. Viscosupplementation in the hip: evaluation of hyaluronic acid formulations. Acta Orthop Trauma Surg. 2008;128(3):275-280.

101. Richette $P$, Ravaud $P$, Conrozier T, Euller-Ziegler L, Mazières $B$, Maugar et al. Effect of hyaluronic acid in symptomatic hip osteoarthritis: a multicenter, randomized, placebo-controlled trial. Arthritis Rheum. 2009;60(3):824-830.

102. Migliore A, Massafra U, Bizzi E, Vacca F, Martin-Martin S, Granata M, et al. Comparative, double-blind, controlled study of intra-articular hyaluronic acid (Hyalubrix) injections versus local anesthetic in osteoarthritis of the hip. Arthritis Res Ther. 2009;11(6):R183.

103. Spitzer Al, Bockow BI, Brander VA, Yates JW, McCarter DK, Gudger GK, Haller S, Lake SL, Magilavy DB. Hylan G-F 20 improves hip osteoarthritis: a prospective, randomized study. Phys Sports Med. 2010;38(2):35-47.

104. Atchia I, Kane D, Reed MR, Isaacs JD, Birrell F. Efficacy of a single ultrasound-guided injection for the treatment of hip osteoarthritis. Ann Rheum Dis. 2011;70(1):110-116.

105. Battaglia M, Guaraldi F, Vannini F, Rossi G, Timoncini A, Buda R, Giannini S. Efficacy of ultrasound-guided intra-articular injections of platelet-rich plasma versus hyaluronic acid for hip osteoarthritis.Orthopedics. 2013 Dec;36(12):e1501-8.

106. Piccirilli E, Oliva F, Murè MA, Mahmoud A, Foti C, Tarantino U, Maffulli N.Viscosupplementation with intra-articular hyaluronic acid for hip disorders. A systematic review and meta-analysis. MLTJ. 2016 Dec 21;6(3):293-299.

107. Waddell DD. Viscosupplementation with hyaluronans for osteoarthritis of the knee: clinical efficacy and economic implications. Drugs Aging. 2007;24(8):629-642.

108. Day R, Brooks P, Conaghan PG, Petersen M. Multicenter Trial Group. A double blind, randomized, multicenter, parallel group study of the effectiveness and tolerance of intraarticular hyaluronan in osteoarthritis of the knee. J Rheumatol. 2004;31 (4):775-782.

109. Bannuru RR, Natov NS, Dasi UR, Schmid CH, McAlindon TE.
Therapeutic trajectory following intra-articular hyaluronic acid injection in knee osteoarthritis-meta-analysis. Osteoarthritis Cartilage. 2011;19(6):611-619.

110. Trigkilidas $D \&$ Anand $A$. The effectiveness of hyaluronic acid intra-articular injections in managing osteoarthritic knee pain. Ann R Coll Surg Engl. 2013;95(8):545-551.

111. Strand V, McIntyre LF, Beach WR, Miller LE, Block JE. Safety and efficacy of US-approved viscosupplements for knee osteoarthritis: a systematic review and meta-analysis of randomized, saline-controlled trials. J Pain Res. 2015;8:217-228.

112. Zhao H, Liu H, Liang X, Li Y, Wang J, Liu C. Hylan G-F 20 Versus Low Molecular Weight Hyaluronic Acids for Knee Osteoarthritis: A Meta-Analysis. Bio Drugs. 2016;30(5):387-396.

113. Frizziero L, Govoni E, Bacchini P. Intra-articular hyaluronic acid in the treatment of osteoarthritis of the knee: clinical and morphological study. Clin Exp Rheumatol. 1998;16:441-449.

114. Navarro-Sarabia F, Coronel P, Collantes E, Navarro FJ, de la Serna AR, Naranjo A, et al. AMELIA study group. A 40-month multicentre, randomised placebo-controlled study to assess the efficacy and carry-over effect of repeated intra-articular injections of hyaluronic acid in knee osteoarthritis: the AMELIA project. Ann Rheum Dis. 2011;70(11):1957-1962.

115. Pasquali Ronchetti I, Guerra D, Taparelli F, Boraldi F, Bergamini G, Mori G, et al. Morphological analysis of knee synovial membrane biopsies from a randomized controller clinical study comparing the effects of sodium hyaluronate (Hyalgan) and methylprednisolone acetate (Depomedrol) in osteoarthritis. Rheumatology. 2001;40:158-169.

116. Guidolin DD, Ronchetti IP, Lini E, Guerra D, Frizziero L. Morphological analysis of articular cartilage biopsies from a randomized, clinical study comparing the effects of $500-730 \mathrm{kDa}$ sodium hyaluronate (Hyalgan) and methylprednisolone acetate on primary osteoarthritis of the knee. Osteoarthritis Cartilage. 2001;9:371-381.

117. Turajane T, Amphansap T, Labpiboonpong V, Maungsiri S. Total knee replacement following repeated cycles of intra-articular sodium hyaluronate (500-730 Kda) in failed conservative treatment of knee osteoarthritis: a 54-month follow-up. J Med Assoc Thai. 2009;92(Suppl 6):S63-S68.

118. Waddell DD, Joseph B. Delayed Total Knee Replacement with Hylan G-F 20. J Knee Surg. 2016;29(2):159-168.

119. Neustadt $D H$. Long-term efficacy and safety of intra-articular sodium hyaluronate (Hyalgan) in patients with osteoarthritis of the knee. Clin Exp Rheumatol. 2003;21(3):307-311.

120. Whitman C, Allen D, Comadoll JL, Thomason HC, Oweida SJ. A retrospective study of Supartz and repeat treatment for osteoarthritis pain in the knee. J Manag Care Med. 2010;13(1): 43-47.

121. Sun SF, Chou YJ, Hsu CW, Chen WL. Hyaluronic acid as a treatment for ankle osteoarthritis. Curr Rev Musculoskelet Med. 2009;2(2):78-82.

122. Witteveen AGH, Sierevelt IN, Blankevoort L, Kerkhoffs GMMJ, van Dijk CN. Intra-articular sodium hyaluronate injections in the osteoarthritic ankle joint: effects, safety and dose dependency. Foot Ankle Surg Off J Eur Soc Foot Ankle Surg. 2010;16(4):159-163.

123. Salk RS, Chang TJ, D'Costa WF, Soomekh DJ, Grogan KA. Sodium hyaluronate in the treatment of osteoarthritis of the ankle: a controlled, randomized, double-blind pilot study. J Bone Joint Surg Am. 2006;88(2):295-302.

124. Cohen MM, Altman RD, Hollstrom R, Hollstrom C, Sun C, Gipson B. Safety and efficacy of intra-articular sodium hyaluronate (Hyalgan) in a randomized, double-blind study for osteoarthritis of the ankle. Foot Ankle Int. 2008;29(7):657-663.

125. Karatosun V, Unver B, Ozden A, Ozay Z, Gunal I. Intra-articular hyaluronic acid compared to exercise therapy in osteoarthritis of the ankle. A prospective randomized trial with long-term follow-up. Clin Exp Rheumatol. 2008;26(2):288-294. 
126. Carpenter B, Motley T. The role of viscosupplementation in the ankle using hylan G-F 20. J Foot Ankle Surg. 2008;47(5):377384.

127. Mei-Dan O, Carmont MR, Laver L, Mann G, Maffulli N, Nyska $M$. Platelet-rich plasma or hyaluronate in the management of osteochondral lesions of the talus. Am J Sports Med. 2012; 40(3):534-541.

128. DeGroot H, Uzunishvili S, Weir R, Al-omari A, Gomes B. Intra-articular injection of hyaluronic acid is not superior to saline solution injection for ankle arthritis: a randomized, double-blind, placebo-controlled study. J Bone Joint Surg Am. 2012;94(1):2-8.

129. Sun SF, Hsu CW, Lin HS, Chou YJ, Chen JY, Wang JL. Efficacy of intraarticular botulinum toxin $\mathrm{A}$ and intraarticular hyaluronate plus rehabilitation exercise in patients with unilateral ankle osteoarthritis: a randomized controlled trial. J Foot Ankle Res. 2014;7(1):9.

130. Figen Ayhan $F$, Ustün $N$. The evaluation of efficacy and tolerability of Hylan G-F 20 in bilateral thumb base osteoarthritis: 6 months follow-up. Clin Rheumatol. 2009 May;28(5):535-541.

131. Salini V, De Amicis D, Abate M, Natale MA, Di lorio A. Ultrasound-guided hyaluronic acid injection in carpometacarpal osteoarthritis: short-term results. Int J Immunopathol Pharmacol. 2009;22(2):455-460.

132. Di Sante L, Cacchio A, Scettri P, Paoloni M, loppolo F, Santilli V.Ultrasound-guided procedure for the treatment of trapeziometacarpal osteoarthritis. Clin Rheumatol. 2011 Sep;30(9): 1195-1200.

133. Frizziero A, Maffulli N, Masiero S, Frizziero L. Six-months pain relief and functional recovery after intra-articular injections with hyaluronic acid (mw 500-730 KDa) in trapeziometacarpal osteoarthritis. MLTJ. 2014 Jul 14;4(2):256-261.

134. Roux C, Fontas E, Breuil V, Brocq O, Albert C, Euller-Ziegler L. Injection of intra-articular sodium hyaluronidate (Sinovial) into the carpometacarpal joint of the thumb (CMC1) in osteoarthritis. A prospective evaluation of efficacy. Joint Bone Spine. 2007 Jul;74(4):368-372.

135. Heyworth BE, Lee JH, Kim PD, Lipton CB, Strauch RJ, Rosenwasser MP. Hylan versus corticosteroid versus placebo for treatment of basal joint arthritis: a prospective, randomized, double-blinded clinical trial. J Hand Surg Am. 2008 Jan;33(1): 40-48.

136. Fuchs S, Mönikes R, Wohlmeiner A, Heyse T. Intra-articular hyaluronic acid compared with corticoid injections for the treatment of rhizarthrosis. Osteoarthritis Cartilage. 2006 Jan;14(1): 82-88.

137. Ingegnoli F, Soldi A, Meroni PL. Power Doppler sonography and clinical monitoring for hyaluronic Acid treatment of rhizarthrosis: a pilot study.J Hand Microsurg. 2011 Dec;3(2): 51-54.

138. Bahadir C, Onal B, Dayan VY, Gürer N. Comparison of therapeutic effects of sodium hyaluronate and corticosteroid injections on trapeziometacarpal joint osteoarthritis. Clin Rheumatol. 2009 May;28(5):529-533.

139. Stahl S, Karsh-Zafrir I, Ratzon N, Rosenberg N.Comparison of intraarticular injection of depot corticosteroid and hyaluronicacid for treatment of degenerative trapeziometacarpal joints... Clin Rheumatol. 2005 Dec;11(6):299-302.

140. Munteanu SE, Zammit GV, Menz HB, Landorf KB, Handley CJ, Elzarka A, Deluca J. Effectiveness of intra-articular hyaluronan (Synvisc, hylan G-F 20) for the treatment of first metatarsophalangeal joint osteoarthritis: a randomised placebo-controlled trial. Ann Rheum Dis. 2011 Oct;70(10):18381841.

141. Pons M, Alvarez F, Solana J, Viladot R, Varela L. Sodium hyaluronate in the treatment of hallux rigidus. A single-blind, randomized study. Foot Ankle Int. 2007 Jan;28(1):38-42.

142. Petrella RJ, Cogliano A. Intra-articular Hyaluronic Acid Treat- ment for Golfer's Toe: Keeping Older Golfers on Course. Phys Sportsmed. 2004 Jul;32(7):41-45.

143. Wiig ME, Dahlin LB, Fridén J, Hagberg L, Larsen SE, Wiklund K, Mahlapuu M. PXL01 in sodium hyaluronate for improvement of hand recovery after flexor tendon repair surgery: randomized controlled trial. PLoS One. 2014 Oct 23;9(10): e110735.

144. Ozgenel GY, Etöz A. Effects of repetitive injections of hyaluronic acid on peritendinous adhesions after flexor tendon repair: a preliminary randomized, placebo-controlled clinical trial. Ulus Travma Acil Cerrahi Derg. 2012 Jan;18(1):11-17.

145. Riccio M, Battiston B, Pajardi G, Corradi M, Passaretti U, Atzei A, et al. Study Group on Tendon Adhesion of Italian Society of Hand Surgery. Efficiency of Hyaloglide in the prevention of the recurrence of adhesions after tenolysis of flexor tendons in zone II: a randomized, controlled, multicentre clinical trial. $J$ Hand Surg Eur Vol. 2010 Feb;35(2):130-138.

146. Hagberg L. Exogenous hyaluronate as an adjunct in the prevention of adhesions after flexor tendon surgery: a controlled clinical trial. J Hand Surg Am. 1992 Jan;17(1):132-136.

147. Liu DH, Tsai MW, Lin SH, Chou CL, Chiu JW, Chiang CC, Kao CL. Ultrasound-Guided Hyaluronic Acid Injections for Trigger Finger: A Double-Blinded, Randomized Controlled Trial. Arch Phys Med Rehabil. 2015 Dec;96(12):2120-2127.

148. Callegari L, Spanò E, Bini A, Valli F, Genovese E, Fugazzola C. Ultrasound-guided injection of a corticosteroid and hyaluronic acid: a potential new approach to the treatment of trigger finger. Drugs R D. 2011;11(2):137-145.

149. Tosun HB, Gumustas S, Agir I, Uludag A, Serbest S, Pepele D, Ertem K. Comparison of the effects of sodium hyaluronatechondroitin sulphate and corticosteroid in the treatment of lateral epicondylitis: a prospective randomized trial. J Orthop Sci. 2015 Sep;20(5):837-843.

150. Muneta T, Koga H, Ju YJ, Mochizuki T, Sekiya I. Hyaluronan injection therapy for athletic patients with patellar tendinopathy. J Orthop Sci. 2012 Jul; 17(4):425-431.

151. Chang WH, Im SH, Ryu JA, Lee SC, Kim JS. The effects of scapulothoracic bursa injections in patients with scapular pain a pilot study. Arch Phys Med Rehabil. 2009 Feb;90(2):279284.

152. Chen CP, Hsu CC, Pei YC, Chen RL, Zhou S, Shen HC, et al. Changes of synovial fluid protein concentrations in supra-patellar bursitis patients after the injection of different molecular weights of hyaluronic acid. Exp Gerontol. 2014 Apr;52:30-35.

153. de Campos GC, Rezende MU, Pailo AF, Frucchi R, Camargo OP. Adding triamcinolone improves viscosupplementation: a randomized clinical trial. Clin Orthop Relat Res. 2013 Feb;471(2):613-620.

154. Giraddi GB, Siddaraju A, Kumar A, Jain T. Comparison Between Betamethasone and Sodium Hyaluronate Combination with Betamethasone Alone After Arthrocentesis in the Treatment of Internal Derangement of TMJ-Using Single Puncture Technique: A Preliminary Study. J Maxillofac Oral Surg. 2015 Jun;14(2):403-409.

155. Ozturk C, Atamaz F, Hepguler S, Argin M, Arkun R. The safety and efficacy of intraarticular hyaluronan with/without corticosteroid in knee osteoarthritis: 1-year, single-blind, randomized study. Rheumatol Int. 2006 Feb;26(4):314-319.

156. Petrella RJ, Emans PJ, Alleyne J, Dellaert F, Gill DP, Maroney M. Safety and performance of Hydros and Hydros-TA for knee osteoarthritis: a prospective, multicenter, randomized, doubleblind feasibility trial. BMC Musculoskelet Disord. 2015 Mar 18;16:57.

157. Briggs KK, Matheny LM, Steadman JR. Can Hylan G-F 20 with corticosteroid meet the expectations of osteoarthritis patients? Am J Orthop (Belle Mead NJ). 2012 Jul;41(7):311-315.

158. Lee SC, Rha DW, Chang WH. Rapid analgesic onset of intraarticular hyaluronic acid with ketorolac in osteoarthritis of the 
knee. J Back Musculoskelet Rehabil. 2011;24(1):31-38.

159. Palmieri $B$, Rottigni $V$, lannitti T. Preliminary study of highly cross-linked hyaluronic acid-based combination therapy for management of knee osteoarthritis-related pain. Drug Des Devel Ther. 2013;7:7-12.

160. Saturveithan C, Premganesh G, Fakhrizzaki S, Mahathir M, Karuna K, Rauf K, et al. Intra-articular Hyaluronic Acid (HA) and Platelet Rich Plasma (PRP) injection versus Hyaluronic acid (HA) injection alone in Patients with Grade III and IV Knee Osteoarthritis (OA): A Retrospective Study on Functional Outcome. Malays Orthop J. 2016;10(2).

161. Saw KY, Anz A, Siew-Yoke Jee C, Merican S, Ching-Soong $\mathrm{Ng} \mathrm{R}$, Roohi SA, Ragavanaidu K. Articular cartilage regeneration with autologous peripheral blood stem cells versus hyaluronic acid: a randomized controlled trial. Arthroscopy. 2013 Apr;29(4):684-694

162. Giombini A, Menotti F, Di Cesare A, Giovannangeli F, Rizzo M, Moffa F, Martinelli F. Comparison between intrarticular injection of hyaluronic acid, oxygen ozone, and the combination of both in the treatment of knee osteoarthrosis. J Biol Regul Homeost Agents. 2016 Apr-Jun;30(2):621-625.

163. Conrozier T, Bozgan AM, Bossert M, Sondag M, Lohse-Walliser A, Balblanc JC. Standardized Follow-up of Patients with Symptomatic Knee Osteoarthritis Treated with a Single Intraarticular Injection of a Combination of Cross-Linked Hyaluronic Acid and Mannitol. Clin Med Insights Arthritis Musculoskelet Disord. 2016 Sep 25;9:175-179.

164. Henrotin Y, Hauzeur JP, Bruel P, Appelboom T. Intra-articular use of a medical device composed of hyaluronic acid and chondroitin sulfate (Structovial CS): effects on clinical, ultrasonographic and biological parameters. BMC Res Notes. 2012 Aug 4;5:407.

165. Lee HJ, Lim KB, Kim DY, Lee KT. Randomized controlled trial for efficacy of intra-articular injection for adhesive capsulitis: ultrasonography-guided versus blind technique. Arch Phys Med Rehabil. 2009 Dec; 90(12):1997-2002.

166. Kim YS, Park JY, Lee CS, Lee SJ. Does hyaluronate injection work in shoulder disease in early stage? A multicenter, randomized, single blind and open comparative clinical study. J Shoulder Elbow Surg. 2012 Jun;21(6):722-727.

167. Orlandi D, Corazza A, Fabbro E, Ferrero G, Sabino G, Serafini $\mathrm{G}$, et al. Ultrasound-guided percutaneous injection to treat de Quervain's disease using three different techniques: a randomized controlled trial. Eur Radiol. 2015 May;25(5):15121519.

168. Monfort J, Rotés-Sala D, Segalés N, Montañes FJ, Orellana C Llorente-Onaindia J, et al. Comparative efficacy of intra-articular hyaluronic acid and corticoid injections in osteoarthritis of the first carpometacarpal joint: results of a 6-month singlemasked randomized study. Joint Bone Spine. 2015 Mar;82(2): 116-121.

169. Bum Park Y, Ah Choi W, Kim YK, Chul Lee S, Hae Lee J. Accuracy of blind versus ultrasound-guided suprapatellar bursal injection. J Clin Ultrasound. 2012 Jan;40(1):20-25.

170. Karatosun V, Unver B, Gocen Z, Sen A, Gunal I. Intra-articular hyaluranic acid compared with progressive knee exercises in osteoarthritis of the knee: a prospective randomized trial with long-term follow-up. Rheumatol Int. 2006 Feb;26(4):277-284.

171. Kawasaki T, Kurosawa $H$, Ikeda $H$, Takazawa $Y$, Ishijima $M$, Kubota M, et al. Therapeutic home exercise versus intraarticular hyaluronate injection for osteoarthritis of the knee: 6-month prospective randomized open-labeled trial. J Orthop Sci. 2009 Mar;14(2):182-191.

172. Saccomanno MF, Donati F, Careri S, Bartoli M, Severini G, Milano G. Efficacy of intra-articular hyaluronic acid injections and exercise-based rehabilitation programme, administered as isolated or integrated therapeutic regimens for the treatment of knee osteoarthritis. Knee Surg Sports Traumatol Arthrosc.
2016 May;24(5):1686-1694.

173. Monticone M, Frizziero A, Rovere G, Vittadini F, Uliano D, La Bruna S, et al. Hyaluronic acid intra-articular injection and exercise therapy: effects on pain and disability in subjects affected by lower limb joints osteoarthritis. A systematic review by the Italian Society of Physical and Rehabilitation Medicine (SIMFER). Eur J Phys Rehabil Med. 2016 Jun;52(3):389-399.

174. Di Giacomo G, De Gasperis N. The role of hyaluronic acid in patients affected by glenohumeral osteoarthritis.J Biol Regul Homeost Agents. 2015 Oct-Dec;29(4):945-951.

175. Huang MH, Yang RC, Lee CL, Chen TW, Wang MC. Preliminary results of integrated therapy for patients with knee osteoarthritis. Arthritis Rheum. 2005;53:812-820.

176. Ip D, Fu NY. Can combined use of low-level lasers and hyaluronic acid injections prolong the longevity of degenerative knee joints? Clin Interv Aging. 2015 Aug 5;10:1255-1258.

177. Bayramoğlu M, Karataş M, Cetin N, Akman N, Sözay S, Dilek A. Comparison of two different viscosupplements in knee osteoarthritis: a pilot study. Clin Rheumatol. 2003 May;22 (2):118-122.

178. Mathies B. Effects of Viscoseal, a synovial fluid substitute, on recovery after arthroscopic partial meniscectomy and joint lavage. Knee Surg Sports Traumatol Arthrosc. 2006;14:32-39.

179. Thein R, Haviv B, Kidron A, Bronak S. Intra-articular injection of hyaluronic acid following arthroscopic partial meniscectomy of the knee. Orthopedics. 2010;33:724.

180. Filardo G, Di Matteo B, Tentoni F, et al. No Effects of Early Viscosupplementation After Arthroscopic Partial Meniscectomy: A Randomized Controlled Trial. Am J Sports Med 2016;44 (12)3119-3125.

181. Chau J, Chan WL, Woo SB. Hyaluronic acid instillation following arthroscopic anterior cruciate ligament reconstruction: a double-blinded, randomized controlled study. Journal of Orthop Surg. 2012;20:162-165.

182. Di Martino A, Tentoni F, Di Matteo B, et al. Early Viscosupplementation After Anterior Cruciate Ligament Reconstruction: A Randomized Controlled Trial. Am J Sport Med 2016.

183. Heybeli N, Doral MN, Atay OA, Leblebicioglu G, Uzumcugil A. Intra-articular sodium hyaluronate injections after arthroscopic debridement for osteoarthritis of the knee: a prospective, randomized, controlled study. Acta Orthop Traumatol Turc. 2008:42:221-227.

184. Westrich G, Schaefer S, Walcott-Sapp S, et al. Randomized prospective evaluation of adjuvant hyaluronic acid therapy administered after knee arthroscopy. Am J Orthop (Belle Mead NJ). 2009;38:612-616.

185. Hempfling $\mathrm{H}$. Intra-articular hyaluronic acid after knee arthroscopy: a two-year study. Knee Surg Sports Traumatol Arthrosc. 2007:15:537-546.

186. Oh CH, Oh JH, Kim SH, Cho JH, Yoon JP, Kim JY. Effectiveness of subacromial anti-adhesive agent injection after arthroscopic rotator cuff repair: prospective randomized comparison study. Clin in Orthop Surg. 2011;3:55-61.

187. Doral MN, Bilge O, Batmaz G, et al. Treatment of osteochondral lesions of the talus with microfracture technique and postoperative hyaluronan injection. Knee Surg Sports Traumato Arthrosc. 2012;20:1398-1403.

188. Görmeli G, Karakaplan M, Görmeli CA, Sarıkaya B, Elmalı N, Ersoy Y. Clinical Effects of Platelet-Rich Plasma and Hyaluronic Acid as an Additional Therapy for Talar Osteochondral Lesions Treated with Microfracture Surgery: A Prospective Randomized Clinical Trial. Foot Ankle Int. 2015;36:891-900.

189. Abate M, Pelotti P, De Amicis D, Di lorio A, Galletti S, Salini V. Viscosupplementation with hyaluronic acid in hip osteoarthritis (a review). Ups J Med Sci. 2008;113(3):261-277.

190. Shi Z, Guo C, Awad M. Hyaluronate for temporomandibular joint disorders. Cochrane Database Syst Rev. 2003;(1) 
CD002970.

191. Saito S, Furuya T, Kotake S. Therapeutic effects of hyaluronate injections in patients with chronic painful shoulder: a meta-analysis of randomized controlled trials. Arthritis Care Res (Hoboken). 2010 Jul;62(7):1009-1018.

192. Altman RD, Moskowitz R. Intraarticular sodium hyaluronate (Hyalgan) in the treatment of patients with osteoarthritis of the knee: a randomized clinical trial. Hyalgan Study Group. J Rheumatol. 1998 Nov;25(11):2203-2212.

193. Altman RD, Rosen JE, Bloch DA, Hatoum HT, Korner P. A double-blind, randomized, saline-controlled study of the efficacy and safety of EUFLEXXA for treatment of painful osteoarthritis of the knee, with an open-label safety extension (the FLEXX trial). Semin Arthritis Rheum. 2009 Aug;39(1):1-9.

194. Altman RD, Rosen JE, Bloch DA, Hatoum HT. Safety and efficacy of retreatment with a bioengineered hyaluronate for painful osteoarthritis of the knee: results of the open-label Extension Study of the FLEXX Trial. Osteoarthritis Cartilage. 2011 Oct;19(10):1169-1175.

195. Arden NK, Åkermark C, Andersson M, Todman MG, Altman RD. A randomized saline-controlled trial of NASHA hyaluronic acid for knee osteoarthritis. Curr Med Res Opin. 2014 Feb;30(2):279-286.

196. Arrich J, Piribauer F, Mad P, Schmid D, Klaushofer K, Müllner M. Intra-articular hyaluronic acid for the treatment of osteoarthritis of the knee: systematic review and meta-analysis. CMAJ. 2005 Apr 12;172(8):1039-1043.

197. Bannuru RR, Vaysbrot EE, Sullivan MC, McAlindon TE. Relative efficacy of hyaluronic acid in comparison with NSAIDs for knee osteoarthritis: a systematic review and meta-analysis. Semin Arthritis Rheum. 2014 Apr;43(5):593-599.

198. Bellamy N, Campbell J, Robinson V, Gee T, Bourne R, Wells G. Viscosupplementation for the treatment of osteoarthritis of the knee. Cochrane Database Syst Rev. 2005 Apr 18;(2): CD005321.

199. Bellamy N, Campbell J, Robinson V, Gee T, Bourne R, Wells G. Viscosupplementation for the treatment of osteoarthritis of the knee. Cochrane Database Syst Rev. 2006 Apr 19;(2):CD005321.

200. Brandt KD, Block JA, Michalski JP, Moreland LW, Caldwell JR, Lavin PT. Efficacy and safety of intraarticular sodium hyaluronate in knee osteoarthritis. ORTHOVISC Study Group. Clin Orthop Relat Res. 2001 Apr;(385):130-143.

201. Brzusek D, Petron D. Treating knee osteoarthritis with intra-articular hyaluronans. Curr Med Res Opin. 2008 Dec;24(12): 3307-3322.

202. Chevalier X, Jerosch J, Goupille P, van Dijk N, Luyten FP, Scott DL, et al. Single, intra-articular treatment with $6 \mathrm{ml}$ hylan G-F 20 in patients with symptomatic primary osteoarthritis of the knee: a randomised, multicentre, double-blind, placebo controlled trial. Ann Rheum Dis. 2010 Jan;69(1):113-119.

203. Espallargues M, Pons JM. Efficacy and safety of viscosupplementation with Hylan G-F 20 for the treatment of knee osteoarthritis: a systematic review. Int J Technol Assess Health Care. 2003 Winter;19(1):41-56.

204. Filardo G, Kon E, Di Martino A, Di Matteo B, Merli ML, Cenacchi A, et al. Platelet-rich plasma vs hyaluronic acid to treat knee degenerative pathology: study design and preliminary results of a randomized controlled trial. BMC Musculoskelet Disord. 2012 Nov 23;13:229.

205. Jørgensen A, Stengaard-Pedersen K, Simonsen O, PfeifferJensen M, Eriksen C, Bliddal $H$, et al. Intra-articular hyaluronan is without clinical effect in knee osteoarthritis: a multicentre, randomised, placebo-controlled, double-blind study of $337 \mathrm{pa}-$ tients followed for 1 year. Ann Rheum Dis. 2010 Jun;69(6): 1097-1102.

206. Lee PB, Kim YC, Lim YJ, Lee CJ, Sim WS, Ha CW, et al. Comparison between high and low molecular weight hyaluronates in knee osteoarthritis patients: open-label, randomized, multicentre clinical trial. J Int Med Res. 2006 Jan-Feb;34(1):77-87.

207. Leighton R, Akermark C, Therrien R, Richardson JB, Andersson M, Todman MG, Arden NK. NASHA hyaluronic acid vs methylprednisolone for knee osteoarthritis: a prospective, multi-centre, randomized, non-inferiority trial. Osteoarthritis Cartilage. 2014 Jan;22(1):17-25.

208. Maheu E, Zaim M, Appelboom T, Jeka S, Trc T, Berenbaum F, et al. Comparative efficacy and safety of two different molecular weight (MW) hyaluronans F60027 and Hylan G-F20 in symptomatic osteoarthritis of the knee (KOA). Results of a non inferiority, prospective, randomized, controlled trial. Clin Exp Rheumatol. 2011 May-Jun;29(3):527-535.

209. Neustadt D, Caldwell J, Bell M, Wade J, Gimbel J. Clinical effects of intraarticular injection of high molecular weight hyaluronan (Orthovisc) in osteoarthritis of the knee: a randomized, controlled, multicenter trial. J Rheumatol. 2005 Oct;3 2(10):1928-1936.

210. Petrella RJ, Petrella M. A prospective, randomized, doubleblind, placebo controlled study to evaluate the efficacy of intraarticular hyaluronic acid for osteoarthritis of the knee. $\mathrm{J}$ Rheumatol. 2006 May;33(5):951-956.

211. Reichenbach S, Blank S, Rutjes AW, Shang A, King EA, Dieppe PA, et al. Hylan versus hyaluronic acid for osteoarthritis of the knee: a systematic review and meta-analysis. Arthritis Rheum. 2007 Dec 15;57(8):1410-1418.

212. Saito $S$, Kotake $S$. Is there evidence in support of the use of intra-articular hyaluronate in treating rheumatoid arthritis of the knee? A meta-analysis of the published literature. Mod Rheumatol. 2009;19(5):493-501.

213. Wang CT, Lin J, Chang CJ, Lin YT, Hou SM. Therapeutic effects of hyaluronic acid on osteoarthritis of the knee. A metaanalysis of randomized controlled trials. J Bone Joint Surg Am. 2004 Mar;86-A(3):538-545.

214. Wobig M, Bach G, Beks P, Dickhut A, Runzheimer J, Schwieger $\mathrm{G}$, et al. The role of elastoviscosity in the efficacy of viscosupplementation for osteoarthritis of the knee: a comparison of hylan G-F 20 and a lower-molecular-weight hyaluronan. Clin Ther. 1999 Sep;21(9):1549-1562.

215. Yu FF, Xia CT, Fang H, Han J, Younus MI, Guo X. Evaluation of the therapeutic effect of treatment with intra-articular hyaluronic acid in knees for Kashin-Beck disease: a metaanalysis. Osteoarthritis Cartilage. 2014 Jun;22(6):718-725.

216. Chang KV, Hsiao MY, Chen WS, Wang TG, Chien KL. Effectiveness of intra-articular hyaluronic acid for ankle osteoarthritis treatment: a systematic review and meta-analysis. Arch Phys Med Rehabil. 2013 May;94(5):951-960.

217. Wobig M, Dickhut A, Maier R, Vetter G. Viscosupplementation with hylan G-F 20: a 26-week controlled trial of efficacy and safety in the osteoarthritic knee. Clin Ther. 1998 MayJun;20(3):410-423.

218. Ishijima M, Nakamura T, Shimizu K, Hayashi K, Kikuchi H, Soen $\mathrm{S}$, et al. Intra-articular hyaluronic acid injection versus oral non-steroidal anti-inflammatory drug for the treatment of knee osteoarthritis: a multi-center, randomized, open-label, non-inferiority trial. Arthritis Res Ther. 2014 Jan 21;16(1):R18.

219. Jüni $P$, Reichenbach $S$, Trelle $S$, Tschannen $B$, Wandel $S$, Jordi B, et al. Efficacy and safety of intraarticular hylan or hyaluronic acids for osteoarthritis of the knee: a randomized controlled trial. Arthritis Rheum. 2007 Nov;56(11):3610-3619.

220. Medina JM, Thomas A, Denegar CR. Knee osteoarthritis: should your patient opt for hyaluronic acid injection? J Fam Pract. 2006 Aug;55(8):669-675.

221. Tang X, Pei FX, Zhou ZK, Liu G, Shen B, Kang PD, et al. A randomized, single-blind comparison of the efficacy and tolerability of hyaluronate acid and meloxicam in adult patients with Kashin-Beck disease of the knee. Clin Rheumatol. 2012 Jul;31(7):1079-1086. 
222. Diracoglu D, Vural M, Baskent A, Dikici F, Aksoy C. The effect of viscosupplementation on neuromuscular control of the knee in patients with osteoarthritis. J Back Musculoskelet Rehabil. 2009;22(1):1-9.

223. Fuchs S, Erbe T, Fischer HL, Tibesku CO. Intraarticular hyaluronic acid versus glucocorticoid injections for nonradicular pain in the lumbar spine. J Vasc Interv Radiol. 2005 Nov; 16(11):1493-1498.

224. Fernández López JC, Ruano-Ravina A. Efficacy and safety of intraarticular hyaluronic acid in the treatment of hip osteoarthritis: a systematic review. Osteoarthritis Cartilage. 2006 Dec;14(12):1306-1311.

225. Lundsgaard C, Dufour N, Fallentin E, Winkel P, Gluud C. Intraarticular sodium hyaluronate $2 \mathrm{~mL}$ versus physiological saline
$20 \mathrm{~mL}$ versus physiological saline $2 \mathrm{~mL}$ for painful knee osteoarthritis: a randomized clinical trial. Scand J Rheumatol. 2008 Mar-Apr;37(2):142-150.

226. Oliveras-Moreno JM, Hernandez-Pacheco E, Oliveras-Quintana T, Infante-Cossio P, Gutierrez-Perez JL. Efficacy and safety of sodium hyaluronate in the treatment of Wilkes stage II disease. J Oral Maxillofac Surg. 2008 Nov;66(11):22432246.

227. Strand V, Baraf HS, Lavin PT, Lim S, Hosokawa H. A multicenter, randomized controlled trial comparing a single intra-articular injection of Gel-200, a new cross-linked formulation of hyaluronic acid, to phosphate buffered saline for treatment of osteoarthritis of the knee. Osteoarthritis Cartilage. 2012 May;20(5):350-356. 